\author{
Universidade de São Paulo \\ Instituto de Física
}

\title{
Interação de nanotubos de carbono e cadeias de polifluoreno: \\ Dinâmica molecular e espectroscopia
}

Elton José Figueiredo de Carvalho

Orientadora:

Profa. Dra. Maria Cristina dos Santos

Tese de doutorado apresentada ao

Instituto de Física para a obtenção do título de Doutor em Ciências

Comissão examinadora:

Prof. Dr. Renato de Figueiredo Jardim - Presidente (IFUSP)

Prof. Dr. Luis Gregorio Godoy de Vasconcelos Dias da Silva (IFUSP)

Prof. Dr. Alexandre Reily Rocha (IFT-UNESP/IFUSP)

Prof. Dr. Antonio Gomes de Souza Filho (UFC)

Profa. Dra. Dora Izzo (UFRJ)

São Paulo

2014 


\section{FICHA CATALOGRÁFICA \\ Preparada pelo Serviço de Biblioteca e Informação do Instituto de Física da Universidade de São Paulo}

Carvalho, Elton José Figueiredo de

Interação de nanotubos de carbono e cadeias de polifluoreno: dinâmica molecular e espectroscopia. São Paulo, 2014.

Tese (Doutorado) - Universidade de São Paulo. Instituto de Física. Departamento de Física dos Materiais e Mecânica

Orientador: Profa. Dra. Maria Cristina dos Santos

Área de Concentração: Física

Unitermos: 1. Física da matéria condensada;

2. Nanopartículas; 3. Espectroscopia molecular;

4. Fotoluminescência.

USP/IF/SBI-012/2014 
à Vó Maria ao Vô Dair 



\section{Agradecimentos}

Este trabalho somente se tornou realidade devido ao apoio de diversas pessoas e entidades, a quem devo minha mais profunda gratidão. À Profa. Dra. Maria Cristina dos Santos, minha orientadora desde a iniciação científica, agradeço a orientação, o apoio, as lições, a paciência e as incríveis oportunidades de crescimento a que nunca hesitou em me apresentar. Ao CNPq agradeço o fomento na forma de bolsa de doutorado. À CAPES agradeço o fomento na forma de bolsa de doutorado sanduíche nos Países Baixos. À FAPESP, o apoio na aquisição de equipamentos e infraestrutura fundamentais para a execução deste trabalho.

Às equipes da Universidade de Groningen (Rijksuniversiteit Groningen $R U G)$, nos Países Baixos, agradeço a hospitalidade, cooperação e apoio, em particular ao co-orientador Prof. Siewert-Jan Marrink. À Profa. Maria Antonietta Loi, também da RUG, pela colaboração experimental ao liderar os colegas Jia Gao, Widianta Gomulya e Guadalupe Constanzo em muito frutíferas discussões e experimentos que deram corpo a este trabalho. Agradeço também às entidades holandesas NWO e SARA pelo tempo de processamento cedido no supercomputador nacional holandês Cartesius, onde os cálculos do Capítulo 6 foram realizados.

Lembro - ciente do risco de cometer injustiças devidas à falível memória e em ordem alfabética de sobrenome - os companheiros Rodrigo Caro, Jeconias Guimarães e Claudio Padilha, no Brasil, e Clément Arnarez, Floris van Eerden, Felipe Franco, Helgi Ingólfsson, Djurre de Jong, César López, Manuel Melo, Xavier Perriole, Jaakko Uusitalo, Alex de Vries e Tsjerk Wassenaar, nos Países Baixos, pela convivência acadêmica, que inclui, além das discussões científicas, entretenimento e apoio para enfrentar o dia-a-dia no laboratório.

Na preparação deste texto, os amigos Juliana Belko, Flavia Budant, Daniel Guariento, Leonardo Jorge, Kaonan Micadei, Francisco M. Neto, Carlos Pellicer e Gabriel Weber colaboraram com opiniões sobre a redação, comentários artísticos em figuras ou com o próprio $\mathrm{LT}_{\mathrm{E}} \mathrm{X}$ e seus pormenores. Registro aqui minha gratidão. 
Não posso deixar de agradecer às secretárias do departamento, Rosana Gimenes e Sandra Ribeiro. Sem sua eficiência e presteza não teria sido possível navegar pelos meandros burocráticos a que tantas vezes somos lançados.

No âmbito pessoal, agradeço à minha mãe pelo suporte, confiança e paciência ao longo desta jornada. À Juliana pela inesgotável paciência, irretribuível tolerância e incondicionais apoio e afeto. Ao Oleksandr Mikhnenko, da RUG, que me vendeu uma bicicleta na minha primeira semana em Groningen. Não posso deixar de agradecer aos meus amigos - que não enumero por temor de cometer mais injustiça - sem quem duvido ser capaz de manter a sanidade após todos esses anos. 


\section{Resumo}

A aplicação de nanotubos de carbono em nanotecnologia está condicionada ao controle das propriedades eletrônicas e geométricas das amostras. Recentemente, tem crescido o uso de polímeros conjugados para suspender seletivamente nanotubos semicondutores com uma distribuição estreita de diâmetro. Em 2007, Adrian Nish e colaboradores mostraram que o polímero conjugado poli[9,9-dioctilfluorenil-2,7-diil] (PFO) suspende seletivamente nanotubos semicondutores de cerca de $1,0 \mathrm{~nm}$ de diâmetro e ângulo quiral próximo de $25^{\circ}$. Em seguida, o grupo de Maria Antonietta Loi foi capaz de medir a fluorescência do PFO envolvido em nanotubos, medindo pela primeira vez as propriedades ópticas de um polímero ao interagir com os nanotubos. Mais recentemente, diversos grupos conseguiram suspender nanotubos semicondutores com diâmetros maiores que $1,0 \mathrm{~nm}$ através do enovelamento de polímeros conjugados. Diferentes cadeias principais apresentaram resultados, como homopolímeros derivados dos fluorenos e tiofenos e copolímeros em que unidades fluoreno foram combinadas com piridinas, antracenos e outros compostos aromáticos. A natureza da cadeia principal parece ter um papel na seletividade de quiralidades específicas. Entretanto, a solubilização de nanotubos de grandes diâmetros com frequência utiliza polímeros com cadeias laterais alquiladas com pelo menos 12 carbonos.

Neste trabalho, desenvolvemos um método para simular o espectro de emissão de uma molécula em condições dinâmicas a fim de capturar a variedade de conformações acessíveis à molécula interagindo com o ambiente. Isso nos permitiu obter um espectro de emissão mais realista. Aplicamos esse método no sistema $\mathrm{PFO}$ + nanotubos e observamos, juntamente com uma análise das energias de interação, que o polímero se encontra enrolado em hélice ao redor do tubo e que a interação entre as cadeias laterais rege o o comportamento do polímero.

Buscamos compreender o mecanismo de seletividade e suspensão de nanotubos de maior diâmetro através de dinâmica e mecânica molecular. Observamos, com o uso de simulações de dinâmica de impulso, que a eficiência do recobrimento da superfície do tubo pelo polímero está associada à relação entre a circunferência do tubo e o comprimento da cadeia lateral. Tubos de diâmetro 
incompatível com os radicais acabam por ter suas paredes expostas ao solvente e, consequentemente, ao reagrupamento com outros nanotubos.

Finalmente, propusemos um modelo granulado que permitiria obter informações sobre a interação entre os polímeros e os nanotubos em uma escala temporal maior, da ordem de $\mu$ s. Relatamos aqui os resultados parciais dos testes deste modelo e a rota para seu futuro desenvolvimento. 


\section{Abstract}

The effective use of carbon nanotubes in nanotechnology depends on the fine tuning of electronic and geometric properties of the samples. Recently, the use of conjugated polymers to selectively suspend semiconducting nanotubes of a narrow diameter distribution has received attention in the literature. In 2007, Andrian Nish and collaborators showed that the conjugated polymer poly[9,9dioctylfluorenyl-2,7-diyl] (PFO) selectively suspends nanotubes with diameter of the order of $1.0 \mathrm{~nm}$ and chiral angles close to $25^{\circ}$. Subsequently, Maria Antonietta Loi's group was able to measure the fluorescence of PFO chains wrapped around nanotubes, hence for the first time measuring the optical properties of a polymer interacting with nanotubes. More recently, various groups reported the successful suspension of semiconducting nanotubes with diameters larger than $1.0 \mathrm{~nm}$ by wrapping with conjugated polymers. Different polymer backbones showed positive results, such as homopolymers based on fluorene and thiophene and copolymers based on fluorene units combined with pyridines, anthracenes and other aromatic compounds. The backbone structure seems to have an effect on the chirality selectivity. On the other hand, the solubilization of large-diameter nanotubes frequently involves polymers having alkyl sidechains with at least 12 carbon atoms.

In this work, we developed a method to simulate the emission spectrum of a molecule in dynamic conditions in order to capture the variety of accessible conformations of the molecule interacting with the environment. This allowed us to obtain a more realistic emission spectrum. We applied this method to the $\mathrm{PFO}+$ nanotube system and observed, in association with binding energy analysis, that the polymer wraps around the nanotube in an helical conformation and that the sidechain interaction governs the polymer behavior.

We were able to understand the selectivity mechanism for large-diameter tubes through molecular mechanics and molecular dynamics simulations. We observed, using impulse dynamics simulations, that the nanotube surface coverage efficiency depends on the relation between the nanotube circumference and the sidechain length. Tubes whose diameter is incompatible with the sidechain 
length present wall regions that are exposed to the solvent, therefore exposed to rebundling with other tubes.

Lastly, we proposed a coarse-grained model that could provide information about the long-term behavior of the NT + PFO complexes, in the $\mu$ s range. Here we report partial test results for this model and outline the route for future developments. 


\section{Sumário}

Resumo vii

Abstract $\quad$ ix

Lista de abreviações $\quad \mathbf{x v}$

I Introdução 1

1 Apresentação 3

2 Estruturas de carbono $\quad 7$

2.1 Estrutura eletrônica . . . . . . . . . . . . . . . . 7

2.2 Nanotubos de carbono . . . . . . . . . . . . . . . 9

2.2 .1 Grafite e grafeno . . . . . . . . . . . . . . 10

2.2 .2 Propriedades geométricas . . . . . . . . . . . . . . . . 13

2.2.3 Estrutura eletrônica . . . . . . . . . . . . . . . 14

2.2 .4 Síntese . . . . . . . . . . . . . . . 15

2.2 .5 Técnicas de caracterização . . . . . . . . . . . 17

2.2 .6 Técnicas de separação . . . . . . . . . . . . . . . . . . . 20

2.3 Polímeros conjugados . . . . . . . . . . . . . . . . 22

3 Métodos $\quad 25$

3.1 Teoria quântica em física molecular . . . . . . . . . . . . 25

3.2 Mecânica molecular clássica . . . . . . . . . . . . . 27

3.2.1 Otimização de geometria . . . . . . . . . . . . . 31

3.2 .2 Dinâmica molecular . . . . . . . . . . . . . . . 31

3.3 Métodos ab initio e semiempíricos . . . . . . . . . . 33

3.3.1 O Método Hartree-Fock . . . . . . . . . . . . . . 33

3.3.2 Funções de base . . . . . . . . . . . . . . . . . . 36

3.3 .3 O método ZINDO . . . . . . . . . . . . . 38 
3.3.4 Interação de configurações . . . . . . . . . . . . . . 39

3.3.5 Teoria do funcional da densidade . . . . . . . . . . . . . 40

3.4 Espectro de absorção de luz . . . . . . . . . . . . . . . . . . 47

3.5 Introdução à fluorescência . . . . . . . . . . . . . . . 51

3.6 Fotoluminescência: espectro semiempírico . . . . . . . . . 52

II Resultados e discussão $\quad 55$

4 Mecanismo de suspensão de nanotubos em solução de polifluoreno $\quad 57$

4.1 Estado atual . . . . . . . . . . . . . . . . . 57

4.2 Adaptação do campo de força . . . . . . . . . . . . . . . 59

4.3 Dinâmica molecular . . . . . . . . . . . . . . . . 61

4.3.1 Preparação das estruturas . . . . . . . . . . 63

4.3.2 Energia de interação . . . . . . . . . . . . . . . 66

4.4 Cálculo de espectros de emissão . . . . . . . . . . . . . . 67

4.4.1 Comparação com resultados experimentais . . . . . 70

5 Efeito da cadeia lateral na seletividade $\quad 75$

5.1 Revisão experimental . . . . . . . . . . . . . . . . . . 75

5.2 Simulação . . . . . . . . . . . . . . . . . . . . . 79

5.3 Resultados da dinâmica . . . . . . . . . . . . . . . . . 82

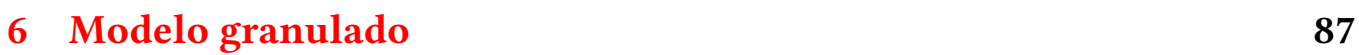

6.1 O campo de forças MARTINI . . . . . . . . . . . . . . . . . . 88

6.2 Modelagem do tolueno . . . . . . . . . . . . . . . . 89

6.3 Modelagem do nanotubo . . . . . . . . . . . . . . . . 91

6.4 Modelagem do polifluoreno . . . . . . . . . . . . . . . . 92

6.5 Dinâmica molecular . . . . . . . . . . . . . . . . . . . 96

6.5.1 Resultados ..................... 97

$\begin{array}{lr}\text { III Conclusão } & 101\end{array}$

$\begin{array}{llr}7 & \text { Conclusão } & 103\end{array}$ 


\section{Lista de Figuras}

1.1 Estrutura do $\mathrm{PFO} \ldots \ldots \ldots \ldots \ldots$

2.1 Estrutura do grafite . . . . . . . . . . . . . 8

2.2 Estrutura do fulereno $\mathrm{C}_{60} \ldots \ldots \ldots \ldots \ldots$

2.3 Célula unitária do diamante . . . . . . . . . . . . 9

2.4 Propriedades geométricas do grafeno . . . . . . . . . . . 10

2.5 Rede recíproca do grafeno . . . . . . . . . . . . . . . 11

2.6 Estrutura de bandas do grafeno . . . . . . . . . . . . . . . 12

2.7 Propriedades geométricas de um nanotubo . . . . . . . . . . . 13

2.8 Nanotubos de diferentes quiralidades . . . . . . . . . . . . 14

2.9 Estados permitidos aos elétrons do nanotubo . . . . . . . . . . 15

2.10 Densidade de estados de nanotubos zigzag . . . . . . . . . . . . 16

2.11 Kataura plot . . . . . . . . . . . . . . . . 18

2.12 Processo de fotoluminescencia em um nanotubo $(10,0) \ldots 19$

2.13 Exemplos de polímeros conjugados . . . . . . . . . . . 22

2.14 Exemplos de polímeros derivados por funcionalização com alquilas 23

2.15 Exemplos de polímeros derivados por copolimerização . . . . . 23

3.1 Tipos de torção e inversão . . . . . . . . . . . . . . . . 30

3.2 Ilustração do processo de fluorescência . . . . . . . . . . . . . 51

3.3 Estrutura vibrônica . . . . . . . . . . . . . . . . 52

4.1 Tipos atômicos usados no CVFF . . . . . . . . . . . . 59

4.2 Dimensões relevantes na estrutura do difluoreno. . . . . . . . 61

4.3 Duas conformações de PFO sobre nanotubos consideradas neste trabalho. .......................... 63

4.4 Fluxograma da preparação e simulação dos sistemas NT + PFO . 64

4.5 Exemplo de sistema nanotubo + PFO envolto por uma camada de tolueno . . . . . . . . . . . . . . 65

4.6 Energias de ligação $(\Delta E)$ em função do diâmetro e do ângulo quiral 66

4.7 Detalhe de duas conformações de PFO sobre um nanotubo $(8,6) .67$ 
4.8 Espectro de emissão calculados: tubos $(7, n) \ldots \ldots \ldots$

4.9 Espectro de emissão calculados: tubos $(8, n) \ldots \ldots$. . . . . . . 69

4.10 Espectro do PFO livre em tolueno. . . . . . . . . . . . . 70

4.11 Comparação entre espectros medidos CoMoCAT e simulados . . 71

4.12 Comparação entre espectros medidos HiPCO e simulados . . . . 72

4.13 Comparação entre espectros de alto e baixo peso molecular . . . 73

5.1 Polimeros capazes de suspender nanotubos . . . . . . . . . . 76

5.2 Nanotubos suspensos por diferentes cadeias de polifluoreno . . 78

5.3 Energias de absorção de suspensões de nanotubos com diferentes polifluorenos . . . . . . . . . . . . . . 79

5.4 Conformações $T$ e $P \ldots \ldots \ldots \ldots \ldots$. . . . . . . . 80

5.5 Fluxograma da simulação de dinâmica de impulso . . . . . . . . 81

5.6 Estruturas de polifluoreno em torno de nanotubo $(14,7)$ após dinâmica de impulso ................. 83

5.7 Energias de ligação entre polifluorenos e nanotubos . . . . . . . 84

6.1 Mapeamento dos grãos MARTINI . . . . . . . . . . . . . . . . 90

6.2 Procedimento para equilibrar uma caixa de solvente . . . . . . . 90

6.3 Mapeamento dos grãos em um nanotubo de carbono. . . . . . . 92

6.4 Mapeamento dos grãos no modelo do polifluoreno. . . . . . . . . . 93

6.5 Torções para manter o núcleo na molécula planar. . . . . . . . . 93

6.6 Torções que determinam a flexibilidade da cadeia . . . . . . . . 94

6.7 Histogramas das torções . . . . . . . . . . . . . . . . . . . 95

6.8 Configuração da caixa simulação do sistema NT + PFO em tolueno 97

6.9 Conformações do PFO granulado sobre tubo $(14,7) \ldots 98$ 


\section{Lista de abreviações}

BLYP Funcional de troca Becke e correlação de Lee-Yang-Parr

B3LYP Funcional de troca e correlação híbrido, com três parâmetros, troca de Becke e correlação de Lee-Yang-Parr

CI Configuration interaction - Interação de configurações

CIS / CI-Singles Configuration interaction - Single excitation - Interação de configurações - Excitação simples

CNT Carbon nanotube - Nanotubo de carbono

CoMoCAT Cobalt-Molybdenum catalyst - Catalizador de cobalto e molibdênio

CVFF Consistent-valence force field - Campo de força de valência consistente

DFT Density-functional theory - Teoria do funcional da densidade

DGU Density-gradient ultracentrifugation - Ultracentrifugação em gradiente de densidade

DOS Density of states - Densidade de estados

GGA Generalized-gradient approximation - Aproximação de gradiente generalizado

HIPCO High pressure $C O$ - Monóxido de carbono a alta pressão

HRTEM High-resolution transmission electron microscopy-Microscopia de transmissão eletrônica de alta resolução

INDO Intermediate neglect of differential overlap - Descarte intermediário de sobreposição diferencial

LCAO Linear combination of atomic orbitals - Combinação linear de orbitais atômicos

LDA Local density approximation - Aproximação de densidade local 
LSDA Local spin-density approximation - Aproximação de densidade de spin local

NPT Número - Pressão - Temperatura

NVE Número - Volume - Energia

NVT Número - Volume - Temperatura

OPLS Optimized potentials for liquid simulations - Potenciais otimizados para simulações de líquidos

P3DDT poli-(3-dodeciltiofeno)

P8BT poli-[(9,9-dioctilfluorenil)-alt-benzotiadiazol]

PFO poli-[9,9-dioctilfluorenil-2,7-diil]

PF8 sinônimo para PFO

PF12 poli-[9,9-didodecilfluorenil-2,7-diil]

PFH poli-[9,9-di-hexilfluorenil-2,7-diil]

PFH-A poli[(9,9-di-hexilfluorenil)-co-(9,10-antraceno)]

PFO-Bpy poli[(9,9-dioctilfluorenil)-alt- $\left\{6,6^{\prime}\left(2,2^{\prime}\right.\right.$-bipiridina $\left.\left.)\right\}\right]$

PLE Photoluminescence excitation - Excitação de fotoluminescência

RBM Radial breathing mode - Modo de respiração radial

SC Sodium cholate - Colato de sódio

SDBS Sodium dodecylbenzene sulfonate - Dodecilbenzeno sulfonato de sódio

SDS Sodium dodecyl sulfate - Dodecil sulfato de sódio

STO Slater-type orbitals - Orbitais tipo Slater

SWNT Single-wall nanotube - Nanotubo de parede simples

TEM Transmission electron microscopy - Microscopia de transmissão eletrônica

THF Tedra-hidrofurano

UA United-atom - Átomos unidos

ZINDO Zerner's intermediate neglect of differential overlap - Descarte intermediário de sobreposição diferencial de Zerner 


\section{Parte I}

\section{Introdução}





\section{Capítulo 1}

\section{Apresentação}

Nanotubos de carbono de parede simples (SWNT - Single-wall carbon nanotube) são estruturas cilíndricas cujas paredes são formadas por uma camada única de átomos de carbono ${ }^{[1 ; 2]}$. Podemos descrever sua estrutura como se fosse uma das folhas do grafite, chamada de grafeno, enrolada para formar um cilindro de diâmetro de $0,7 \mathrm{~nm}$ a poucas dezenas de $\mathrm{nm}$ e comprimento de vários micrômetros a poucos centímetros ${ }^{[3 ; 4]}$.

Uma propriedade importante dos SWNTs é sua estrutura eletrônica dependente da geometria: dependendo da direção em que a folha de grafeno é enrolada em relação a sua estrutura atômica, os tubos podem ser metálicos ou semicondutores. Descreveremos mais detalhadamente esse comportamento na Seção 2.2.3. Essa propriedade garante aos nanotubos grande potencial de aplicação em diversas áreas ${ }^{[5]}$, incluindo reforço mecânico de materiais ${ }^{[6]}$, eletrônica molecular, na forma de transistores moleculares ${ }^{[7-9]}$ ou condutores entre esses dispositivos, geração e armazenamento de energia, aumentando a eficiência de células solares ${ }^{[10]}$, baterias de lítio ${ }^{[11]}$ e armazenamento de hidrogênio para uso em células a combustível ${ }^{[12]}$, sensores químicos ${ }^{[13 ; 14]}$ - inclusive detectores de armas químicas ${ }^{[15]}$. Nanotubos também têm potencial para aplicações em medicina como no tratamento de câncer ${ }^{[16]}$ e em microscopia, melhorando a resolução de microscópios de força atômica ${ }^{[17-19]}$.

Essas aplicações dependem de propriedades bem definidas dos nanotubos, como por exemplo o gap eletrônico ou o diâmetro. Entretanto, os nanotubos são sintetizados em processos com características estocásticas, de forma que não é possível produzir amostras monodispersas de nanotubos, com diâmetro e ângulo quiral bem definidos a priori, propriedades necessárias para sua efetiva aplicação em tecnologia.

Recentemente, as técnicas de síntese têm evoluído no que diz respeito ao controle da variedade de quiralidades e diâmetros dos tubos sintetizados. O método de monóxido de carbono a alta pressão (HiPCO) ${ }^{[20]}$ produz nanotubos 
numa faixa estreita de diâmetro, de $0,8 \mathrm{~nm}$ a $1,2 \mathrm{~nm}$. Já outra técnica, que utiliza catalizadores de cobalto e molibdênio (CoMoCAT) ${ }^{[21]}$, rende amostras ricas em nanotubos de geometrias específicas - cerca de $43 \%$ da população de tubos $(6,5)$ e $22 \%$ de tubos $(7,5)^{[22]}$.

Ainda assim, é necessário separar dessas amostras polidispersas os nanotubos de interesse quando a aplicação exige uma geometria específica. Diversas estratégias foram desenvolvidas nos últimos anos ${ }^{[23]}$ e consistem, por exemplo, em destruir os tubos que não têm as características de interesse, fazendo passar uma corrente elétrica que faça evaporar os tubos condutores; cromatografia e eletroforese; solubilização seletiva e centrifugação e outras técnicas derivadas dessas. Discutiremos detalhadamente as técnicas não-destrutivas na Seção 2.2.6.

No contexto de solubilização seletiva, uma variedade de substâncias pode ser utilizada para suspender os nanotubos em solução, incluindo surfactantes ${ }^{\text {[24;25], }}$, cadeias de DNA ${ }^{[8 ; 26]}$ e polímeros ${ }^{[3 ; 27 ; 28]}$. Em particular, um desses polímeros chama a atenção devido a propriedades eletrônicas e geométricas que o tornam interessante em diversas aplicações. O polímero conjugado poli[9,9-dioctilfluorenil-2,7-diil] (PFO), cuja estrutura está reproduzida na Fig. 1.1, é um semicondutor e fluorescente, o que o torna atraente para aplicações de optoeletrônica em dispositivos como LEDs ${ }^{[29]}$ e painéis fotovoltaicos ${ }^{[30]}$. Com sua condutividade, fluorescência e capacidade de absorção de luz dependentes da estrutura, o PFO também se mostra útil em aplicações de eletrônica biocompatível, como biossensores e eletrodos para células nervosas. A solubilidade dos polifluorenos em diferentes substâncias, de acordo com as propriedades das cadeias laterais, permite sua aplicação através de diversos métodos, como impressão a jato de tinta de circuitos eletrônicos ${ }^{[31]}$.

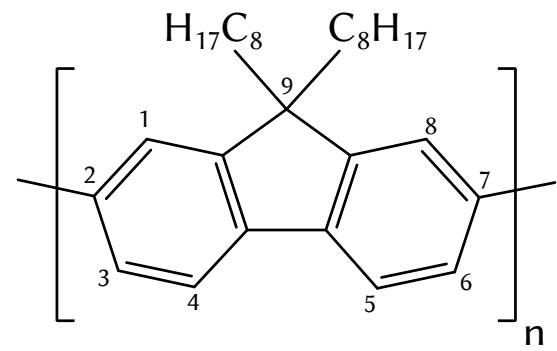

Figura 1.1: Estrutura do PFO. Estrutura do poli[9,9-dioctilfluorenil-2,7-diil], com $\mathrm{R}=\mathrm{C}_{8} \mathrm{H}_{17}$. Os números indicam o índice dos átomos de carbono para caracterizar a estrutura.

Chama atenção o fato de os nanotubos serem suspensos seletivamente ${ }^{[28]}$, dependendo de sua quiralidade e diâmetro. Ou seja, os nanotubos são encapsulados pelo polímero, isoladamente, de maneira dependente de suas propriedades geométricas, de forma que nanotubos com geometria incompatível com o polímero se reagrupam e precipitam. Isso se observa através de medidas de absorção de luz e de fluorescência, que confirmam que os tubos estão suspensos 
individualmente e que a suspensão privilegia tubos semicondutores ${ }^{[28 ; 32]}$. Essas medidas também mostram que, no caso de nanotubos produzidos pelo método de monóxido de carbono de alta pressão (HiPCO), os tubos $(8,6),(9,7),(8,7),(7,5)$ e $(7,6)$, todos semicondutores com grande ângulo quiral, são os mais comumente observados em suspensão de $\mathrm{PFO}$, em ordem decrescente de concentração. A seletividade dos polifluorenos depende fortemente do solvente utilizado e da cadeia lateral anexada à unidade de fluoreno ${ }^{[3 ; 34]}$, de forma que a seletividade parece estar relacionada às propriedades estruturais e geométricas do polifluoreno em solução de tolueno.

O comportamento do PFO em solução tem sido foco de estudos recentes ${ }^{\text {[31] }}$ e experimentos associados a cálculos quânticos ${ }^{[35]}$ trouxeram luz à natureza das interações entre cadeias de PFO, especialmente sobre a chamada fase $\beta$. À medida que a concentração de PFO em tolueno aumenta, mostrou-se que a tendência é que as cadeias se agreguem, ligando-se umas às outras através da interdigitação dos radicais octil, que, por interações do tipo van der Waals, conectam-se alternadamente como um zíper. Essa interconexão é fortemente dependente da estrutura das cadeias laterais, uma vez que cadeias muito longas estão sujeitas a deformações que dificultam o contato e cadeias curtas permitem que as cadeias principais de fluoreno interajam mais fortemente, competindo com os radicais.

Neste trabalho, estudamos a seletividade do PFO por nanotubos de grande ângulo quiral, comparando medidas experimentais de fluorescência ${ }^{[32 ; 36]} \mathrm{com}$ simulações de dinâmica molecular e com o espectro de emissão calculado a partir de estruturas provenientes dessas simulações. Estudaremos como as mudanças geométricas oriundas das diferentes formas com que uma cadeia de PFO pode interagir com um nanotubo afetam o espectro de fotoluminescência. Para isto, desenvolvemos um procedimento que permite calcular o espectro de emissão utilizando técnicas conhecidas para calcular o espectro de absorção da molécula.

Para apresentar o progresso, começamos por uma introdução às estruturas derivadas de carbono no Capítulo 2, seguida por uma breve descrição das propriedades de polímeros conjugados como o PFO na Seção 2.3. No Capítulo 3, descrevemos os métodos computacionais aplicados neste trabalho. Em particular, na Seção 3.6 demonstramos os princípios que regem o método de cálculo do espectro de emissão. Em seguida, o Capítulo 4 contém o desenvolvimento do projeto, detalhes do processo de simulação e comparação com resultados experimentais. No Capítulo 5 relatamos o uso das técnicas descritas neste texto para compreender o mecanismo que rege a inédita suspensão de tubos de grande diâmetro com o uso de derivados do polifluoreno. Descrevemos uma técnica para refinar a fase de amostragem de estruturas com o uso de um campo de forças granulado e apresentamos o desenvolvimento desse modelo no Capítulo 6. Finalmente, no Capítulo 7 resumimos os resultados deste trabalho e mencionamos possíveis desenvolvimentos futuros da técnica aqui produzida. 



\section{Capítulo 2}

\section{Estruturas de carbono}

Carbono é um elemento químico versátil quanto à sua capacidade de formar ligações químicas. Sua estrutura eletrônica permite que se ligue com dois, três ou quatro átomos em diferentes configurações geométricas. Carbono puro se apresenta em algumas formas alotrópicas, como grafite, diamante, fulerita (cristais de fulerenos $\mathrm{C}_{60}$ ), nanotubos de carbono, entre outras, com propriedades muito diferentes uma das outras.

Iniciamos este capítulo explorando os fenômenos eletrônicos que concedem essa versatilidade ao carbono. Em seguida, descreveremos em algum detalhe as propriedades dos nanotubos de carbono, foco dos estudos neste trabalho. Finalmente, discutiremos brevemente as técnicas de síntese, caracterização e separação dos nanotubos.

\subsection{Estrutura eletrônica}

Os seis elétrons do carbono se distribuem em duas camadas na configuração $1 s^{2} 2 s^{2} 2 p^{2}$, de modo que dois elétrons desemparelhados dos orbitais $p$ estão disponíveis para fazer ligações covalentes. Entretanto, como a energia necessária para promover um dos elétrons do orbital $2 s$ para o $2 p$ é pequena ${ }^{[2]}$, a energia proveniente de uma ligação química permite que o átomo de carbono salte para o estado $1 s^{2} 2 s^{1} 2 p^{3}$, com quatro elétrons desemparelhados à disposição de ligações químicas.

Existem três formas de combinar linearmente os orbitais $|2 s\rangle$ e $|2 p\rangle$ de modo a obtermos orbitais ortogonais entre si: combinando um orbital $|2 s\rangle$ com um, dois ou três orbitais $\left|2 p_{i}\right\rangle$. A combinação do orbital $|2 s\rangle$ com um orbital $|2 p\rangle$, por exemplo, dá origem à chamada hibridização $s p$, caso em que se formam os orbitais $\left|s p_{+}\right\rangle$e $\left|s p_{-}\right\rangle$. Esses dois orbitais são assimétricos em relação à reflexão no eixo paralelo ao orbital $|2 p\rangle$ utilizado na combinação, então o $\left|s p_{+}\right\rangle$é mais 
alongado na direção positiva desse eixo e o $\left|s p_{-}\right\rangle$na direção negativa. Essa assimetria fornece uma possibilidade de combinação mais intensa da função de onda do elétron desemparelhado com um elétron de um átomo vizinho, reduzindo a energia do sistema e formando uma ligação covalente.

A ligação entre dois átomos de carbono que apresentam hibridização $s p$ forma uma ligação tripla. O orbital $\left|s p_{+}\right\rangle$de um átomo se combina com o orbital $\left|s p_{-}\right\rangle$de seu vizinho, e forma uma ligação $\sigma$. Já os orbitais $\left|2 p_{y}\right\rangle$ desses dois átomos se combinam para formar um orbital molecular com um plano nodal, chamado de orbital $\pi$. O mesmo acontece com os orbitais $\left|2 p_{z}\right\rangle$, de modo que três orbitais de cada átomo estão envolvidos na ligação. Um exemplo de átomo de carbono neste estado de hibridização aparece na molécula de acetileno $\left(\mathrm{C}_{2} \mathrm{H}_{2}\right)$.

É possível também combinar o orbital $|2 s\rangle$ com dois orbitais $\left|2 p_{i}\right\rangle$, formando três novos orbitais, caso em que temos a hibridização $s p^{2}$. Os três orbitais $\left|s p^{2}\right\rangle$ são combinações lineares de três orbitais que compartilham um plano de simetria de reflexão, então devem herdar essa propriedade. Como vimos, orbitais do tipo $s p^{n}$ são alongados em uma direção, portanto os três orbitais $\left|s p_{i}^{2}\right\rangle$ devem ser ortogonais entre si, alongados em três direções diferentes e coplanares. Para que essas condições sejam obedecidas as três direções devem se distribuir formando ângulos de $120^{\circ}$ entre si. Átomos de carbono $s p^{2}$ podem fazer três ligações $\sigma$ coplanares e o orbital $\left|2 p_{z}\right\rangle$ permanece disponível para realizar ligações $\pi$. É neste estado de hibridização que se encontram os átomos de carbono no grafite (Fig. 2.1), fulerenos (Fig. 2.2) e nanotubos. A molécula de etileno $\left(\mathrm{C}_{2} \mathrm{H}_{4}\right)$ é um exemplo de carbono $s p^{2}$ ligado a outros elementos.

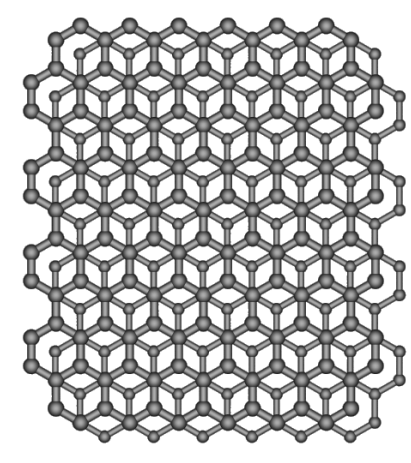

(a) Vista do topo

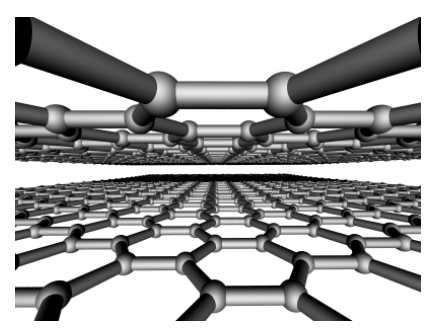

(b) Vista frontal

Figura 2.1: Estrutura do grafite. Composto por folhas de estrutura hexagonal, chamadas de grafenos, ligadas fracamente através de interações de van der Waals, o grafite tem aplicações que dependem de sua baixa dureza, como lubrificação e a escrita.

O carbono forma estruturas tetragonais com quatro ligações $\sigma$ quando seu orbital $|2 s\rangle$ se combina com os três orbitais $\left|2 p_{i}\right\rangle$ formando os quatro orbitais $\left|s p^{3}\right\rangle$, na condição chamada de hibridização $s p^{3}$. Neste estado se encontra o 


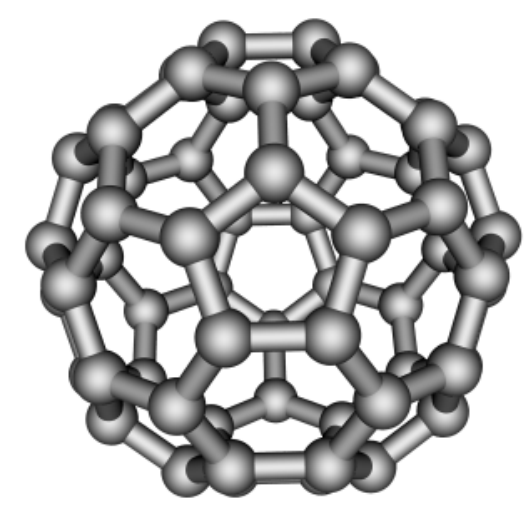

Figura 2.2: Estrutura do fulereno $\mathbf{C}_{60}$. Esta estrutura altamente simétrica foi proposta em $1985^{[37]}$ e batizada em homenagem ao arquiteto R. Buckminster Fuller e suas estruturas geodésicas ${ }^{[38]}$.

átomo de carbono da molécula de metano $\left(\mathrm{CH}_{4}\right)$ e do diamante (Fig 2.3), por exemplo.

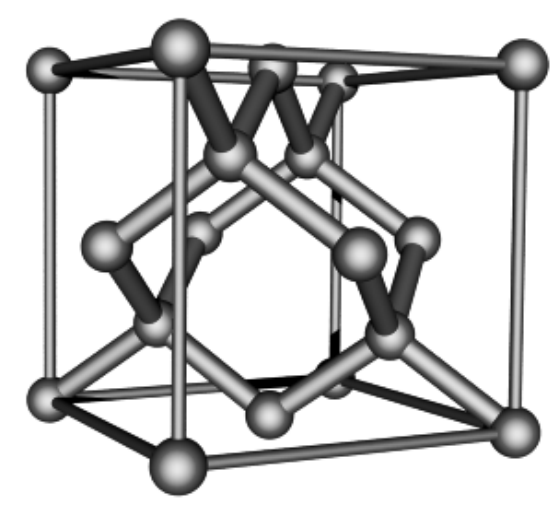

Figura 2.3: Célula unitária do diamante. Formado por átomos de carbono no estado de hibridização $s p^{3}$, é a substância natural mais dura conhecida. Transparente, isolante elétrico e, devido a sua dureza, excelente condutor térmico. Pode-se observar na figura a estrutura cúbica de face centrada que forma o diamante, com átomos nos vértices e nos centros das faces.

\subsection{Nanotubos de carbono}

Nanotubos de carbono (CNT - carbon nanotube) são cilindros ocos de carbono, com diâmetro muito menor que o comprimento. Tipicamente, os nanotubos têm diâmetro em torno de $1 \mathrm{~nm}$ e seu comprimento pode ser de algumas dezenas de nanometros até alguns centímetros ${ }^{[3 ; 4]}$. Essas estruturas receberam 
destaque $^{[39]}$ após serem sintetizadas por Sumio Iijima, em $1991^{[40]}$, inicialmente como tubos de paredes múltiplas. Em 1993 Iijima publicou ${ }^{[1]}$ um método para gerar CNTs cuja parede é formada por apenas uma camada de átomos de carbono. Esses nanotubos de carbono de parede simples (conhecidos como SWNT Single-wall carbon nanotubes) despertam bastante interesse devido à sua grande resistência mecânica e flexibilidade e a suas propriedades eletrônicas dependentes da geometria ${ }^{[2]}$, pois podem ser metálicos ou semicondutores. Isso os torna bastante úteis em eletrônica molecular, microscopia de força atômica ${ }^{[17-19]} \mathrm{e} e m$ diversas áreas de aplicação.

\subsubsection{Grafite e grafeno}

Estruturalmente, pode-se entender um nanotubo de carbono como uma única folha de grafeno enrolada, portanto esses materiais compartilham algumas de suas propriedades geométricas e eletrônicas. Dessa forma, iniciaremos o estudo dos nanotubos de carbono pela geometria e estrutura eletrônica do grafeno.

O grafeno consiste em uma camada de átomos de carbono ligados, cada um, a três vizinhos através de ligações covalentes em uma rede hexagonal como na Fig. 2.4. Embora seja conhecido teoricamente há algum tempo e sirva de base

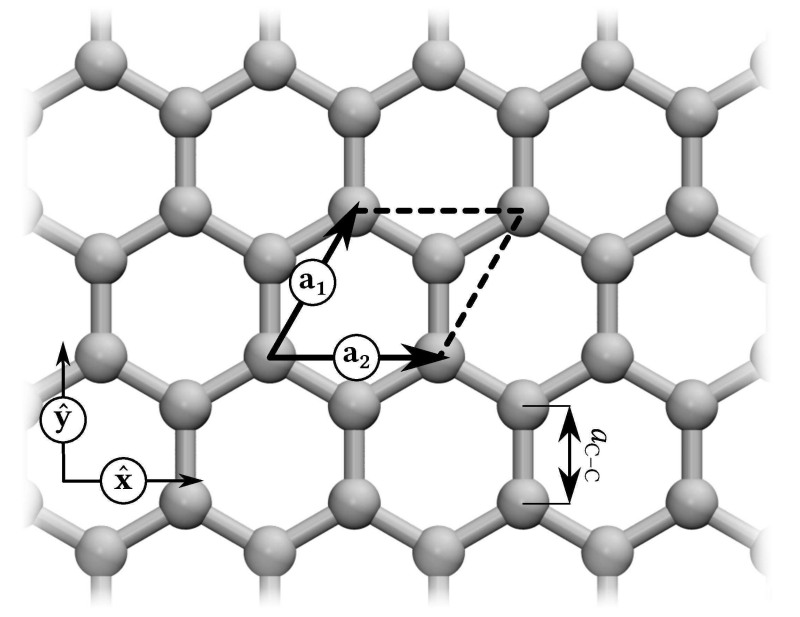

Figura 2.4: Propriedades geométricas do grafeno. Os vetores de rede $\mathbf{a}_{1}$ e $\mathbf{a}_{2}$ definem a célula unitária, destacada no losango pontilhado. $a_{\mathrm{C}-\mathrm{C}}$ é a ligação carbono-carbono e tem comprimento de $1,42 \AA$.

teórica para a modelagem do grafite e dos nanotubos, foi isolado experimentalmente pela primeira vez em $2004^{[41]}$ pelo grupo de Andre Geim e Konstantin Novoselov, feito que lhes rendeu o Prêmio Nobel de física em 2010 por inovadores experimentos a respeito do material bidimensional grafeno ${ }^{[42]}$. Folhas de grafeno empilhadas e ligadas entre si por forças de van der Waals formam o grafite. Essa 
fraca ligação entre as folhas paralelas é responsável pela baixa dureza característica do grafite, apesar da rigidez das ligações entre os átomos de uma mesma folha. Por isso ele é utilizado como lubrificante sólido e na aplicação que lhe rendeu seu nome: a escrita.

Uma folha de grafeno é um cristal bidimensional com dois átomos cristalograficamente não-equivalentes na célula unitária, como vemos na Fig. 2.4. A distância $a_{\mathrm{C}-\mathrm{C}}$ entre esses átomos é de $1,42 \AA$ e os vetores de rede são dados por

$$
\begin{aligned}
\mathbf{a}_{1} & =a \hat{\mathbf{x}} \quad \mathrm{e} \\
\mathbf{a}_{2} & =\frac{a}{2} \hat{\mathbf{x}}+\frac{\sqrt{3} a}{2} \hat{\mathbf{y}}, \quad \text { com } \\
a & =\sqrt{3} a_{\mathrm{C}-\mathrm{C}} .
\end{aligned}
$$

A rede recíproca, definida pelos vetores de base $\mathbf{g}_{1}$ e $\mathbf{g}_{2}$ que devem satisfazer $\mathbf{g}_{\mathbf{i}} \cdot \mathbf{a}_{\mathbf{j}}=2 \pi \delta_{i j}$, resulta em uma rede hexagonal rotacionada de $30^{\circ}$ em relação à rede direta, com

$$
\begin{aligned}
& \mathbf{g}_{1}=\frac{2 \pi}{a} \hat{\mathbf{k}}_{\mathbf{x}}-\frac{2 \pi}{\sqrt{3} a} \hat{\mathbf{k}}_{\mathbf{y}} \quad \mathrm{e} \\
& \mathbf{g}_{2}=2 \pi \frac{2}{\sqrt{3} a} \hat{\mathbf{k}}_{\mathbf{y}},
\end{aligned}
$$

ilustrados na Fig. 2.5. A primeira zona de Brillouin, portanto, forma um hexágono rotacionado de $30^{\circ}$ em relação à estrutura atômica. A rede hexagonal apresenta três pontos de alta simetria:

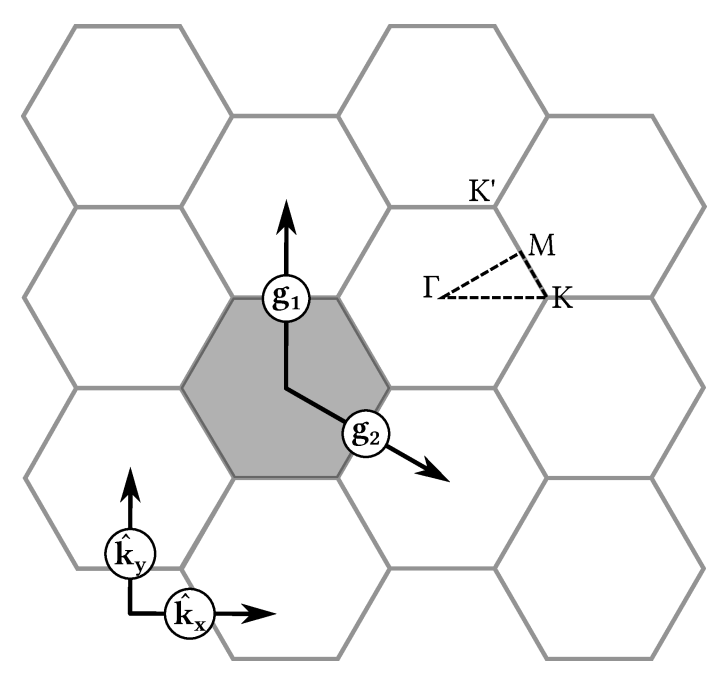

Figura 2.5: Rede recíproca do grafeno. Os vetores de rede $\mathbf{g}_{1}$ e $\mathbf{g}_{2}$ definem a célula unitária. $\mathrm{O}$ hexágono destacado representa a primeira zona de Brillouin. Destacamos também os pontos de alta simetria, $\Gamma, K$ e $M$. 
O ponto $\Gamma$, no centro da zona de Brillouin, que define quatro planos de reflexão, rotações de $120^{\circ}$ e $180^{\circ}$;

Os pontos $K$ e $K^{\prime}$, nos vértices da zona de Brillouin, com três reflexões e rotações de $120^{\circ} \mathrm{e}$

O ponto $M$, no ponto médio do lado da zona de Brillouin, com dois planos de reflexão e rotações de $180^{\circ}$.

Podemos calcular as bandas de energia do grafeno através do método de tight binding ${ }^{[2 ; 43]}$, levando em conta que cada átomo da base está ligado com três imagens periódicas de seu vizinho inequivalente. Obtemos, para as bandas $\pi$, as energias

$$
E(\mathbf{k})=\frac{\epsilon_{2 p}+t w(\mathbf{k})}{1+s w(\mathbf{k})}
$$

para a banda $\pi$ de valência e

$$
E^{*}(\mathbf{k})=\frac{\epsilon_{2 p}-t w(\mathbf{k})}{1-s w(\mathbf{k})}
$$

para a banda $\pi$ de condução. Nessas expressões,

$$
s=\left\langle\phi_{A}\left(\mathbf{r}_{A}\right) \mid \phi_{B}\left(\mathbf{r}_{B}\right)\right\rangle=0,129
$$

é a integral de sobreposição entre os dois átomos da base,

$$
t=\left\langle\phi_{A}\left(\mathbf{r}_{A}\right)|\mathcal{H}| \phi_{B}\left(\mathbf{r}_{B}\right)\right\rangle=-3,033 \mathrm{eV}
$$

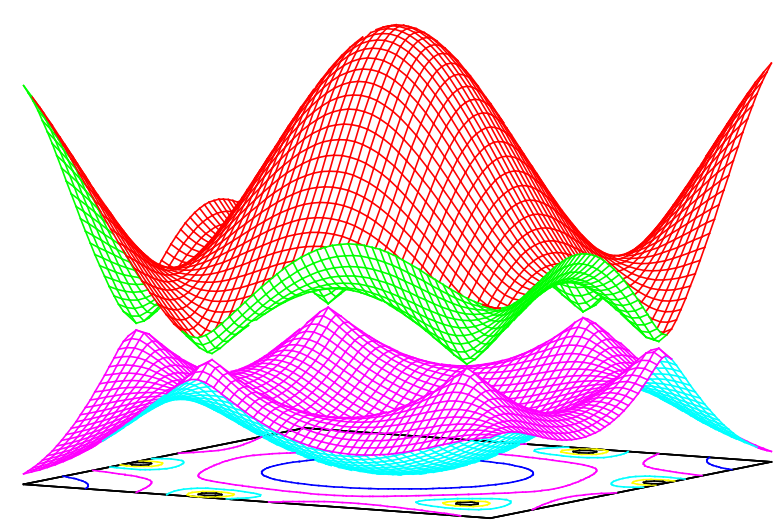

Figura 2.6: Estrutura de bandas do grafeno. Representamos a mais alta banda $\pi$ de valência e a mais baixa banda $\pi$ de condução do grafeno calculada pelo método de tight binding ${ }^{[2 ; 4]}$. 
é a integral de transferência entre os dois átomos e

$$
w(\mathbf{k})=\sqrt{1+4 \cos \frac{\sqrt{3} k_{x} a}{2} \cos \frac{k_{y} a}{2}+4 \cos ^{2} \frac{k_{y} a}{2}}
$$

é um fator de forma que leva em conta a disposição dos três vizinhos de cada átomo. Isso resulta nas bandas de energia ilustradas na Figura 2.6. Nela vemos que as bandas de valência e de condução tocam a região da energia de Fermi nos vértices da primeira zona de Brillouin, mas não o cruzam. Por isso, uma folha de grafeno é classificada como um semicondutor de gap nulo. Além disso, nos pontos $K$, a relação de dispersão se comporta de forma linear, não quadrática. Essa é uma característica de partículas sem massa, regidas pela equação de Dirac e por isso os pontos $K$ também são chamados pontos de Dirac.

\subsubsection{Propriedades geométricas}

Os nanotubos podem ser entendidos como seções retangulares da folha de grafeno, enroladas em forma de cilindro. Um dos lados desse retângulo é paralelo ao comprimento do tubo e o outro, chamado vetor quiral $\left(\mathbf{C}_{\mathbf{h}}\right)$, representa a circunferência do cilindro. $\mathrm{O}$ vetor quiral é uma combinação linear dos vetores $\mathbf{a}_{1}$ e $\mathbf{a}_{2}$ da rede do grafeno, de forma que $\mathrm{C}_{\mathbf{h}}=n \mathbf{a}_{1}+m \mathbf{a}_{2}$, com os coeficientes $n$ e $m$ inteiros. Utiliza-se as coordenadas $(n, m)$ do vetor quiral para indexar os nanotubos, já que elas definem univocamente o diâmetro e a quiralidade dos tubos.

As propriedades geométricas mais importantes de um nanotubo são seu diâmetro $D$ e o ângulo quiral $\theta$, ilustrados na Figura 2.7. Calculamos o diâmetro a partir do comprimento do vetor quiral:

$$
D=\frac{\left|\mathbf{C}_{\mathbf{h}}\right|}{\pi}=\frac{\sqrt{3} a_{C-C}}{\pi} \sqrt{n^{2}+m^{2}+n m} .
$$

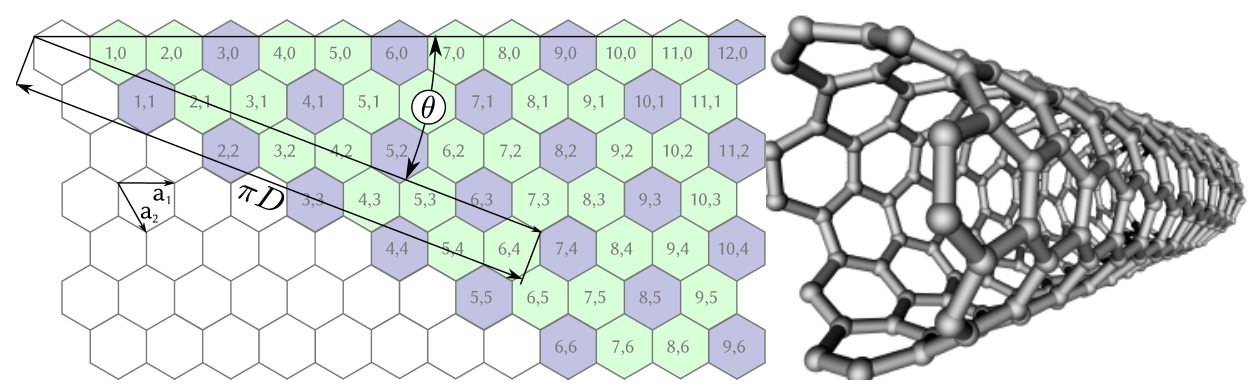

Figura 2.7: Propriedades geométricas de um nanotubo de carbono. $\mathrm{O}(7,4)$ (à direita) é um nanotubo metálico. $\theta$ : ângulo quiral; $D$ : Diâmetro. Hexágonos verdes (mais claros) nanotubos semicondutores. Hexágonos azuis (mais escuros): nanotubos metálicos. 


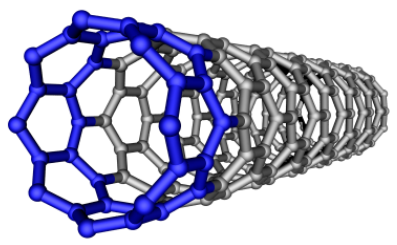

(a) $(8,0)$, zigzag

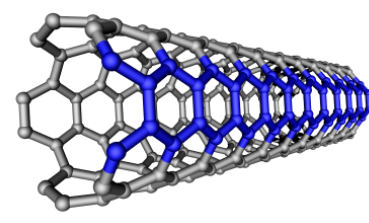

(b) $(5,5)$, armchair

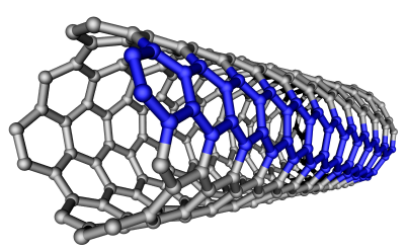

(c) $(7,4)$, quiral

Figura 2.8: Exemplos de nanotubos de diferentes quiralidades. As fileiras de anéis aromáticos destacadas em azul mostram o efeito da quiralidade.

Obtemos o ângulo quiral através da expressão ${ }^{[2]}$

$$
\cos \theta=\frac{2 n+m}{2 \sqrt{n^{2}+m^{2}+n m}}
$$

Essas duas expressões vêm de relações de geometria plana utilizando a base não ortogonal de vetores $\mathbf{a}_{1}$ e $\mathbf{a}_{2}$, que formam um ângulo de $60^{\circ}$ entre si e desprezam distorções na rede grafítica causadas pela curvatura.

Com base no ângulo quiral, podemos definir três grupos de nanotubos: os aquirais zigzag $(n, 0)$ e $\operatorname{armchair}(n, n)$ e os tubos quirais $(n, m)$, com $m \neq 0$ e $m \neq n$. Os primeiros são chamados de aquirais pois as fileiras de anéis aromáticos se fecham formando uma circunferência (zigzag, Fig. 2.8(a)) ou são paralelos ao eixo do tubo (armchair, Fig. 2.8(b)). Esses tubos apresentam simetria de reflexão por um plano paralelo ao eixo. Nos demais nanotubos, cada fileira de anéis aromáticos forma uma hélice ao redor do eixo do tubo. Reflexões por planos paralelos ao eixo levam a geometrias invertidas, com as hélices equivalentes girando em sentido oposto à original, por isso o nome de tubos quirais.

\subsubsection{Estrutura eletrônica}

Uma vez que o nanotubo de carbono apresenta condições cíclicas de contorno na direção do vetor quiral - e consiste, portanto, em um sistema finito os estados eletrônicos são quantizados nessa direção e somente alguns vetores de onda $\mathbf{k}$ serão permitidos aos elétrons: aqueles que representarem um número inteiro de comprimentos de onda ao longo da circunferência do tubo. Essas condições de contorno levam ao surgimento de linhas de estados permitidos, tantas quanto o número de pares de átomos em uma célula unitária do nanotubo. Somente se essas linhas interceptarem algum vértice da zona de Brillouin, onde o gap é nulo, teremos um nanotubo metálico, em vez de semicondutor. É possível mostrar ${ }^{[2]}$ que essa intersecção ocorre quando $(n-m)$ é múltiplo de 3 , por isso a natureza metálica ou semicondutora dos nanotubos depende dos índices $n$ e $m$. 
Já que os vetores $\mathbf{k}$ permitidos aos elétrons somente são contínuos na direção perpendicular ao vetor quiral $\mathrm{C}_{\mathrm{h}}$, podemos entender os nanotubos de carbono como sistemas unidimensionais e as várias linhas de estados permitidos como bandas independentes ${ }^{[44]}$. Um resultado dessa característica unidimensional é o surgimento das singularidades de van Hove, descontinuidades na densidade de estados como ilustradas na Fig. 2.10 que variam de acordo com a geometria do nanotubo e desempenham um papel fundamental na identificação de nanotubos por fotoluminescência e espectroscopia Raman, como veremos na Seção 2.2.5.

Em espectroscopia óptica, as transições recebem nomes com índices que identificam as singularidades de van Hove envolvidas: o intervalo entre a mais alta singularidade da banda de valência e a mais baixa singularidade da banda de condução é chamada de $E_{11}$ ou $S_{11}$ e $M_{11}$ para distinguir transições em tubos semicondutores e metálicos, respectivamente. Entre a segunda singularidade mais alta ocupada e a segunda mais baixa livre, $E_{22}$, e assim por diante.

Dessa forma, a seleção de nanotubos de acordo com suas propriedades geométricas é uma etapa importante na aplicabilidade dessas estruturas em dispositivos que dependam propriedades eletrônicas bem definidas, como microscópios de força atômica que exigem nanotubos metálicos ou transistores moleculares, que dependem de nanotubos semicondutores.

\subsubsection{Síntese}

Existe um conjunto de técnicas para síntese de nanotubos de carbono de parede simples que consistem essencialmente em depositar partículas de carbono sobre um substrato, na presença de um catalisador metálico, e purificar esse depósito para separar os nanotubos de impurezas como fulerenos, nanopartículas metálicas, fibras etc. ${ }^{[2]}$
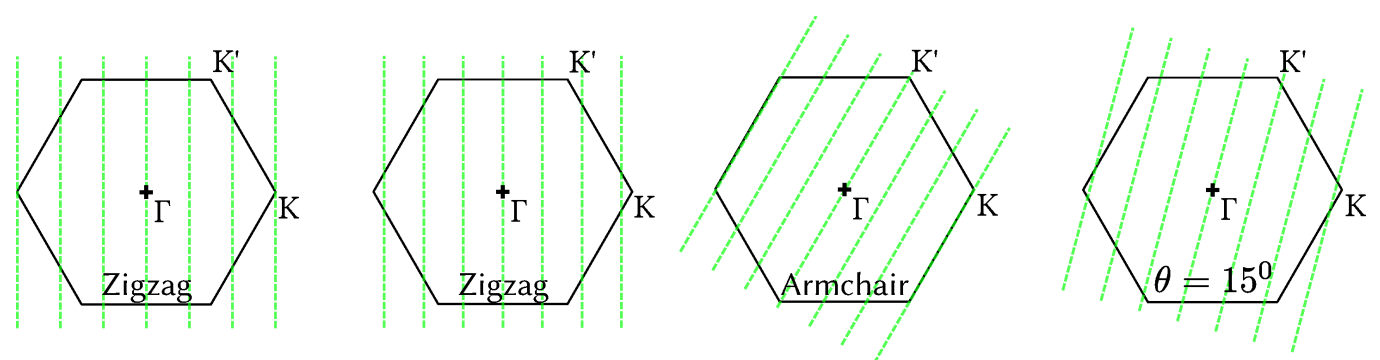

Figura 2.9: Estados permitidos aos elétrons do nanotubo Em preto, a borda da primeira zona de Brillouin da folha de grafeno que forma o nanotubo. Em verde tracejado, os vetores $\mathbf{k}$ permitidos aos elétrons do tubo. Nanotubos tipo armchair são metálicos. Tubos zigzag podem ser metálicos (primeira figura) ou semicondutores (segunda figura), dependendo do diâmetro. O mesmo vale para outros ângulos quirais. 


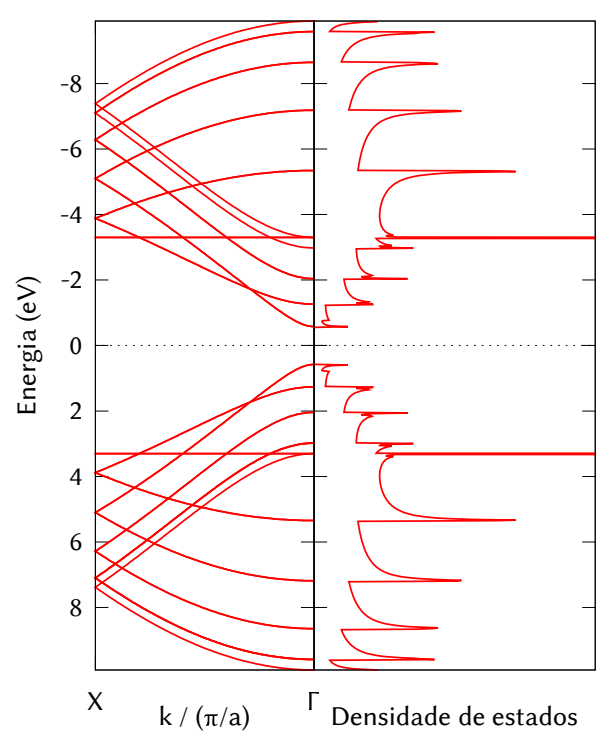

(a) $(10,0)$, semicondutor

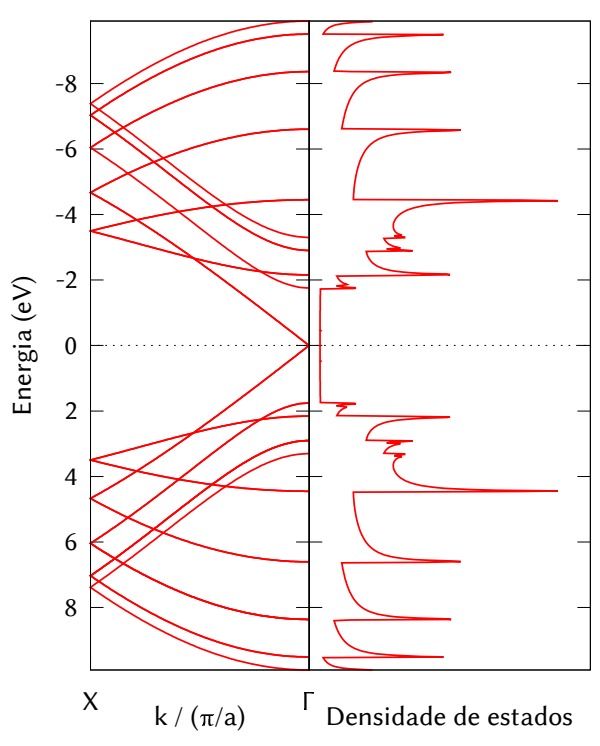

(b) $(9,0)$, metálico

Figura 2.10: Densidade de estados de nanotubos zigzag calculada pelo método de tight binding ${ }^{[2]}$. As singularidades de van Hove aparecem como picos na densidade de estados quando a derivada da relação de dispersão se anula. No tubo metálico $(9,0)$ podemos observar a dispersão linear herdada dos pontos de Dirac do grafeno que leva a uma densidade de estados constante na região do nível de Fermi (linha pontilhada).

Trataremos aqui dos métodos de síntese de nanotubos utilizados nos experimentos a que fazemos referência neste trabalho: ablação a laser, CoMoCAT ${ }^{[21]}$, $\mathrm{HiPCO}^{[20]}$ e arco-jato de plasma ${ }^{[45]}$.

O processo de ablação a laser, que produz nanotubos de $1,1 \mathrm{~nm}$ a $1,6 \mathrm{~nm}$ de diâmetro consiste em bombardear com pulsos de laser de neodímio-ítrioalumínio uma pastilha de grafite impregnada com $1,2 \%$ de átomos de níquel e cobalto em um forno cilíndrico mantido a $1200^{\circ} \mathrm{C}$. Pelo forno passa um fluxo de argônio que varre o vapor de carbono até um coletor de cobre resfriado a água. Sobre esse coletor forma-se um "feltro" de feixes de nanotubos de cerca de $100 \mu \mathrm{m}$ de comprimento ${ }^{[2]}$.

Um processo mais recente, conhecido como CoMoCAT ${ }^{[21]}$, envolve a dissociação de monóxido de carbono, formando partículas de carbono e $\mathrm{CO}_{2}$. Em uma atmosfera de $\mathrm{CO}$ puro sob pressão de $1 \mathrm{~atm}$ a $10 \mathrm{~atm}$, bombeia-se um aerossol de catalizador à base de cobalto e molibdênio através de uma rede de quartzo pulverizado armada em um forno vertical mantido entre $700{ }^{\circ} \mathrm{C}$ e $950^{\circ} \mathrm{C}$. No topo do forno há um filtro para captura dos nanotubos formados e um sistema para reformar o $\mathrm{CO}_{2}$ em $\mathrm{CO}$ e reabastecer o ciclo. 
Este método gera nanotubos com diâmetro entre $0,7 \mathrm{~nm}$ e $1,1 \mathrm{~nm}$ e grande concentração $(\sim 50 \%)$ das espécies $(6,5)$ e $(7,5)$, o que o torna interessante como ponto de partida para produção de amostras altamente purificadas dessas espécies.

Já o método de alta pressão de $\mathrm{CO}$, High pressure $\mathrm{CO}-\mathrm{HiPCO}^{[20]}$, consiste em uma câmara em que se faz fluir monóxido de carbono a alta pressão (30 atm a $50 \mathrm{~atm})$ e temperatura $\left(1000^{\circ} \mathrm{C}\right)$. Injeta-se, então, uma mistura de $\mathrm{CO}$ e o catalizador $\mathrm{Fe}(\mathrm{CO})_{5}$ à temperatura ambiente para formar feixes de nanotubos de diâmetro da ordem de $1 \mathrm{~nm}$ que se condensam sobre superfícies refrigeradas adiante ao longo do fluxo de gás.

É possível obter eficientemente nanotubos de maior diâmetro, de $1,2 \mathrm{~nm}$ a $1,5 \mathrm{~nm}$, através da técnica de arco-jato de plasma ${ }^{[45]}$. Em uma câmara selada e preenchida com hélio a $500 \mathrm{mmHg}$, faz-se saltar um arco elétrico entre dois eletrodos de carbono. O anodo é dopado com níquel e ítrio, enquanto o catodo é formado de carbono puro e posicionado em ângulo em relação ao anodo. A corrente ioniza o hélio e forma um jato de plasma, que é desviado pelo catodo em ângulo. Sobre a superfície da câmara se forma uma fuligem semelhante a algodão que contém os feixes de nanotubos.

O ambiente gasoso em que se formam esses nanotubos apresenta um empecilho para um controle mais fino da geometria ou das propriedades eletrônicas durante a síntese, dando importância aos processos de seleção pós-síntese. Outra característica desses métodos de síntese é produzir nanotubos com as extremidades fechadas, usualmente com hemisférios de fulerenos.

\subsubsection{Técnicas de caracterização}

\section{Microscopia}

Quando sintetizados, os nanotubos de carbono se apresentam unidos em feixes e depositados com a aparência de fuligem sobre um substrato ou uma placa de captura. Nesses depósitos também se encontram impurezas, como resíduos de catalizador, carbono amorfo etc. A fim de verificar a presença de nanotubos nos diversos ${ }^{[45, \text { Seção } 2]}$ depósitos de fuligem que se formam no equipamento de síntese, submete-se as amostras a microscopia eletrônica de transmissão ${ }^{[2]}$. Esta técnica, que consiste em detectar a intensidade de um feixe de elétrons transmitido através da amostra, permite obter imagens de alta resolução (décimos de $\mathrm{nm}$ ) quando associada à informação sobre o contraste de fase nos elétrons transmitidos ${ }^{[46]}$, técnica conhecida como HRTEM (High Resolution Transmission Eletctron Microscopy - Microscopia eletrônica de transmissão de alta resolução). Com a HRTEM pode-se observar nanotubos de parede simples isolados e até mesmo moléculas alojadas no interior do tubo ${ }^{[47 ; 48]}$. 
É possível também observar nanotubos depositados sobre um substrato através de microscopia de força atômica, ao varrer a amostra com uma sonda em formato de agulha cuja ponta tem um diâmetro da ordem de poucos nm. Utilizase esta técnica, por exemplo, para observar se nanotubos em uma amostra se encontram isolados ou se um dispositivo formado por nanotubos depositados ${ }^{[9]}$ apresenta defeitos.

\section{Absorção óptica}

Como vimos na Seção 2.2.3, a densidade de estados eletrônicos dos nanotubos apresenta picos acentuados chamados de singularidades de van Hove, cujas energias dependem dos índices $(n, m)$ do tubo. Essas singularidades levam o nanotubo a absorver luz na faixa do infravermelho, em comprimentos de onda que dependem da sua geometria. Em 1999, Hiromichi Kataura e colaboradores catalogaram $^{[49]}$ os vários gaps entre os picos na densidade de estados e, ao organizá-los em função do diâmetro dos tubos, deu origem ao que R. Saito chamou ${ }^{[50]}$ de Kataura plot. De posse desses dados, é possível, em princípio, atribuir

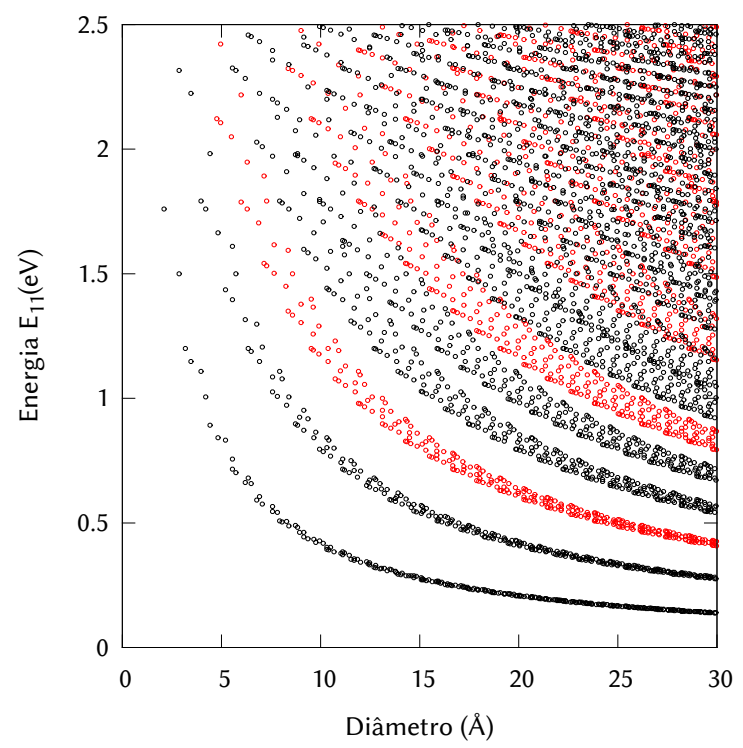

Figura 2.11: Kataura plot. Energia da transição $E_{11}$ em função do diâmetro do tubo, calculada através do método de tight-binding. Em vermelho, tubos metálicos. Em preto, tubos semicondutores. Elaborado com dados disponíveis na página de Shigueo Maruyama $^{[51]}$ e utilizados com permissão.

índices $(n, m)$ a picos de absorção no infravermelho com base no comprimento de onda absorvido. A influência do solvente nas medidas de absorção, bem como de moléculas aderidas à superfície do tubo, deve ser levada em conta ${ }^{[9 ; 52]}$ ao caracterizar amostras por esse método. 


\section{Fotoluminescência}

Uma desvantagem da absorção óptica é, como se vê na Fig. 2.11, a distribuição das energias de absorção, que concentra diversas espécies de tubos em intervalos estreitos de energia, principalmente no caso de tubos de maior diâmetro.

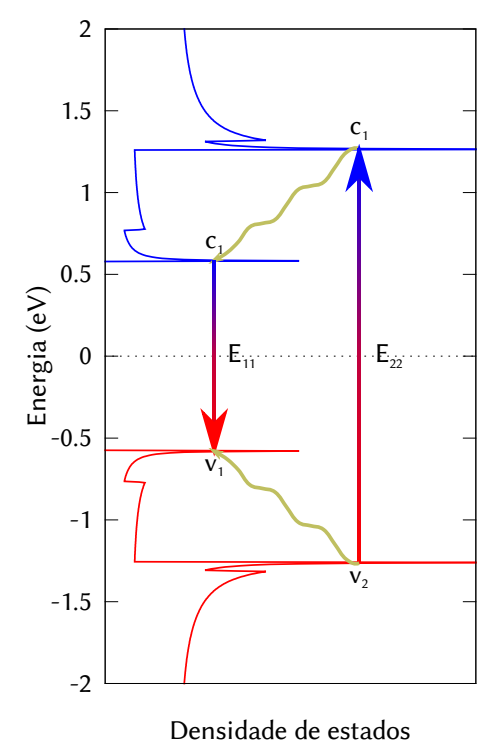

Figura 2.12: Processo de fotoluminescencia em um nanotubo (10,0). Em vermelho, densidade de estados ocupados. Em azul, densidade de estados desocupados. Seta azul: absorção $E_{22}$. Setas onduladas, relaxamento não-radiativo. Seta vermelha, emissão $E_{11}$.

Para identificar tubos semicondutores, é possível fazer uso de mapas de excitação de fotoluminescência ${ }^{[53]}$ (Photoluminescence excitation - PLE), construídos medindo o espectro de emissão de nanotubos em função do comprimento de onda da excitação. Esse processo utiliza o fato de as excitações $E_{11}$ e $E_{22}$ variarem de acordo com a geometria do tubo. Caso o fóton incidente tenha frequência compatível com a excitação $E_{22}$ do tubo em questão, ele poderá ser absorvido e formar um par elétron-buraco nos níveis $c_{2}$ e $v_{2}$ da Figura 2.12. O par então decai não-radiativamente para os níveis $c_{1}$ e $v_{1}$ e se recombina emitindo um fóton de energia $E_{11}$. O resultado é um gráfico bidimensional com picos de intensidade nos pontos com coordenadas $\left(E_{11}, E_{22}\right)$ dos tubos presentes na amostra. Esta técnica permite identificar apenas nanotubos semicondutores, uma vez que em tubos metálicos o par elétron-buraco decai não-radiativamente até o nível de Fermi e se aniquila. 


\section{Espectroscopia Raman}

Espectroscopia Raman é outra forma de identificar as espécies de nanotubos presentes em uma amostra. O espalhamento Raman parte da absorção de um fóton e a criação de um par elétron-buraco. No caso do espalhamento Raman de primeira ordem, o elétron excitado cede energia $\Delta E$ aos modos vibracionais da rede e dá origem a um fônon. Quando o elétron recombina com o buraco, emite um fóton de energia mais baixa que aquele absorvido. Esse processo recebe o nome de espalhamento Raman Stokes. Quando o elétron absorve energia do fônon, o fóton espalhado tem energia maior que o absorvido e o processo é chamado de anti-Stokes. A diferença $\Delta E$ de energia entre os fótons absorvido e espalhado é conhecida como deslocamento Raman e o espectro Raman é construído como uma curva de intensidade espalhada em função do deslocamento.

Quando a energia do fóton absorvido ou do fóton espalhado coincide com a diferença de energia entre estados reais do sistema, a probabilidade de transição aumenta consideravelmente e o processo recebe o nome de espalhamento Raman ressonante ${ }^{[54]}$. Explora-se esse fenômeno com nanotubos ao sintonizar a energia do laser incidente na amostra com a energia $E_{11}$ dos tubos para obter uma resposta acentuada de cada espécie ${ }^{[5 ; 56]}$.

Os valores de deslocamento Raman dependem dos modos normais de vibração do sistema. Os nanotubos de carbono herdam alguns de seus modos normais do grafeno. A banda G, por exemplo, está relacionada com a vibração de estiramento, em fase, das ligações carbono-carbono. A banda D está associada a defeitos na estrutura grafítica ${ }^{[55]}$. Uma nova banda, de deslocamentos Raman da ordem de $100 \mathrm{~cm}^{-1}$ a $250 \mathrm{~cm}^{-1[56]}$, provém da estrutura cilíndrica do nanotubo. Chamada de modo de respiração radial ou RBM - Radial breathing mode, está relacionada a oscilações no diâmetro do tubo. A frequência $\omega_{\mathrm{RBM}}$ desse modo é inversamente proporcional ao raio do tubo ${ }^{[55]}$. Com o controle da energia do fóton incidente pode-se, então, fazer um mapa da frequência do RBM em função da energia de excitação $E_{11}$ a fim de identificar os índices $(n, m)$ dos tubos presentes em uma amostra. O resultado desse tipo de medida é um mapa análogo a um Kataura plot, com as espécies presentes na amostra representadas como picos de intensidade do modo radial no espectro.

\subsubsection{Técnicas de separação}

As técnicas conhecidas para separar nanotubos em função de suas propriedades geométricas envolvem ${ }^{[3 ; 57]}$ i) funcionalização química seletiva dos nanotubos - ligando covalentemente radicais químicos aos nanotubos ${ }^{[58]}$; ii) encapsulamento seletivo - através de adesão não covalente de moléculas que permitam a suspensão dos tubos, como detergentes, polímeros ou DNA; iii) destruição 
seletiva - fazer passar correntes elétricas intensas que destroem nanotubos metálicos; iv) eletroforese; v) cromatografia e vi) ultracentrifugação, os três últimos adaptados de técnicas comuns no tratamento de biomoléculas.

Dessas, as que têm aplicação mais simples são aquelas que não envolvem ligações covalentes com o nanotubo, pois esse tipo de interação pode afetar e até destruir as propriedades eletrônicas que se busca ao isolar os tubos, além de dificultar a recuperação dos tubos em seu estado original após a separação.

Quando sintetizados, os nanotubos se apresentam em feixes, ligados por interações de van der Waals entre suas paredes externas. Para separá-los desses feixes, o primeiro passo ${ }^{[59]}$ consiste em colocá-los em um meio líquido e submetê-los a ondas de ultrassom. Esse processo, chamado de sonicação, agita os tubos e os afasta, temporariamente, dos vizinhos. Um agente presente no meio líquido, como um surfactante ${ }^{[24 ; 59]}$ ou um polímero ${ }^{[9 ; 36 ; 60]}$, pode então aderir à superfície dos tubos e evitar o reagrupamento do feixe. Com isso, se obtém uma suspensão de nanotubos encapsulados isolados em meio a nanotubos livres que tendem a se reagrupar num processo conhecido como rebundling.

Os feixes de tubos reagrupados podem ser separados do solvente e dos tubos isolados através de centrifugação. O agente encapsulante dispersa os nanotubos isolados, enquanto os feixes precipitam durante o processo. O tipo e a quantidade de nanotubos suspensos depende da interação entre os tubos e o agente encapsulante.

Surfactantes, como o dodecil sulfato de sódio (SDS), o dodecil benzeno sulfonato de sódio (SDBS) e o colato de sódio (SC), são capazes de suspender tubos de diâmetro pequeno de forma mais eficiente que tubos maiores ${ }^{[61]}$. Uma ou mais etapas de ultracentrifugação em gradiente de densidade $-D G U^{[24]}$ permitem obter amostras purificadas de tubos do diâmetro desejado. $\mathrm{O}$ funcionamento desse processo se baseia no fato de que tubos de diâmetros diferentes admitem diferentes moléculas de surfactante em seu interior ${ }^{[25]}$ e, por isso, apresentam densidades que dependem de seu diâmetro. Ao centrifugar esses tubos em uma coluna com um gradiente de densidade, eles se distribuem de forma que tubos de maior diâmetro, mais densos, se encontram na parte inferior do tubo da centrífuga e aqueles de menor diâmetro, menos densos, se posicionam próximo ao topo. É possível repetir esse procedimento num processo em cascata que permite a produção de amostras de alta pureza de tubos específicos, com rendimento de gramas por dia ${ }^{[62]}$.

Já polímeros, como o DNA, politiofenos e polifluorenos (vide Seção 2.3), apresentam propriedades geométricas que podem afetar sua interação com nanotubos de certas quiralidades e diâmetros. Dessa forma, o tipo de nanotubos suspensos depende da estrutura do polímero e isso nos leva a pensar que pode ser possível projetar moléculas capazes de suspender seletivamente tubos de interesse. Em 2007, Adrian Nish e colaboradores ${ }^{[28 ; 33]}$ demonstraram que o 
poli[9,9-dioctilfluorenil-2,7-diil] (PFO) é capaz de suspender seletivamente nanotubos de diâmetro da ordem de $1 \mathrm{~nm}$ e ângulo quiral maior que $25^{\circ}$. Em 2012, o grupo de M. A. Loi observou ${ }^{[9]}$ que polifluorenos de cadeia lateral mais longa são capazes de suspender nanotubos de maior diâmetro. Neste trabalho lançamos luz sobre as propriedades do polifluoreno que lhe garantem essa seletividade.

\subsection{Polímeros conjugados}

Embora não sejam compostos exclusivamente por carbono, os polímeros conjugados apresentam importantes propriedades derivadas da estrutura eletrônica desse elemento. Estruturas conjugadas são formadas por ligações simples e duplas alternadas ${ }^{[63]}$ que permitem que os orbitais $p$ de uma ligação dupla interajam com os de outra. Isso dá origem a estados deslocalizados, orbitais que se estendem por longas regiões das moléculas.

Os orbitais $\pi$ deslocalizados podem conferir aos polímeros conjugados características únicas dentre os polímeros, como fotoluminescência e absorção na região do visível ou comportamento semicondutor ou condutor, cuja descoberta, com o poliacetileno ${ }^{[64]}$ (Fig. 2.13(a)), rendeu a Alan Heeger, Alan G. MacDiarmid e Hideki Shirakawa o Prêmio Nobel de Química do ano 2000 pelo descobrimento e desenvolvimento de polimeros condutores ${ }^{[65]}$.

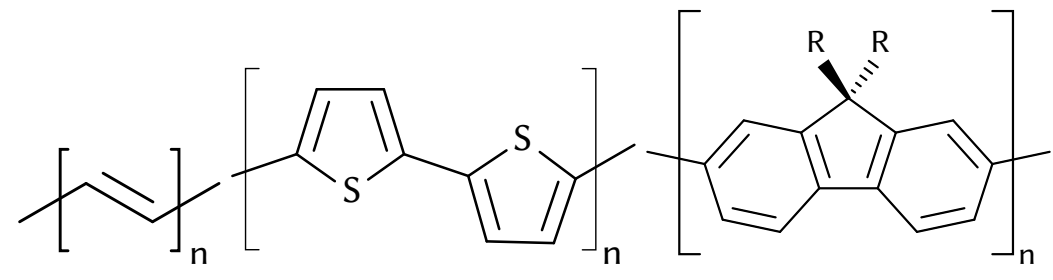
(a) Trans-
(b) Politiofeno
(c) Polifluoreno
Poliacetileno

Figura 2.13: Exemplos de polímeros conjugados

Em particular, interessam-nos os polímeros conjugados capazes de suspender nanotubos de carbono. Polímeros aromáticos, como politiofenos ${ }^{[66]}$ (Fig. 2.13(b)), polifluorenos $^{[28]}$ (Fig. 2.13(c)) e seus derivados têm destaque nessa aplicação devido ao fenômeno de empilhamento $\pi$, em que os orbitais $\pi$ dos anéis do polímero interagem com os orbitais $\pi$ dos anéis do nanotubo e levam ao alinhamento dos anéis, de forma análoga ao que acontece no grafite. Além de favorecer a adesão dos polímeros aos tubos, essa interação tem potencial para melhorar propriedades eletrônicas nos tubos ${ }^{[33]}$. 
<smiles>CCCCCCCc1sc(CCCCCC)cc1CC</smiles>

(a) P3DDT

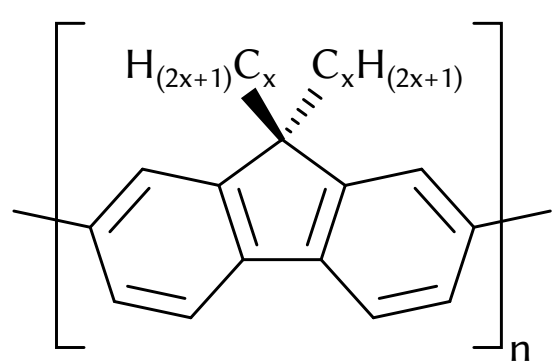

(b) PFO/PF8: $\mathrm{x}=8$; PF12: $\mathrm{x}=12$

Figura 2.14: Exemplos de polímeros derivados por funcionalização com alquilas. Em geral, utilizamos o número de carbonos da alquila na abreviação do nome do polímero, ou uma expressão derivada do nome da alquila: hexil: $\mathrm{H}$; octil: $\mathrm{O}$; decil: D; dodecil: DD

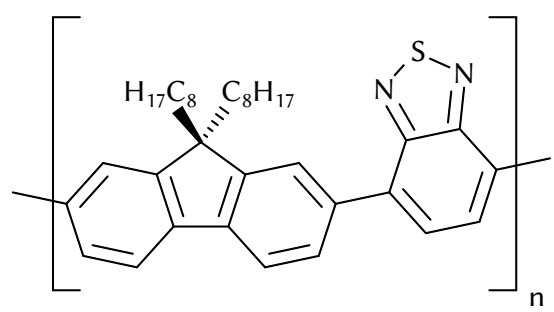

(a) P8BT

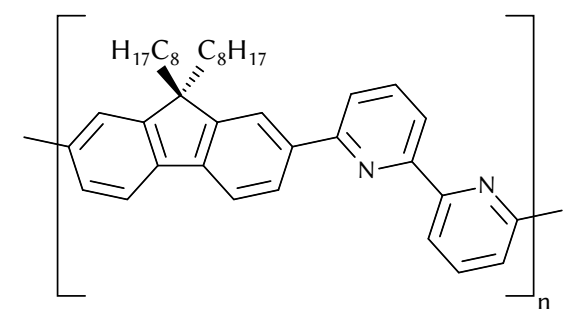

(b) PFO-BPy

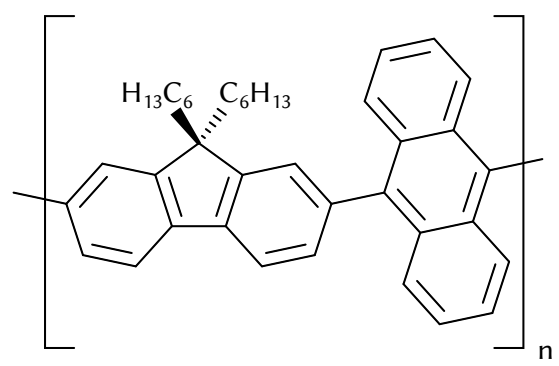

(c) PFH-A

Figura 2.15: Exemplos de polímeros derivados por copolimerização.

Em busca de otimizar as interações entre polímeros, nanotubos e solventes, utiliza-se derivados desses polímeros, seja na forma de copolímeros ou de funcionalização através de cadeias laterais. Um derivado do politiofeno que mostrou sucesso ${ }^{[66]}$ em suspender nanotubos é o poli-(3-dodeciltiofeno) (P3DDT), ilustrado na Fig. 2.14(a). Neste trabalho, lidamos com os poli-(alquilfluorenos), como na Figura 2.14(b), com cadeias saturadas de 6, 8, 10, 12, 15 e 18 carbonos ligadas à cadeia principal. Dentre os copolímeros baseados em fluoreno, aqueles 
compostos com benzotiadiazol ${ }^{[67]}$ (Fig. 2.15(a)), bipiridina (Fig 2.15(b)) e antraceno (Fig 2.15(c)) ${ }^{[68]}$ se mostraram capazes de suspender nanotubos de grande diâmetro. Funcionalizar os polímeros conjugados, cuja cadeia é geralmente hidrofóbica, também permite alterar sua dispersibilidade em água ao ligar radicais polares à cadeia principal ${ }^{[34]}$.

As propriedades eletrônicas de polímeros conjugados são sensíveis ao chamado comprimento de conjugação, uma medida da extensão dos orbitais deslocalizados. Particularmente, quanto maior o comprimento de conjugação, maior o comprimento de onda de absorção ${ }^{[69]}$. No caso de polímeros aromáticos, o comprimento de conjugação está associado ao alinhamento dos anéis, de maneira que deformações na cadeia polimérica levam a alterações no espectro de absorção observado. É neste fenômeno que se baseia a investigação descrita no Capítulo 4. 


\section{Capítulo 3}

\section{Métodos}

Este trabalho consiste em uma investigação computacional das propriedades eletrônicas e mecânicas de polímeros interagindo com nanotubos de carbono. Passamos agora a descrever os fundamentos teóricos e aproximações que norteiam os métodos que aplicamos nesta investigação.

\subsection{Teoria quântica em física molecular}

Um sistema de átomos interagindo na escala molecular pode ser descrito por uma função de onda $\Psi$ determinada pela equação de Schrödinger

$$
H \Psi(\mathbf{R}, \mathbf{r})=E \Psi(\mathbf{R}, \mathbf{r})
$$

onde o vetor $\mathbf{R}$ representa todas as coordenadas de todos os núcleos atômicos, o vetor $\mathbf{r}$ representa as coordenadas de todos os elétrons e $H$ é o operador hamiltoniano que contém as informações sobre as interações entre as partículas:

$$
H=T_{\mathrm{N}}+T_{\mathrm{el}}+V_{\mathrm{N}-\mathrm{N}}+V_{\mathrm{el}-\mathrm{N}}+V_{\mathrm{el}-\mathrm{el}},
$$

composta por termos de energia cinética dos núcleos $T_{\mathrm{N}}$ e dos elétrons $T_{\mathrm{el}}$, energia potencial coulombiana entre os núcleos $V_{\mathrm{N}-\mathrm{N}}$, entre núcleos e elétrons $V_{\mathrm{el}-\mathrm{N}}$ e entre os elétrons $V_{\text {el-el }}$. Essa equação apresenta grande complexidade e não possui solução exata, portanto algumas aproximações se fazem necessárias.

A primeira delas, chamada de aproximação adiabática, leva em conta o fato de que os elétrons possuem massa muito menor (três ordens de grandeza) que os núcleos, de forma a podermos considerar que seguem adiabaticamente os núcleos em seu movimento. Dessa forma, a energia cinética dos núcleos, $T_{\mathrm{N}}=-\frac{\hbar}{2 M_{N}} \nabla_{\mathrm{R}}^{2}$, pode ser desprezada ${ }^{[70]} \mathrm{e}$ assim podemos separar o hamiltoniano 
em

$$
\begin{aligned}
H & =V_{\mathrm{N}-\mathrm{N}}+H_{\mathrm{el}} \\
H_{\mathrm{el}} & =T_{\mathrm{el}}+V_{\mathrm{el}-\mathrm{N}}+V_{\mathrm{el}-\mathrm{el}}
\end{aligned}
$$

Agora, $H$ comuta com as coordenadas $\mathbf{R}$ dos núcleos e podemos separar a função de onda total em uma parte eletrônica e uma parte nuclear:

$$
\Psi(\mathbf{R}, \mathbf{r})=\psi(\mathbf{r} ; \mathbf{R}) \Phi(\mathbf{R}),
$$

onde $\psi(\mathbf{r} ; \mathbf{R})$ é a função de onda eletrônica, que depende explicitamente das coordenadas eletrônicas mas apenas parametricamente das coordenadas nucleares, e $\Phi(\mathbf{R})$ é a função de onda nuclear. Esta separação dos movimentos eletrônico e nuclear é chamada separação de Born-Oppenheimer ${ }^{[70]}$. Levando em conta os termos do hamiltoniano dependentes das coordenadas eletrônicas $H_{\mathrm{el}}$ e os dependentes das coordenadas nucleares $H_{\mathrm{N}}$ temos duas equações:

$$
\begin{aligned}
H_{\mathrm{el}} \psi(\mathbf{r} ; \mathbf{R}) & =E_{\mathrm{el}}(\mathbf{R}) \psi(\mathbf{r} ; \mathbf{R}) \mathrm{e} \\
\left(H_{\mathrm{N}}+E_{\mathrm{el}}(\mathbf{R})\right) \Phi(\mathbf{R}) & =E \Phi(\mathbf{R}) .
\end{aligned}
$$

A equação para a função de onda eletrônica (3.2) nos dá uma energia que depende das coordenadas nucleares $E_{\mathrm{el}}(\mathbf{R})$. Essa energia aparece como energia potencial na (3.3) para o movimento dos núcleos devido à rapidez do ajuste de $\psi(\mathbf{r} ; \mathbf{R})$ ao movimento nuclear. Incorporamos esse potencial à repulsão núcleonúcleo $V_{\mathrm{N}-\mathrm{N}}$ e recuperamos a energia cinética nuclear $T_{\mathrm{N}}$ para obter a equação de Schrödinger para os núcleos (3.3), que agora não depende das coordenadas dos elétrons.

Ainda assim, a equação (3.2) é bastante complicada até para sistemas relativamente pequenos, com poucos átomos. Há, portanto, diversas abordagens para obter suas soluções e a forma de $E_{\mathrm{el}}(\mathbf{R})$. Métodos ab initio consistem em resolver as integrais necessárias, partindo diretamente das equações diferenciais. O método de Hartree-Fock, por exemplo, busca resolver a equação (3.2) através de uma abordagem de campo médio, transformando a equação de muitos corpos num sistema de equações de um e dois corpos, como veremos na Seção 3.3.1. Outros métodos, como a teoria do funcional da densidade (DFT) buscam obter $E_{\mathrm{el}}(\mathbf{R})$ através de outras equações, contornando a (3.2) completamente. Exploraremos esse método em mais detalhes na Seção 3.3.5.

Métodos semiempíricos simplificam a resolução da (3.2) utilizando tabelas de valores parametrizados a partir de cálculos mais sofisticados ou resultados experimentais. Técnicas de mecânica molecular eliminam inteiramente o problema de resolver as equações de autovalores obtendo os valores da energia potencial $E_{\mathrm{el}}(\mathrm{R})$ de tabelas conhecidas como campos de força e considerando os núcleos 
como pontos materiais clássicos para os quais vale a equação de movimento de Newton.

Cada abordagem apresenta suas vantagens e limitações. Enquanto há métodos $a b$ initio que levam a resultados mais detalhados, com informações sobre densidade eletrônica, possíveis quebras de ligação e estados excitados, eles são computacionalmente onerosos, tanto em termos de tempo de processamento quanto de memória. Sua aplicação, portanto, se torna dispendiosa para sistemas com mais de algumas dezenas de átomos. Métodos semiempíricos são menos custosos mas, como ocorre com todo método parametrizado, estão sujeitos à qualidade do conjunto de parâmetros adotado.

\subsection{Mecânica molecular clássica}

Nesta seção vamos nos concentrar em mecânica molecular clássica, a técnica utilizada para realizar as simulações descritas neste trabalho. Métodos clássicos são menos complexos computacionalmente, pois fazem uso de aproximações como uma carga elétrica pontual em cada átomo e ligações químicas do modelo na forma de funções harmônicas dependentes de parâmetros de entrada.

Em mecânica molecular clássica entendemos os núcleos atômicos como pontos materiais dotados de massa e carga elétrica que interagem sob um potencial $V(\mathbf{r})$ e obedecem às equações de movimento

$$
\mathbf{F}=-\frac{\partial V}{\partial \mathbf{r}}=m_{i} \frac{\partial^{2} \mathbf{r}}{\partial t^{2}}
$$

O potencial $V(\mathbf{r})$ tem o mesmo papel da energia eletrônica $E_{\mathrm{el}}(\mathbf{R})$ da separação de Born-Oppenheimer associada à repulsão núcleo-núcleo $V_{\mathrm{N}-\mathrm{N}}$. Para determinar o potencial $V(\mathbf{r})$ de um sistema em particular utiliza-se um conjunto de parâmetros ${ }^{[71]}$, provenientes de cálculos mais sofisticados ou de resultados experimentais, conhecido como campo de força:

Tipo atômico consiste em informações como o elemento químico, sua hibridização, o tipo de ligações que ele faz e sua carga líquida;

Regras de definição de tipo atômico atribuem a cada átomo do modelo um tipo atômico de acordo com o elemento químico e as ligações que efetua;

Formas funcionais de interação definem a forma da energia potencial com base no tipo de interação entre os átomos;

Parâmetros de interação dependem dos tipos atômicos envolvidos e determinam o valor numérico da energia potencial. 
Uma simulação de mecânica molecular inicia com um modelo com a geometria aproximada do sistema e informações sobre os elementos envolvidos e as ligações químicas entre eles, definidas pelo usuário. Aqui surge uma das limitações da mecânica molecular: a energia do sistema depende das ligações químicas previamente definidas, de forma que fenômenos como quebras de ligação e reações químicas não ocorrem espontaneamente, a menos que sejam consideradas explicitamente pelo campo de forças, como no caso dos campos de força reativos ${ }^{[72]}$.

Uma vez definidos os dados do modelo, o próximo passo consiste em calcular a expressão de energia com base nas formas funcionais do campo de força e nas interações do modelo. Uma expressão de energia se parece com

$$
V=V_{\text {ligação }}+V_{\text {ângulo }}+V_{\text {torção }}+V_{\text {inversão }}+V_{\text {cruzado }}+V_{\text {vdW }}+V_{\text {Coulomb }} \text {. }
$$

Cada termo tem sua origem em um tipo de interação entre pares, trios e quartetos de átomos, ligados ou não. $V_{\text {Coulomb }}$, por exemplo, é proveniente da interação eletrostática entre pares de átomos carregados.

O próximo termo mais simples, $V_{\mathrm{vdW}}$, representa a interação de van der Waals entre pares de átomos na forma

$$
V_{\mathrm{vdW}}=\sum_{\substack{i, j \\ i<j}} \epsilon_{i j}\left[\left(\frac{r_{i j}^{*}}{r_{i j}}\right)^{12}-2\left(\frac{r_{i j}^{*}}{r_{i j}}\right)^{6}\right],
$$

onde $\epsilon_{i j}$ é o parâmetro de Lennard-Jones entre os átomos $i$ e $j$ e $r_{i j}^{*}$ é a distância de equilíbrio dos átomos $i$ e $j$ na ausência de outros termos. Usualmente, a interação entre átomos ligados é modelada exclusivamente como um termo explícito de ligação, então este termo de van der Waals não é calculado para pares de átomos ligados (primeiros vizinhos) ou ligados a um átomo em comum (segundos vizinhos). A aplicação deste termo para terceiros vizinhos depende da forma com que o campo de força é parametrizado e costuma vir acompanhada de um fator multiplicativo. O mesmo tipo de restrição de vizinhos é feito quando se considera o termo eletrostático.

Outro termo que envolve pares de átomos está relacionado às ligações quí-

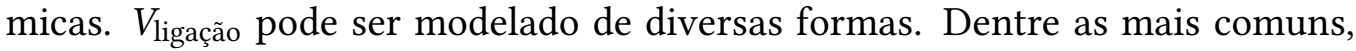
uma considera a ligação equivalente a uma mola e tem a forma de um potencial harmônico:

$$
V_{\text {ligação }}=\sum_{i, j \text { ligados }}^{i<j} K_{i j}\left(r_{i j}-r_{i j}^{*}\right)^{2} .
$$

Outra, conhecida como potencial de Morse, melhora a aproximação harmônica fazendo com que a energia de interação vá a zero quando a distância vai ao 
infinito, como observado em métodos mais sofisticados:

$$
V_{\text {ligação }}=\sum_{i, j} D_{i<j} D_{i j}\left[1-e^{-\alpha_{i j}\left(r_{i j}-r_{i j}^{*}\right)}\right]^{2} .
$$

Esta forma funcional é útil quando se deseja levar em conta termos anarmônicos em eventos como possíveis quebras de ligação ou deformações moleculares em condições extremas. Deve ser aplicado com cuidado, pois casos com deslocamentos grandes dos átomos, como em condições de alta energia ou com passos de integração grandes, o potencial de Morse pode levar a configurações pouco realistas $^{[71]}$.

O termo seguinte envolve três átomos e está relacionado ao ângulo entre as ligações de dois átomos com um átomo em comum. Se $\theta_{\widehat{i k j}}$ for o ângulo centrado no átomo $k$ formado entre os átomos $i$ e $j$, esse termo, harmônico em torno do ângulo de equilíbrio $\theta_{\overparen{i k j}}^{*}$, será dado por

$$
V_{\text {ângulo }}=\sum_{\widehat{i k j}} H_{\widehat{i k j}}\left(\theta_{\widehat{i k j}}-\theta_{\overparen{i k j}}^{*}\right)^{2} .
$$

Também é possível definir esse termo como harmônico nos cossenos dos ângulos, de forma que

$$
V_{\text {ângulo }}=\sum_{\widehat{i k j}} H_{\widehat{i k j}}\left(\cos \theta_{\widehat{i k j}}-\cos \theta_{\overparen{i k j}}^{*}\right)^{2} .
$$

Termos relacionados a quartetos de átomos podem envolver átomos encadeados ligados dois a dois ou um átomo ligado a três outros. No primeiro caso, temos as torções: a cadeia de átomos $i-j-k-l$ pode torcer em torno da ligação $j-k$, de modo a mudar o ângulo $\phi$ formado pelos planos $i j k$ e $j k l$ (vide fig. 3.1(a)). O termo energético, em relação ao ângulo de equilíbrio $\omega^{*}$, pode ser harmônico no cosseno do ângulo $\omega$ :

$$
V_{\text {torção }}=\sum_{\text {torções }} C\left(\cos \omega-\cos \omega^{*}\right)^{2}
$$

harmônico no ângulo $\omega$ :

$$
V_{\text {torção }}=\sum_{\text {torções }} K_{\omega}\left(\omega-\omega^{*}\right)^{2},
$$

ou periódico, com período $n$

$$
V_{\text {torção }}=\sum_{\text {torções }} K_{\omega}\left(1-B_{\omega}(-1)^{n} \cos n \omega\right) .
$$


No segundo caso, chamado de inversãa ${ }^{[71]}$ ou torção imprópria ${ }^{[73]}$, temos o átomo $i$ ligado a três outros átomos, $j, k$ e $l$. Dados os planos $j k l$ e $i j k$, definidos respectivamente pelos três átomos ligados ao átomo central e pelo átomo central e dois periféricos, como na Fig. 3.1(b), a energia potencial depende harmonicamente do ângulo entre esses planos:

$$
V_{\text {inversão }}=\sum_{\text {inversões }} K_{\omega}\left(\omega-\omega^{*}\right)^{2} .
$$

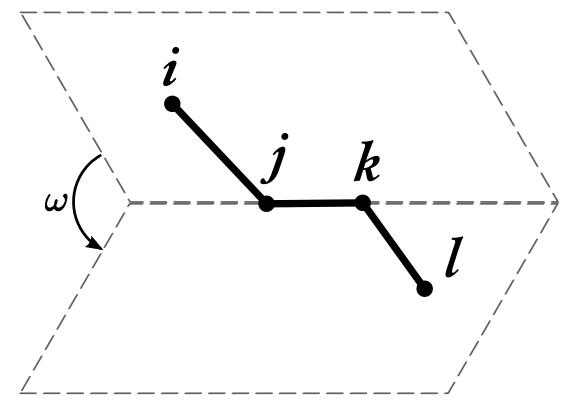

(a) Torção

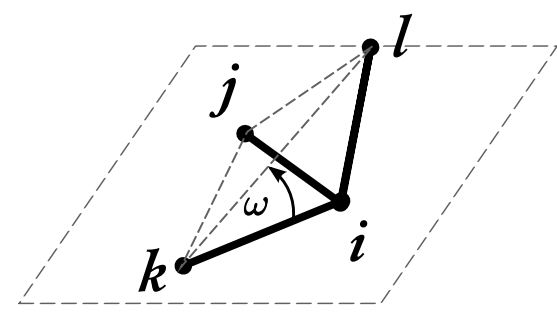

(b) Torção imprópria

Figura 3.1: Tipos de torção e inversão. $\omega$ é o ângulo de torção ou inversão. Figuras tracejadas esmaecidas representam os planos entre os quais $\omega$ é calculado.

A escolha da forma funcional dos termos de inversão depende da parametrização do campo de força. Entretanto, dados quatro átomos que podem formar uma inversão há três inversões possíveis, oriundas das permutações entre os átomos $j k l$. Novamente, a decisão sobre qual das três inversões considerar depende da implementação particular do campo de força e usualmente consiste em adotar a primeira torção encontrada, a média aritmética das três torções possíveis $^{[71]}$ ou apenas aquelas definidas explicitamente pelo usuário. ${ }^{[73]}$

Existem também os termos cruzados, que envolvem pares de ligações, pares de ângulos entre três ligações, comprimentos de ligações e torções etc. Esses termos aparecem em campos de força mais sofisticados para melhor ajustar resultados experimentais.

Através dessas relações de energia, dos parâmetros tabelados no campo de força e da descrição do modelo, com coordenadas, cargas e posições é possível calcular a energia do sistema para uma dada geometria. Neste trabalho, aplicamos dois métodos que utilizam essa informação energética: otimização de geometria e dinâmica molecular. 


\subsubsection{Otimização de geometria}

Otimização de geometria consiste em buscar a estrutura mais estável de uma molécula ou composto. Isso é feito procurando minimizar a energia interna da estrutura. No caso de mecânica molecular clássica, a energia interna é a soma dos termos de energia potencial descritos anteriormente. Uma vez que a força está relacionada ao gradiente da energia potencial, a estrutura mais estável será aquela que tiver as forças nulas em cada átomo.

Existem várias formas de se encontrar o mínimo de energia, cujo detalhamento foge do escopo deste trabalho. Todas elas consistem em avaliar as forças atuantes nos átomos e determinar deslocamentos que levem a minimizá-las e então repetir o procedimento, iterativamente, com as novas coordenadas. Os algoritmos diferem na forma de se obter o deslocamento. Os mais comuns são:

Steepest Descent: determina o deslocamento na direção em que a energia diminui mais intensamente, útil para critérios grossos de convergência;

Newton-Raphson: usa informações da segunda derivada para evitar realizar buscas lineares e converge quadraticamente, mas pode apresentar comportamento errático em alguns casos, sendo mais adequado quando a estrutura já se encontra próximo ao mínimo e

Gradiente conjugado: usa informações das derivadas em passos anteriores para evitar que um certo passo desfaça o progresso obtido anteriormente.

Esses métodos são explorados detalhadamente no livro de Frenkel e Smit ${ }^{[74]}$. A escolha sobre qual desses métodos utilizar depende de fatores como o tamanho e as forças presentes no sistema, a capacidade de processamento e de memória disponíveis e o objetivo da minimização. Como exemplo, a preparação do sistema para um cálculo de modos vibracionais tipicamente exige uma precisão maior do que uma preparação para dinâmica molecular, em que o objetivo é apenas eliminar forças extremas que possam deformar o sistema. Alguns programas que implementam esses métodos contam com algoritmos que "decidem" qual método utilizar a cada passo, em função da intensidade das forças. Devido às características intrínsecas de métodos numéricos, consideramos que a estrutura está otimizada quando a mudança na energia em um passo é menor que um certo valor de referência e quando as forças nos átomos estão abaixo de um dado critério de convergência.

\subsubsection{Dinâmica molecular}

Utilizamos a dinâmica molecular para calcular a evolução temporal de um sistema molecular e com ela montarmos trajetórias desse sistema no espaço de 
fase. Por razões de eficiência computacional, quando o número de átomos envolvidos é grande, fazemos uso da dinâmica molecular clássica, em que integramos as equações de movimento de Newton

$$
\mathbf{F}_{i}(t)=m_{i} \mathbf{a}_{i}(t),
$$

onde $\mathbf{F}_{i}$ é a força, $m_{i}$ é a massa e $\mathbf{a}_{i}$ é a aceleração do átomo $i$. A força sobre cada átomo é determinada pelo campo de força adotado, através de uma diferenciação em função das coordenadas $\mathbf{r}_{\mathbf{i}}$, de modo que a equação de movimento se torna

$$
-\frac{\partial V}{\partial \mathbf{r}_{i}}=m_{i} \frac{\partial^{2} \mathbf{r}_{i}}{\partial t^{2}}
$$

Temos, então, um conjunto de equações diferenciais que podem ser resolvidas por métodos de diferenças finitas, em que, dadas as coordenadas e as velocidades dos átomos no instante $t$, podemos calcular diretamente essas variáveis no instante $t+\Delta t$. Um método empregado comumente em pacotes de dinâmica molecular é do tipo Verlet ${ }^{[74]}$, que pode ser deduzido da expansão de Taylor para a posição da partícula nos instantes $t \pm \Delta t$ :

$$
\begin{aligned}
& \mathbf{r}(t+\Delta t)=\mathbf{r}(t)+\mathbf{v}(t) \Delta t+\frac{\mathbf{F}(t)}{2 m} \Delta t^{2}+\frac{\Delta t^{3}}{3 !} \dddot{\mathbf{r}}+O\left(\Delta t^{4}\right) \mathrm{e} \\
& \mathbf{r}(t-\Delta t)=\mathbf{r}(t)-\mathbf{v}(t) \Delta t+\frac{\mathbf{F}(t)}{2 m} \Delta t^{2}-\frac{\Delta t^{3}}{3 !} \dddot{\mathbf{r}}+O\left(\Delta t^{4}\right),
\end{aligned}
$$

onde, por simplicidade, omitimos os índices dos átomos $i$. Somando as equações (3.12) e (3.13) e isolando $\mathbf{r}(t+\Delta t)$ temos

$$
\mathbf{r}(t+\Delta t)=2 \mathbf{r}(t)-\mathbf{r}(t-\Delta t)+\frac{\mathbf{F}(t)}{m} \Delta t^{2}+O\left(\Delta t^{4}\right),
$$

ou seja, obtemos as posições atômicas seguintes com um erro da ordem $\Delta t^{4}$ utilizando as posições atuais, anteriores e as forças sobre os átomos. Uma vez que esse algoritmo não utiliza a velocidade, esta grandeza deve ser calculada separadamente.

Um modo é calcular a velocidade em um ponto intermediário entre um passo e outro ${ }^{[74]}$ :

$$
\begin{aligned}
& \mathbf{v}(t-\Delta t / 2)=\frac{\mathbf{r}(t)-\mathbf{r}(t-\Delta t)}{\Delta t} \\
& \mathbf{v}(t+\Delta t / 2)=\frac{\mathbf{r}(t+\Delta t)-\mathbf{r}(t)}{\Delta t},
\end{aligned}
$$

isso significa que devemos calcular as posições atualizadas $\mathbf{r}(t+\Delta t)$ para sabermos a velocidade $\mathbf{v}(t+\Delta t / 2)$. Podemos, entretanto, utilizar a equação (3.16) para calcular as posições atualizadas

$$
\mathbf{r}(t+\Delta t)=\mathbf{r}(t)+\mathbf{v}(t+\Delta t / 2) \Delta t
$$


se calcularmos a velocidade intermediária como

$$
\mathbf{v}(t+\Delta t / 2)=\mathbf{v}(t-\Delta t / 2)+\Delta t \frac{\mathbf{F}(t)}{m}
$$

de modo que os valores de velocidade e posição dos átomos são conhecidos para intervalos de tempo alternados, como crianças pulando em uma brincadeira de pula-sela (leapfrog em inglês). Por isso este algoritmo é conhecido como Leapfrog. Uma desvantagem desse algoritmo é o fato de sempre termos as informações sobre velocidade e posição defasadas de $\Delta t / 2$, entretanto é simples ${ }^{[75]}$ calcular $\mathbf{v}(t)$ :

$$
\mathbf{v}(t)=\frac{\mathbf{v}(t+\Delta t / 2)+\mathbf{v}(t-\Delta t / 2)}{2}
$$

\subsection{Métodos ab initio e semiempíricos}

Descreveremos agora alguns métodos utilizados para calcular a energia e as funções de onda eletrônicas de sistemas moleculares. Iniciamos descrevendo o método $a b$ initio de Hartree-Fock, que serve de ponto de partida para as aproximações conhecidas como métodos semiempíricos que estudaremos em seguida. Depois, exploraremos a técnica de interação de configurações que dá acesso à estrutura dos estados excitados.

\subsubsection{O Método Hartree-Fock}

Para resolver a equação (3.2), podemos partir ${ }^{[76]}$ de uma aproximação um tanto grosseira para $H_{\mathrm{el}}$, que desconsidera a interação elétron-elétron, dessa forma:

$$
H_{\mathrm{el}}^{\circ}=\sum_{i=1}^{N} h_{i}
$$

e

$$
H_{\mathrm{el}}^{\circ} \psi^{\circ}(\mathbf{r} ; \mathbf{R})=E^{\circ} \psi^{\circ}(\mathbf{r} ; \mathbf{R}),
$$

com $h_{i}$ o hamiltoniano da interação do elétron $i$ com os núcleos do sistema e $\psi^{\circ}(\mathbf{r} ; \mathbf{R})$ a aproximação não interagente para a função de onda total do sistema. Esta forma de soma de hamiltonianos de partícula única em (3.20) indica que podemos separar a solução em um produto de funções de um elétron. Para garantir que o princípio de exclusão de Pauli seja obedecido, $\psi^{\circ}(\mathbf{r} ; \mathbf{R})$ deve ser assimétrica por permutação, levando em conta o spin. Dessa forma, definimos o spin-orbital do $i$-ésimo elétron $\phi_{a}(i)$ e escrevemos a função de onda do sistema 
como o seguinte determinante de Slater:

$$
\psi^{\circ}(\mathbf{r} ; \mathbf{R})=\frac{1}{\sqrt{n !}} \operatorname{det}\left[\begin{array}{cccc}
\phi_{a}(1) & \phi_{b}(1) & \cdots & \phi_{z}(1) \\
\phi_{a}(2) & \phi_{b}(2) & \cdots & \phi_{z}(2) \\
\vdots & \vdots & \ddots & \vdots \\
\phi_{a}(n) & \phi_{b}(n) & \cdots & \phi_{z}(n)
\end{array}\right]
$$

que garante a antissimetria da solução.

Para levar em conta o efeito dos demais elétrons na função de onda, fazemos uso de uma abordagem de campo médio, em que cada spin-orbital está sujeito à repulsão coulombiana dos demais elétrons do sistema. A inclusão do termo de repulsão entre elétrons, associada ao vínculo de antissimetria da função de onda nos leva, através da aplicação de uma técnica variacional, às equações de Hartree-Fock para cada spin-orbital:

$$
F_{1} \phi_{a}(1)=\epsilon_{a} \phi_{a}(1),
$$

de forma que o operador de Fock é dado por

$$
F_{1}=h_{1}+\sum_{j}\left[J_{j}(1)-K_{j}(1)\right]
$$

com os operadores de Coulomb $J_{j}$ e de troca $K_{j}$, que, aplicados a uma função genérica $f$, resultam em

$$
\begin{aligned}
J_{j}(1) f(1) & =f(1) \int\left|\phi_{j}(2)\right|^{2} \frac{1}{r_{12}} \mathrm{~d} \mathbf{r}_{2} \\
K_{j}(1) f(1) & =\phi_{j}(1) \int \phi_{j}^{*}(2) \frac{1}{r_{12}} f(2) \mathrm{d} \mathbf{r}_{2},
\end{aligned}
$$

a menos de constantes que dependem do sistema de unidades adotado.

Quando o sistema é de camada fechada, o número de elétrons é par e os orbitais estão duplamente ocupados, por isso costumamos considerar apenas a parte espacial dos spin-orbitais, integrando as funções de spin, o que resulta no método de Hartree-Fock restrito - RHF, com o operador de Fock dado por

$$
F_{1}=h_{1}+\sum_{j}\left[2 J_{j}(1)-K_{j}(1)\right] .
$$

Por questões de eficiência computacional, convém manipular a equação diferencial (3.23) para uma forma de equação secular, por isso escrevemos os orbitais (espaciais, no contexto RHF) como combinações de funções de base $\chi_{i}$ tais que

$$
\phi_{i}=\sum_{s=1}^{M} c_{s i} \chi_{s} .
$$


Substituir esses orbitais na (3.23) resulta em

$$
\sum_{s} c_{s i} F_{1} \chi_{s}=\epsilon_{i} \sum_{s} c_{s i} \chi_{s}
$$

que podemos converter para forma matricial multiplicando por $\chi_{r}^{*}$ à esquerda e integrando, obtendo as equações de Hartree-Fock-Roothaan:

$$
\sum_{s=1}^{M} c_{s i}\left(F_{r s}-\epsilon_{i} S_{r s}\right)=0 \quad r=1, \ldots, M
$$

com as seguintes matrizes de Fock $F_{r s}$ e de sobreposição $S_{r s}$ :

$$
F_{r s}=\left\langle\chi_{r}|F| \chi_{s}\right\rangle \quad S_{r s}=\left\langle\chi_{r} \mid \chi_{s}\right\rangle .
$$

Isso resulta num conjunto de equações acopladas, de forma que temos de satisfazer à equação secular

$$
\operatorname{det}\left(F_{r s}-\epsilon_{i} S_{r s}\right)=0
$$

para obter as energias dos orbitais. Essa equação deve ser resolvida de forma autoconsistente, uma vez que os elementos da matriz de Fock $F_{r s}$ dependem das autofunções, como veremos a seguir.

Utilizando o operador de Fock dado pela (3.27), o elemento da matriz de Fock é

$$
\begin{aligned}
F_{r s}= & \left\langle\chi_{r}(1)|F| \chi_{s}(1)\right\rangle \\
= & \left\langle\chi_{r}(1)\left|h_{1}\right| \chi_{s}(1)\right\rangle+ \\
& +\sum_{j}\left[2\left\langle\chi_{r}(1)\left|J_{j}(1)\right| \chi_{s}(1)\right\rangle-\left\langle\chi_{r}(1)\left|K_{j}(1)\right| \chi_{s}(1)\right\rangle\right]
\end{aligned}
$$

As integrais de dois elétrons envolvendo $K_{j}$ e $J_{j}$, explicitamente, são da forma

$$
\left\langle\chi_{r}(1)\left|J_{j}(1)\right| \chi_{s}(1)\right\rangle=\iint \chi_{r}^{*}(1) \phi_{j}^{*}(2) \frac{1}{r_{12}} \phi_{j}(2) \chi_{s}^{*}(1) \mathrm{d} \mathbf{r}_{1} \mathrm{~d} \mathbf{r}_{2} .
$$

Escrevendo os $\phi_{j}$ como combinações lineares das funções de base, obtemos

$$
\left\langle\chi_{r}(1)\left|J_{j}(1)\right| \chi_{s}(1)\right\rangle=\sum_{t} \sum_{u} c_{t j}^{*} c_{u j} \iint \chi_{r}^{*}(1) \chi_{t}^{*}(2) \frac{1}{r_{12}} \chi_{u}(2) \chi_{s}^{*}(1) \mathrm{d} \mathbf{r}_{1} \mathrm{~d} \mathbf{r}_{2},
$$

que, por ser uma expressão um tanto poluída, costuma ser simplificada através da notação

$$
(\underbrace{r s}_{\text {elétron } 1} \mid \underbrace{t u}_{\text {elétron } 2})=\iint \underbrace{\chi_{r}^{*}(1) \chi_{s}(1)}_{\text {elétron } 1} \frac{1}{r_{12}} \underbrace{\chi_{t}^{*}(2) \chi_{u}(2)}_{\text {elétron } 2} \mathrm{~d} \mathbf{r}_{1} \mathrm{~d} \mathbf{r}_{2}
$$


e o elemento de matriz de Fock fica

$$
F_{r s}=h_{r s}+\sum_{t} \sum_{u} P_{t u}[(r s \mid t u)-1 / 2(r u \mid t s)]
$$

com a matriz de densidade $P$ dada pelos seus elementos

$$
P_{t u}=2 \sum_{j} c_{t j}^{*} c_{u j}
$$

Uma conveniência da forma (3.31) é que as integrais ( $r s \mid t u)$, computacionalmente custosas, não mudam durante o processo autoconsistente, uma vez que as funções de base $\chi_{r}$ permanecem constantes. As soluções da equação de Hartree-Fock-Roothaan são construídas a partir dessa base com os coeficientes $c_{i j}$ de forma que apenas a matriz $P$ deve ser atualizada ao longo do processo autoconsistente. Isso permite calcular apenas uma vez as integrais ( $r s \mid t u)$ e armazená-las em disco. Convém notar, entretanto, que com o uso de computadores para o cálculo de sistemas cada vez maiores, o número de integrais a serem armazenadas e lidas do disco a cada interação passou a ser muito grande, de forma que é habitual o uso do $S C F$ direto $^{[70]}$, que recalcula as integrais a cada passo.

\subsubsection{Funções de base}

Escrever os orbitais como combinações lineares de funções de base, como na equação (3.28), apenas rende soluções iguais à solução analítica da equação de Hartree-Fock (3.23) quando se utiliza uma base completa. No caso do espaço das funções quadraticamente integráveis a que pertencem as funções de onda, tratase de uma base infinita. Aplicações reais do método de Hartree-Fock-Roothaan, entretanto, fazem uso de bases finitas e a escolha da base é um fator importante a ser considerado na preparação de cálculos de química quântica.

Uma estratégia comum, conhecida como LCAO - linear combination of atomic orbitals, combinação linear de orbitais atômicos - consiste em formar a base a partir de funções que descrevem orbitais centrados em cada átomo.

Duas formas são comuns para descrever os orbitais atômicos. Uma delas é chamada de STO - Slater-type orbitals, orbitais tipo Slater - e utiliza para cada orbital uma ou mais funções normalizadas formadas pelo produto entre uma potência da distância ao centro do átomo, $r_{B}$, um fator exponencial de decaimento e um harmônico esférico:

$$
\chi_{\mathrm{STO}}=N r_{B}^{n-1} e^{-\zeta r_{B}} Y_{l}^{m}\left(\theta_{B}, \phi_{B}\right),
$$

em que os índices inteiros $n, l$ e $m$ equivalem aos números quânticos do orbital representado e as coordenadas são referentes ao centro do átomo $B$. $O$ expoente 
orbital $\zeta$ é um parâmetro real positivo que costuma ser ajustado para representar bem moléculas pequenas. Uma base mínima representa cada orbital por uma única função tipo Slater. Já uma base double-zeta ou duplo-zeta utiliza duas funções de Slater para cada orbital, triple-zeta utiliza três e assim por diante. O uso de mais de uma função de Slater para representar cada orbital permite, com escolhas apropriadas de expoentes orbitais, que o orbital mude de forma ou de alcance em resposta ao ambiente eletrônico em que está inserido, levando a resultados mais precisos.

Essa precisão, entretanto, apresenta um custo, já que a equação de HartreeFock-Roothaan (3.31) envolve integrais de até quatro centros, ou seja, o número de integrais a ser calculado cresce com a quarta potência do número de orbitais presentes no sistema e o custo computacional de cada integral aumenta consideravelmente com o número de funções de Slater utilizadas na base. Para reduzir a complexidade desse cálculo, uma estratégia possível consiste em adotar bases de valência dividida ou split-valence, que representam os orbitais de valência com um número maior de funções de Slater que os de caroço, que contam com apenas uma.

Outra forma de reduzir essa complexidade é descrever os orbitais atômicos em função de gaussianas cartesianas ${ }^{[70]}$ :

$$
g=N x_{B}^{i} y_{B}^{j} z_{B}^{k} e^{-\alpha r_{B}^{2}}
$$

Uma vantagem dessa representação é a simplificação dos produtos de orbitais centrados em átomos diferentes: o produto das gaussianas centradas em pontos diferentes é uma gaussiana centrada num ponto intermediário, computacionalmente menos complexa do que o produto de funções de Slater.

Os expoentes $i, j$ e $k$ na gaussiana (3.33) são inteiros não negativos e a soma deles determina a natureza do orbital: se $i+j+k=0$, dizemos tratar-se de uma gaussiana tipo-s, usada para representar os orbitais atômicos $s$. Se $i+j+k=1$, trata-se de uma gaussiana tipo-p e assim por diante.

Essas gaussianas primitivas costumam ser contraídas em combinações lineares de funções com os mesmos índices $i, j$ e $k$, mas diferentes expoentes alpha:

$$
\chi_{\mathrm{G}}=\sum_{u} d_{u r} g_{u}
$$

em que o coeficiente de contração $d_{u r}$ é um parâmetro ajustado e permanece fixo durante os cálculos.

As bases gaussianas são comumente de valência dividida, duplo- ou triplozeta e seguem uma nomenclatura que descreve o número de gaussianas primitivas em cada orbital. A base 6-31G, por exemplo, utiliza uma gaussiana contraída formada por seis primitivas nos orbitais de caroço e duas gaussianas contraídas 
nos orbitais de valência: uma formada por três primitivas e outra por apenas uma. Símbolos como ${ }^{*}$ e + em, por exemplo $6-31+G^{*}$, representam a inclusão de orbitais de polarização $\left({ }^{*}\right)$ ou de funções difusas $(+)$, com expoentes muito pequenos.

\subsubsection{O método ZINDO}

Como vimos, o número de integrais $(r s \mid t u)$ cresce com a quarta potência do número de funções de base, que está relacionado com o número de átomos. Para tratar sistemas com algumas dezenas a centenas de átomos em tempo razoável, podemos reduzir a complexidade dos cálculos através de algumas aproximações.

Neste trabalho, fazemos uso do método conhecido como ZINDO ${ }^{[77 ; 78]}$, uma reparametrização do método INDO/S que, além de usar dados experimentais espectroscópios, aplica as aproximações que discutiremos nesta Seção.

Inicialmente, reduz-se consideravelmente o número de elétrons a se tratar explicitamente, separando os átomos em uma parte de caroço e uma de valência. Assim, os elétrons de valência reagem ao potencial gerado pelos caroços fixos e temos uma matriz de Fock dada por

$$
F_{r s}^{\mathrm{V}}=h_{r s}^{\mathrm{V}}+\sum_{t} \sum_{u} P_{t u}[(r s \mid t u)-1 / 2(r u \mid t s)]
$$

com $h_{r s}^{\mathrm{V}}$ calculada considerando cada caroço como um ponto de carga $Z$ menos a carga dos $n-n^{\mathrm{V}}$ elétrons de caroço. Os orbitais de valência $\chi_{r}$ são do tipo Slater (3.32).

Além disso, as integrais envolvendo mais de duas funções de base são consideradas nulas: $(r s \mid t u)=\delta_{r s} \delta_{t u}(r r \mid t t)$, a não ser que $\chi_{r}, \chi_{s}, \chi_{t}$ e $\chi_{u}$ estejam todas centradas no mesmo átomo. Com isso, a soma dupla em (3.35) passa a ser uma soma simples que só chega a ser calculada em alguns casos, reduzindo ainda mais a complexidade do problema. Para preservar a invariância rotacional ${ }^{[77]}$, as integrais de repulsão eletrônica consideram que todos os orbitais atômicos têm simetria esférica, de forma que as integrais dependem apenas do átomo em que o orbital está centrado. Portanto, se $\chi_{r}$ estiver centrado no átomo $\mathrm{A}$ e $\chi_{t}$ estiver centrado no átomo $\mathrm{B}$,

$$
\left(r_{\mathrm{A}} r_{\mathrm{A}} \mid t_{\mathrm{B}} t_{\mathrm{B}}\right) \equiv \gamma_{\mathrm{AB}}
$$

Da mesma forma, os termos de $h_{r s}^{\mathrm{V}}$ que envolvem orbitais de átomos diferentes, A e B, são considerados proporcionais às integrais de sobreposição dos orbitais:

$$
h_{r_{\mathrm{A}} s_{\mathrm{B}}}^{\mathrm{V}}=\frac{\beta_{\mathrm{A}, r}^{0}+\beta_{\mathrm{B}, s}^{0}}{2}\left\langle\chi_{r} \mid \chi_{s}\right\rangle \text {. }
$$


No contexto da parametrização de Zerner para o método INDO/S, os orbitais $d$ recebem parâmetros $\beta_{d}^{0}$ próprios e diferenciados dos $s$ e $p$, que por sua vez recebem parâmetros $\beta_{s, p}^{0}$ iguais para cada elemento.

Resta agora olharmos para os termos de $h_{r s}^{\mathrm{V}}$ centrados em um único átomo A. Por construção, os orbitais de Slater de um átomo formam um conjunto ortogonal, então $h_{r_{\mathrm{A}} s_{\mathrm{A}}}^{\mathrm{V}}=0$ se $r \neq s$, e resta apenas o termo

$$
h_{r_{\mathrm{A}} r_{\mathrm{A}}}^{\mathrm{V}}=U_{r r}-\sum_{\mathrm{B} \neq \mathrm{A}}\left\{\left(n_{s}+n_{p}\right)_{\mathrm{B}} \gamma_{\mathrm{AB}}(s)+\left(n_{d}\right)_{\mathrm{B}} \gamma_{\mathrm{AB}}(d)\right\},
$$

onde os termos $(s)$ e $(d)$ se referem aos parâmetros envolvendo os respectivos orbitais e $U_{r r}$ é a energia de ligação de um elétron no orbital $\chi_{r}$, obtida empiricamente ${ }^{[77]}$.

\subsubsection{Interação de configurações}

A forma com que o determinante de Slater é construído, ocupando os estados de mais baixa energia, e o uso do princípio variacional para obter o operador de Fock (3.24) restringem o método à obtenção da energia e função de onda do estado fundamental. Para acessar os estados excitados, outras abordagens são necessárias.

Uma delas, conhecida como interação de configurações - CI, consiste em preparar um estado de referência $\psi_{0}$ descrito pelo determinante de Slater

$$
\psi_{0}=\frac{1}{\sqrt{n !}} \operatorname{det}\left[\begin{array}{cccc}
\phi_{a}(1) & \phi_{b}(1) & \cdots & \phi_{z}(1) \\
\phi_{a}(2) & \phi_{b}(2) & \cdots & \phi_{z}(2) \\
\vdots & \vdots & \ddots & \vdots \\
\phi_{a}(n) & \phi_{b}(n) & \cdots & \phi_{z}(n)
\end{array}\right]
$$

formado pelos orbitais $\phi_{a}, \phi_{b} \ldots \phi_{z}$ de forma a descrever o estado fundamental da molécula, e construir outros estados, em que se substitui um orbital ( $\phi_{a}$, por exemplo) por um orbital virtual $\phi_{i}$, de energia mais alta, formando determinantes de Slater simplesmente excitados ou simplesmente substituídos

$$
\psi_{i}^{a}=\frac{1}{\sqrt{n !}} \operatorname{det}\left[\begin{array}{cccc}
\phi_{i}(1) & \phi_{b}(1) & \cdots & \phi_{z}(1) \\
\phi_{i}(2) & \phi_{b}(2) & \cdots & \phi_{z}(2) \\
\vdots & \vdots & \ddots & \vdots \\
\phi_{i}(n) & \phi_{b}(n) & \cdots & \phi_{z}(n)
\end{array}\right]
$$

Também é possível considerar estados duplamente excitados $\phi_{i j}^{a b}$, em que dois orbitais são substituídos por orbitais de maior energia, além de estados triplamente excitados e assim por diante. Cálculos CI que fazem uso de determinantes de 
Slater simplesmente substituídos são descritos como CI-Singles ou CIS. Aqueles que fazem uso dos determinantes duplamente substituídos são chamandos $C I$ Doubles ou CID.

Determinantes de Slater construídos dessa forma não são de maneira geral autoestados do hamiltoniano do sistema, mas podem ser construídas combinações lineares desses determinantes para obter variacionalmente funções de onda que minimizem a energia do sistema:

$$
\psi_{\mathrm{CIS}}=\sum_{a} \sum_{i} c_{i a} \psi_{i}^{a}
$$

sob a condição de que $\psi_{\text {CIS }}$ seja também uma autofunção do spin total $S^{2}$.

Uma vez que o estado fundamental não participa da função de onda CIS, a aplicação do método variacional leva ao estado de mais baixa energia que seja ortogonal ao estado fundamental. Levando em conta o conceito de transições verticais, discutidos na Seção 3.5, podemos calcular a energia de transição eletrônica como a diferença de energia entre o estado CIS e o estado fundamental.

Também é possível utilizar esse procedimento para calcular a geometria do estado excitado de uma molécula utilizando as técnicas da Seção 3.2.1, uma vez que os gradientes da energia do estado CIS estão disponíveis ${ }^{[70]}$.

\subsubsection{Teoria do funcional da densidade}

Mesmo com as várias aproximações que podem ser feitas, resolver a equação (3.31) ainda é um trabalho formidável que acaba resultando em muito mais informação ${ }^{[70]}$ do que se pretende obter. De fato, o que se deseja saber sobre um sistema molecular costumam ser a energia de formação da molécula ou o perfil de $E_{\mathrm{el}}(\mathbf{R})$ para aplicá-lo na equação de Schrödinger para os núcleos (3.2) ou para buscar a geometria de equilíbrio da molécula através dos métodos da Seção 3.2.1.

Uma técnica que permita calcular $E_{\mathrm{el}}(\mathbf{R})$ sem necessitar informações detalhadas sobre as funções de onda de cada elétron pode agilizar sensivelmente os cálculos das propriedades moleculares de interesse, como geometria e modos vibracionais. Esse tipo de técnica foi prevista e desenvolvida nos anos de $1964^{\text {[79] }}$ e $1965^{[80]}$, com Pierre Hohenberg e Walter Kohn propondo em seu teorema que todas as propriedades eletrônicas de uma molécula são unicamente determinadas pela densidade eletrônica $\rho$ do estado fundamental, como veremos a seguir. Depois, Kohn e Lu Jeu Sham apresentaram um método autoconsistente para obter $\rho$ e, a partir dele, $E_{\mathrm{el}}(\mathbf{R})$. Estes trabalhos renderam a Kohn o Prêmio Nobel de química de 1998 por seu desenvolvimento da teoria do funcional da densidad ${ }^{[81]}$, um prêmio comparilhado com John Pople por seu desenvolvimento de métodos computacionais em química quântica. 
O teorema de Hohenberg-Kohn afirma que a energia $E_{0}$, a função de onda e todas as outras propriedades eletrônicas do estado fundamental (incluindo o potencial dos núcleos $V_{\mathrm{N} \text {-el }}$ ) são determinadas pela densidade de probabilidade $\rho_{0}(x, y, z)$, de forma que se pode dizer, por exemplo, que a energia total do estado fundamental é um funcional da densidade

$$
\begin{aligned}
E_{0} \equiv E_{v}\left[\rho_{0}\right] & =\left\langle\psi_{0}\left|H_{\mathrm{el}}\right| \psi_{0}\right\rangle \\
& =\left\langle\psi_{0}\left|T_{\mathrm{el}}\right| \psi_{0}\right\rangle+\left\langle\psi_{0}\left|V_{\mathrm{el}-\mathrm{N}}\right| \psi_{0}\right\rangle+\left\langle\psi_{0}\left|V_{\mathrm{el}-\mathrm{el}}\right| \psi_{0}\right\rangle \\
& =\int v(\mathbf{r}) \rho(\mathbf{r}) \mathrm{d} \mathbf{r}+F_{\mathrm{HK}}\left[\rho_{0}\right],
\end{aligned}
$$

com o chamado funcional universal definido como

$$
F_{\mathrm{HK}}\left[\rho_{0}\right] \equiv\left\langle\psi_{0}\left|T_{\mathrm{el}}+V_{\mathrm{el}-\mathrm{el}}\right| \psi_{0}\right\rangle,
$$

em que $\psi_{0}$ representa a função de onda do estado fundamental e $\rho_{0}$ a densidade associada a ela.

A densidade $\rho_{0}$ determina o número de elétrons do sistema, uma vez que

$$
\int \rho_{0}(\mathbf{r}) \mathrm{d} \mathbf{r}=n
$$

Podemos dizer que o potencial externo ao sistema de elétrons, devido aos núcleos, $V_{\mathrm{N} \text {-el }}(\mathbf{r}) \equiv \sum_{i}^{n} v\left(\mathbf{r}_{\mathbf{i}}\right)$, também é unicamente determinado pela densidade $\rho_{0}(\mathbf{r})$ e, portanto, é um funcional da densidade: $v[\rho(\mathbf{r})]$. Vemos isso quando consideramos um potencial $v_{d}(\mathbf{r})$, diferente de $v(\mathbf{r})$ por algo além de uma constante aditiva, que, por acaso, dê origem à mesma densidade $\rho_{0}(\mathbf{r})$. Nesse caso, teremos duas funções de onda diferentes: uma, $\psi_{0}$, para o estado fundamental do hamiltoniano dado por $v(\mathbf{r})$ e outra, $\psi_{0, d}$, para o o estado fundamental do hamiltoniano dado por $v_{d}(\mathbf{r})$.

Levando em conta estados fundamentais não degenerados:

$$
\begin{aligned}
E_{0}=\left\langle\psi_{0}|H| \psi_{0}\right\rangle & <\left\langle\psi_{0, d}|H| \psi_{0, d}\right\rangle=\left\langle\psi_{0, d}\left|H-H_{d}\right| \psi_{0, d}\right\rangle+E_{0, d} \mathrm{e} \\
E_{0, d}=\left\langle\psi_{0, d}\left|H_{d}\right| \psi_{0, d}\right\rangle & <\left\langle\psi_{0}\left|H_{d}\right| \psi_{0}\right\rangle=\left\langle\psi_{0}\left|H_{d}-H\right| \psi_{0}\right\rangle+E_{0} .
\end{aligned}
$$

Se $\psi_{0}$ e $\psi_{0, d}$ dão origem à mesma densidade eletrônica $\rho_{0}$, então

$$
-\left\langle\psi_{0}, d\left|H-H_{d}\right| \psi_{0, d}\right\rangle=\left\langle\psi_{0}\left|H_{d}-H\right| \psi_{0}\right\rangle=\int \rho_{0}(\mathbf{r})\left[v_{d}(\mathbf{r})-v(\mathbf{r})\right] \mathrm{d} \mathbf{r} \equiv \bar{V}\left[\rho_{0}\right]
$$

e

$$
\begin{aligned}
E_{0} & <-\bar{V}\left[\rho_{0}\right]+E_{0, d} \quad \mathrm{e} \\
E_{0, d} & <\bar{V}\left[\rho_{0}\right]+E_{0},
\end{aligned}
$$


duas desigualdades que, somadas, levam a

$$
E_{0}+E_{0, d}<E_{0, d}+E_{0},
$$

que é falsa. Portanto, as densidades geradas por $\psi_{0}$ e $\psi_{0, d}$ não podem ser iguais e a densidade $\rho_{0}$ está unicamente associada a um potencial externo $v(\mathbf{r})$. Uma vez que o $v(\mathbf{r})$ é univocamente relacionado com a densidade e todas as demais propriedades da molécula são consequência do potencial externo, como solução da equação de Schrödinger que o envolve, todas as demais propriedades da molécula são funcionais da densidade eletrônica.

Apesar de o teorema de Hohenberg-Kohn garantir que as propriedades de interesse do sistema são funcionais da densidade eletrônica, não indica por si só uma forma de obter essa densidade. No mesmo artigo os autores apresentam outro teorema, o teorema variacional de Hohenberg-Kohn. O teorema afirma que, dada uma densidade de teste $\rho_{\mathrm{t}}(\mathbf{r}) \geq 0$ tal que $\int \rho_{\mathrm{t}}(\mathbf{r}) \mathrm{d} \mathbf{r}=n$, a densidade do estado fundamental será aquela que minimiza o o funcional de energia

$$
E_{v}[\rho]=T_{\mathrm{el}}[\rho]+V_{\mathrm{el}-\mathrm{el}}[\rho]+V_{\mathrm{N}-\mathrm{el}}[\rho]
$$

de forma que

$$
E_{0} \leq E_{v}\left[\rho_{t}\right]
$$

A prova, proposta por Mel Levy ${ }^{[82]}$ em uma forma mais geral que aquela do trabalho original de Hohenberg e Kohn ${ }^{[79]}$, consiste em uma busca com víncu$\operatorname{los}^{[83]}$ e começa definindo o funcional universal

$$
F[\rho]=\min \left\langle\psi_{\rho}\left|T_{\mathrm{el}}+V_{\mathrm{el}-\mathrm{el}}\right| \psi_{\rho}\right\rangle \equiv\left\langle\psi_{\rho, 0}\left|T_{\mathrm{el}}+V_{\mathrm{el}-\mathrm{el}}\right| \psi_{\rho, 0}\right\rangle,
$$

em que a minimização é restrita às funções de onda antissimétricas $\psi_{\rho}$ (eq. (3.22)) cuja densidade corresponda a $\rho$. Em seguida, para uma densidade de teste $\rho_{t}$, mostramos que

$$
F\left[\rho_{t}\right]+\int v(\mathbf{r}) \rho_{t} \mathrm{~d} \mathbf{r} \geq E_{0}
$$

já que

$$
\begin{aligned}
F\left[\rho_{t}\right]+\int v(\mathbf{r}) \rho_{t} \mathrm{~d} \mathbf{r} & =\left\langle\psi_{\rho_{t}, 0}\left|T_{\mathrm{el}}+V_{\text {rel-el }}+V_{\mathrm{N}-\mathrm{el}}\right| \psi_{\rho_{t}, 0}\right\rangle \\
& =\left\langle\psi_{\rho_{t}, 0}|H| \psi_{\rho_{t}, 0}\right\rangle \geq E_{0},
\end{aligned}
$$

pelo princípio variacional, com $\psi_{\rho_{t}, 0}$ a função de onda de densidade $\rho_{t}$ que satisfaz $F\left[\rho_{t}\right]$. Se $\rho_{0}$ for a densidade do estado fundamental, mostramos que

$$
F\left[\rho_{0}\right]+\int v(\mathbf{r}) \rho_{0} \mathrm{~d} \mathbf{r}=E_{0}
$$


aplicando novamente o princípio variacional e vendo que

$$
\begin{array}{r}
E_{0}=\left\langle\psi_{0}|H| \psi_{0}\right\rangle \leq\left\langle\psi_{\rho_{0}, 0}\left|T_{\mathrm{el}}+V_{\mathrm{el}-\mathrm{el}}\right| \psi_{\rho_{0}, 0}\right\rangle+\int v(\mathbf{r}) \rho_{0} \mathrm{~d} \mathbf{r} \\
\left\langle\psi_{0}\left|T_{\mathrm{el}}+V_{\mathrm{el}-\mathrm{el}}\right| \psi_{0}\right\rangle+\int v(\mathbf{r}) \rho_{0} \mathrm{~d} \mathbf{r} \leq\left\langle\psi_{\rho_{0}, 0}\left|T_{\mathrm{el}}+V_{\mathrm{el}-\mathrm{el}}\right| \psi_{\rho_{0}, 0}\right\rangle+\int v(\mathbf{r}) \rho_{0} \mathrm{~d} \mathbf{r}
\end{array}
$$

que nos leva a

$$
\left\langle\psi_{0}\left|T_{\mathrm{el}}+V_{\mathrm{el}-\mathrm{el}}\right| \psi_{0}\right\rangle \leq\left\langle\psi_{\rho_{0}, 0}\left|T_{\mathrm{el}}+V_{\mathrm{el}-\mathrm{el}}\right| \psi_{\rho_{0}, 0}\right\rangle,
$$

mas $\psi_{\rho_{0}, 0}$ é justamente aquela que minimiza $F\left[\rho_{0}\right]$, portanto

$$
\left\langle\psi_{0}\left|T_{\mathrm{el}}+V_{\mathrm{el}-\mathrm{el}}\right| \psi_{0}\right\rangle \geq\left\langle\psi_{\rho_{0}, 0}\left|T_{\mathrm{el}}+V_{\mathrm{el}-\mathrm{el}}\right| \psi_{\rho_{0}, 0}\right\rangle
$$

e essas desigualdades só podem ser válidas se

$$
\left\langle\psi_{0}\left|T_{\mathrm{el}}+V_{\mathrm{el}-\mathrm{el}}\right| \psi_{0}\right\rangle=F\left[\rho_{0}\right],
$$

que satisfaz a equação (3.43).

Com isso, mostramos que podemos realizar uma minimização em dois pas$\operatorname{sos}^{[83]}$ :

$$
\begin{aligned}
E_{0} & =\min _{\rho}\left[\min _{\psi_{\rho}}\left\langle\psi_{\rho}\left|T_{\mathrm{el}}+V_{\mathrm{el}-\mathrm{el}}+V_{\mathrm{N}-\mathrm{el}}\right| \psi_{\rho}\right\rangle\right] \\
& =\min _{\rho}\left[\min _{\psi_{\rho}}\left\langle\psi_{\rho}\left|T_{\mathrm{el}}+V_{\mathrm{el}-\mathrm{el}}\right| \psi_{\rho}\right\rangle+\int v(\mathbf{r}) \rho \mathrm{d} \mathbf{r}\right] \\
& =\min _{\rho}\left[F[\rho]+\int v(\mathbf{r}) \rho \mathrm{d} \mathbf{r}\right],
\end{aligned}
$$

que consiste em, para cada densidade, encontrar a respectiva função de onda que minimiza o funcional universal e só então realizar a busca no espaço das densidades levando em conta o potencial externo $v(\mathbf{r})$.

\section{O método de Kohn-Sham}

Os teoremas de Hohenberg-Kohn mostram que, uma vez conhecida a densidade $\rho_{0}$, todas as propriedades moleculares são acessíveis, entretanto não fornecem um método para calcular a densidade do estado fundamental e nem mesmo como obter diretamente as propriedades moleculares, uma vez que o funcional $E[\rho]$ não é conhecido. Em 1965, Kohn e Sham propuseram um método ${ }^{[80]}$ que 
considera um sistema fictício de $n$ elétrons não-interagentes, sujeitos a um potencial externo $v_{s}$ tal que a densidade do estado fundamental seja igual à do sistema interagente.

A hamiltoniana desse sistema não interagente é escrita como ${ }^{[70]}$

$$
H_{s}=\sum_{i}^{n}\left[-1 / 2 \nabla_{i}^{2}+v_{s}\left(\mathbf{r}_{i}\right)\right],
$$

cuja solução é um determinante de Slater (3.22) formado pelos $n$ autoestados $\varphi_{i}^{\mathrm{KS}}$ de menor energia da hamiltoniana não-interagente de partícula única:

$$
h_{s} \varphi_{i}^{\mathrm{KS}}=\left[-1 / 2 \nabla^{2}+v_{s}(\mathbf{r})\right] \varphi_{i}^{\mathrm{KS}}=\epsilon_{i} \varphi_{i}^{\mathrm{KS}} .
$$

Os autoestados $\varphi_{i}^{\mathrm{KS}}$ são chamados de orbitais de Kohn-Sham e levam à densidade do estado fundamental

$$
\rho=\rho_{s}=\sum_{i}^{n}\left|\varphi_{i}^{\mathrm{KS}}\right|^{2} .
$$

A hamiltoniana (3.47) nos rende uma energia cinética $T_{s}[\rho]$, que pode ser calculada exatamente:

$$
T_{S}[\rho]=\sum_{i}^{n}\left\langle\varphi_{i}^{\mathrm{KS}}\left|-1 / 2 \nabla^{2}\right| \varphi_{i}^{\mathrm{KS}}\right\rangle
$$

e, com isso, redefinir o funcional universal $F_{\mathrm{HK}}[\rho]$ (3.38) do funcional de energia (3.37) em função dos termos conhecidos:

$$
F_{\mathrm{KS}}[\rho]=\underbrace{T_{s}[\rho]}_{\text {conhecido: (3.49) }}+\underbrace{J[\rho]}_{\text {conhecido: (3.51) }}+\underbrace{E_{x c}[\rho]}_{\text {desconhecido }}
$$

com a repulsão elétron-elétron dada por

$$
J[\rho]=\frac{1}{2} \iint \frac{\rho(\mathbf{r}) \rho\left(\mathbf{r}^{\prime}\right)}{\left|\mathbf{r}-\mathbf{r}^{\prime}\right|} \mathrm{d} \mathbf{r} \mathrm{d} \mathbf{r}^{\prime}
$$

e o funcional de troca e correlação agrupando os termos desconhecidos restantes:

$$
E_{x c}[\rho]=T[\rho]-T_{s}[\rho]+V_{\mathrm{el}-\mathrm{el}}[\rho]-J[\rho] .
$$

Uma vez que todas essas grandezas são funcionais da densidade $\rho$, que é a mesma para o sistema não-interagente e para o sistema original, calculá-las no sistema não-interagente rende resultados válidos para o sistema original. Note que isto não é válido para os orbitais de Kohn-Sham, que são próprios do sistema fictício. 
Com o funcional universal (3.50) redefinido em função do sistema não interagente, podemos reescrever o funcional de energia como

$$
\begin{aligned}
E[\rho]= & -\frac{1}{2} \sum_{i}^{N}\left\langle\varphi_{i}^{\mathrm{KS}}\left|\nabla^{2}\right| \varphi_{i}^{\mathrm{KS}}\right\rangle \\
& +\int v(\mathbf{r}) \rho(\mathbf{r}) \mathrm{d} \mathbf{r} \\
& +\frac{1}{2} \iint \frac{\rho(\mathbf{r}) \rho\left(\mathbf{r}^{\prime}\right)}{\left|\mathbf{r}-\mathbf{r}^{\prime}\right|} \mathrm{d} \mathbf{r} \mathrm{d} \mathbf{r}^{\prime} \\
& +E_{x c}[\rho] .
\end{aligned}
$$

Agora, aplicando o método variacional para encontrar o conjunto de orbitais ortonormais $\varphi_{i}^{\mathrm{KS}}$ que minimize $E[\rho]$, chegamos às equações de Kohn-Sham:

$$
\begin{gathered}
{\left[-1 / 2 \nabla^{2}+v_{\mathrm{eff}}(\mathbf{r})\right] \varphi_{i}^{\mathrm{KS}}=\epsilon_{i} \varphi_{i}^{\mathrm{KS}}} \\
v_{\mathrm{eff}}=v(\mathbf{r})+\int \frac{\rho\left(\mathbf{r}^{\prime}\right)}{\left|\mathbf{r}-\mathbf{r}^{\prime}\right|} \mathrm{d} \mathbf{r}^{\prime}+v_{x c}(\mathbf{r}),
\end{gathered}
$$

com $v_{\text {eff }}(\mathbf{r})$ fazendo o papel de potencial efetivo em uma equação de Schrödinger de partícula única, ou seja, de elétrons não-interagentes. Essa equação pode ser resolvida escrevendo os orbitais de Kohn-Sham como combinações lineares de orbitais de base:

$$
\varphi_{i}^{\mathrm{KS}}=\sum_{s} c_{s i} \chi_{s}
$$

e realizando o processo auto-consistente de maneira análoga à equação de HartreeFock-Roothaan.

\section{O Funcional de troca e correlação}

O termo $v_{x c}(\mathbf{r})=\frac{\delta E_{x c}}{\delta \rho(\mathbf{r})}$ na equação (3.55) é conhecido como potencial de troca e correlação e sua forma funcional é, em princípio, desconhecida. Algumas aproximações foram sugeridas na literatura ${ }^{[70 ; 83]}$, como aproximações de densidade local - LDA: Local Density Approximation - em que se supõe que a energia de troca e correlação do sistema pode ser escrita como dependente apenas da densidade local:

$$
E_{x c}[\rho]=\int \rho(\mathbf{r}) \epsilon_{x c}(\rho(\mathbf{r})) \mathrm{d} \mathbf{r},
$$

$\operatorname{com} \epsilon_{x c}(\rho(\mathbf{r}))$ a energia de troca e correlação de um gás de elétrons homogêneo de densidade $\rho$. É possível também separar a densidade em duas partes, uma para 
cada estado de spin, e permitir que cada estado e spin ocupe orbitais de KohnSham diferentes. A aproximação local que leva em conta os spins é chamada de LSDA - Local Spin-Density Approximation, aproximação de densidade local de spin.

Por fazer uso da densidade de um gás uniforme de elétrons, os funcionais LDA e LSDA são adequados apenas para casos em que a densidade não varie rapidamente com a posição. Uma generalização do funcional de troca e correlação, que depende explicitamente de derivadas da densidade, permite levar em conta variações mais intensas da densidade. Esse tipo de funcional é chamado de $G G A$ - Generalized-Gradient Approximation, aproximação generalizada de gradiente e geralmente aparece na forma

$$
E_{x c}^{\mathrm{GGA}}[\rho]=\int f(\rho(\mathbf{r}), \nabla \rho(\mathbf{r})) \mathrm{d} \mathbf{r}
$$

Um exemplo de funcional de troca GGA é o funcional de Becke, $E_{x}^{\mathrm{B} 88}$, que combina um termo de troca LSDA com um termo dependente de $\nabla \rho$ através de um parâmetro $b$ ajustado para reproduzir energias de troca calculadas através do método de Hartree-Fock ${ }^{[70]}$. Dentre os funcionais GGA de correlação, podemos citar o funcional de Lee-Yang-Parr $E_{c}^{\mathrm{LYP}}$. Os funcionais de troca e de correlação costumam ser combinados de diversas formas e o funcional de troca e correlação resultante

$$
E_{x c}=E_{x}+E_{c}
$$

é descrito como a combinação dos nomes dos funcionais que o compõem. Assim, um funcional de troca e correlação BLYP é a combinação dos funcionais de troca de Becke e de correlação de Lee-Yang-Parr:

$$
E_{x c}^{\mathrm{BLYP}}=E_{x}^{\mathrm{B} 88}+E_{c}^{\mathrm{LYP}} .
$$

Há também funcionais que levam em conta a energia de troca exata, calculada no formalismo de Hartree-Fock e termos de correlação de diversas origens, formando o termo de troca e correlação como uma combinação linear desses termos. Funcionais construídos desta forma são chamados de funcionais híbridos e entre eles figura o funcional B3LYP ${ }^{[70 ; 84]}$ :

$$
E_{x c}^{\mathrm{B} 3 \mathrm{LYP}}=\left(1-a_{0}-a_{x}\right) E_{x}^{\mathrm{LSDA}}+a_{0} E_{x}^{\mathrm{HF}}+a_{x} E_{x}^{\mathrm{B} 88}+\left(1-a_{c}\right) E_{c}^{\mathrm{VWN}}+a_{c} E_{c}^{\mathrm{LYP}},
$$

que faz uso de três parâmetros ajustados para reproduzir valores experimentais da energia de formação de moléculas ${ }^{[70]}$. 


\subsection{Espectro de absorção de luz}

A função de onda dos estados excitados calculada através do método de interação de configurações nos dá acesso à energia das transições ópticas, entretanto, não temos informações sobre a probabilidade dessas transições ocorrerem. Mais informações são necessárias para podermos construir o espectro de absorção de uma molécula.

Inicialmente, devemos levar em conta a interação da radiação luminosa com os elétrons do sistema. Para isso, lembremos que a força eletromagnética sobre uma carga $q$ é

$$
\mathbf{F}=q(\mathbf{E}+\mathbf{v} \times \mathbf{B})
$$

e que o termo magnético dessa força é $v / c$ vezes o termo elétrico, o que, para o caso de elétrons de valência ${ }^{[85]}$ é da ordem de $1 / 137$. O efeito do campo magnético sobre o spin do elétron também pode ser desconsiderado, uma vez que sua energia é proporcional ao momento magnético de spin do elétron, $\mu_{s}=g \frac{e \hbar}{2 m_{e}} \simeq$ $5,8 \times 10^{-5} \mathrm{eV} \mathrm{T}^{-1}$, desprezível se comparada à grandeza de elétron-volts típica das excitações eletrônicas. Dessa forma, podemos desprezar o termo magnético e a força fica $\mathbf{F}=q \mathbf{E}$.

Vamos agora supor que a radiação incidente sobre a molécula consista em uma onda plana, linearmente polarizada na direção $\hat{x}$, que se propaga na direção $\hat{z}$. O campo elétrico, portanto, tem a forma

$$
\mathbf{E}=\mathcal{E}_{x} \cos \left(2 \pi v t+\frac{2 \pi}{\lambda} z\right) \hat{x}
$$

em que $v$ representa a frequência e $\lambda$ o comprimento de onda. As transições eletrônicas de interesse se dão na região do ultravioleta próximo e do visível, com comprimentos de onda da ordem de $500 \mathrm{~nm}$. Essa é uma medida duas a três ordens de grandeza maior que as moléculas, cujas dimensões vão de um a poucas dezenas de nanometros. Por isso, podemos considerar constante a fase da onda ao longo das dimensões da molécula e então desprezar a dependência espacial em (3.57), que passa a ser escrita como

$$
\mathrm{E}=\mathcal{E}_{x} \cos (\omega t) \hat{x} ; \quad \operatorname{com} \omega=2 \pi v .
$$

A energia potencial de uma carga elétrica $q$ na presença de um campo elétrico uniforme de intensidade $\mathcal{E}$ na direção $\hat{x}$ é dada por

$$
V=-\int \mathbf{F} \cdot \mathrm{d} \mathbf{x}=\int q \mathcal{E}_{x} \mathrm{~d} x=-q \mathcal{E} x,
$$

com a constante de integração arbitrada como zero. Esse termo pode ser considerado uma perturbação no hamiltoniano eletrônico da molécula:

$$
H^{\prime}(t)=-\mathcal{E}_{x} \cos (\omega t) \sum_{i} q_{i} x_{i}
$$


de forma que a equação de Schrödinger dependente do tempo se torna

$$
i \hbar \frac{\partial \Psi}{\partial t}=\left[H_{\mathrm{el}}^{(0)}+H^{\prime}(t)\right] \Psi,
$$

cuja solução $\Psi(\mathbf{x}, t)$ pode ser escrita como uma combinação linear das funções de onda não-perturbadas, que formam uma base completa:

$$
\Psi(\mathbf{x}, t)=\sum_{m} c_{m}(t) \exp \left(-i E_{m}^{(0)} t / \hbar\right) \psi_{m}^{(0)}(\mathbf{x})
$$

e os coeficientes $c_{m}(t)$ são dados ${ }^{[85]}$ pela equação

$$
\frac{\mathrm{d} c_{m}}{\mathrm{~d} t}=-i / \hbar \sum_{k} c_{k} e^{i \omega_{m k} t}\left\langle\psi_{m}^{(0)}\left|H^{\prime}\right| \psi_{k}^{(0)}\right\rangle,
$$

com

$$
\omega_{m k}=\frac{\left(E_{m}^{(0)}-E_{k}^{(0)}\right)}{\hbar} .
$$

Se considerarmos que a perturbação passa a agir em $t=0$ sobre o sistema que se encontra no $n$-ésimo estado não-perturbado, temos

$$
c_{k}(t=0)= \begin{cases}1, & \text { se } k=n \\ 0, & \text { se } k \neq n\end{cases}
$$

e, numa aproximação de primeira ordem, a equação (3.61) se torna

$$
\frac{\mathrm{d} c_{m}}{\mathrm{~d} t}=-\frac{i}{\hbar} e^{i \omega_{m n} t}\left\langle\psi_{m}^{(0)}\left|H^{\prime}\right| \psi_{n}^{(0)}\right\rangle .
$$

Supondo que $H^{\prime}$ aja sobre o sistema até $t=t_{1}$, após esse instante os coeficientes da função de onda perturbada serão dados por

$$
c_{m}\left(t_{1}\right)=\delta_{n m}-i / \hbar \int_{0}^{t_{1}} e^{i \omega_{m n} t}\left\langle\psi_{m}^{(0)}\left|H^{\prime}\right| \psi_{n}^{(0)}\right\rangle \mathrm{d} t .
$$

Podemos agora aplicar $H^{\prime}$ definido em (3.59) para obter os coeficientes da (3.63), definindo o operador dipolo elétrico

$$
\mathbf{d}=\sum_{i} q_{i} \mathbf{x}_{i}
$$

e utilizando $\cos (\theta)=1 / 2\left(e^{i \theta}+e^{-i \theta}\right)$ para obter

$$
\begin{aligned}
c_{m}\left(t_{1}\right) & =\delta_{m n}+\frac{i}{2 \hbar} \mathcal{E}_{x}\left\langle\psi_{m}^{(0)}\left|d_{x}\right| \psi_{n}^{(0)}\right\rangle \int_{0}^{t_{1}}\left[e^{i\left(\omega_{m n}+\omega\right) t}+e^{i\left(\omega_{m n}-\omega\right) t}\right] \mathrm{d} t \\
& =\delta_{m n}+\frac{i}{2 \hbar} \mathcal{E}_{x}\left\langle\psi_{m}^{(0)}\left|d_{x}\right| \psi_{n}^{(0)}\right\rangle\left[\frac{e^{i\left(\omega_{m n}+\omega\right) t}-1}{\omega_{m n}+\omega}+\frac{e^{i\left(\omega_{m n}-\omega\right) t}-1}{\omega_{m n}-\omega}\right] .
\end{aligned}
$$


Após $t=t_{1}$, a probabilidade de uma medida de energia da molécula resultar em $E_{m}$ é $\left|c_{m}\left(t_{1}\right)\right|^{2}$. Para $m \neq n$, essa probabilidade é considerável se o termo entre colchetes na (3.64) não for desprezível, isto é, se

$$
\omega= \pm \omega_{m n} .
$$

No caso positivo, temos um fóton de energia $h v$ sendo absorvido e levando a uma transição do estado $|n\rangle$ para o estado $|m\rangle$ da molécula, já que

$$
h v=E_{m}^{(0)}-E_{n}^{(0)}
$$

ou seja, o estado $|m\rangle$ tem energia maior que o estado $|n\rangle$ e a diferença de energia entre esses estados é igual à energia do fóton.

É possível reescrever a probabilidade de absorção $\left|c_{m}\right|^{2}$ em função da intensidade da radiação através da densidade de energia $\rho$

$$
\rho=\frac{\left(\mathcal{E}_{x}\right)^{2}}{8 \pi}
$$

e levando em conta que, no caso de absorção, o denominador da segunda fração da (3.64) é nulo e domina a expressão. Assim, a probabilidade de absorção será dada por

$$
\left|c_{m}\left(t_{1}\right)\right|^{2}=\frac{8 \pi \rho}{\hbar^{2}}\left|\left\langle\psi_{m}^{(0)}\left|d_{x}\right| \psi_{n}^{(0)}\right\rangle\right|^{2}\left\{\frac{\operatorname{sen}^{2}\left[\left(\omega_{m n}-\omega\right)^{t_{1} / 2}\right]}{\left(\omega_{m n}-\omega\right)^{2}}\right\},
$$

com a aplicação da identidade

$$
e^{i x}-1=2 i e^{i x / 2} \operatorname{sen}(x / 2) .
$$

Se levarmos em conta que a fonte de luz não necessariamente é monocromática, podemos considerar a densidade de energia luminosa $\rho$ como dependente da frequência: $u(v)$ e integrar em todo o espectro. Com isso, obtemos ${ }^{[85]}$

$$
\left|c_{m}\right|^{2}=\frac{2 \pi t_{1}}{\hbar^{2}}\left|\left\langle\psi_{m}^{(0)}\left|d_{x}\right| \psi_{n}^{(0)}\right\rangle\right|^{2} u\left(v_{m n}\right)
$$

com

$$
v_{m n}=\frac{\omega_{m n}}{2 \pi}=\frac{\left(E_{m}^{(0)}-E_{n}^{(0)}\right)}{\hbar} .
$$

Generalizando esse resultado para radiação não-polarizada e isotrópica, somamos as contribuições polarizadas em cada direção, com densidade de energia média $u_{x}=u_{y}=u_{z}=u / 3$ para obtermos

$$
\left|c_{m}\right|^{2}=\frac{2 \pi t_{1}}{3 \hbar^{2}}\left|\left\langle\psi_{m}^{(0)}|\mathbf{d}| \psi_{n}^{(0)}\right\rangle\right|^{2} u\left(v_{m n}\right)
$$


e a quantidade $\left|\left\langle\psi_{m}^{(0)}|\mathbf{d}| \psi_{n}^{(0)}\right\rangle\right|^{2}$ recebe o nome de momento de transição.

A probabilidade de transição (3.70) se refere a uma única molécula. Experimentalmente, costuma-se lidar com um número $N$ de moléculas em solução. Também é conveniente eliminar a dependência de $t_{1}$ levando em conta a taxa de absorção:

$$
\begin{aligned}
\mathcal{A} & =N \frac{\left|c_{m}\right|^{2}}{t_{1}} \\
& =N \frac{2 \pi}{3 \hbar^{2}}\left|\left\langle\psi_{m}^{(0)}|\mathbf{d}| \psi_{n}^{(0)}\right\rangle\right|^{2} u\left(v_{m n}\right) \\
& \equiv B_{n \rightarrow m} N u\left(v_{m n}\right),
\end{aligned}
$$

onde definimos o coeficiente de absorção de Einstein

$$
B_{n \rightarrow m}=\frac{2 \pi}{3 \hbar^{2}}\left|\left\langle\psi_{m}^{(0)}|\mathbf{d}| \psi_{n}^{(0)}\right\rangle\right|^{2} .
$$

A grandeza a que temos acesso em um experimento de absorção de luz é a absorbância, na forma da razão ${ }^{[86]}$ entre a potência de radiação incidente $P_{v}^{0}$ e transmitida $P_{v}^{\text {trans }}$ pela amostra:

$$
A(v)=\log \left(\frac{P_{v}^{0}}{P_{v}^{\text {trans }}}\right)=\log \left(\frac{P_{v}^{0}}{P_{v}^{0}-P_{v}^{\text {abs }}}\right),
$$

que está relacionada à potência luminosa absorvida, calculada como o produto da taxa de absorção pela energia dos fótons absorvidos:

$$
\frac{P_{v_{m n}}^{\mathrm{abs}}}{V}=h v_{m n} n B_{n \rightarrow m} u\left(v_{m n}\right),
$$

$\operatorname{com} n=N / V$ a concentração da substância na amostra.

É útil comparar esse valor com um modelo simplificado formado por um oscilador harmônico de mesma massa e carga do elétron cuja frequência vibracional é a mesma da transição em questão $-v_{m n}-$ sujeito às mesmas condições da molécula: exposição com duração $t_{1}$ à radiação com densidade de energia $u(v)$. Com isso, definimos a força do oscilador $f$ como a razão entre as taxas de absorção da molécula e do oscilador:

$$
f=\frac{8 \pi^{2} v_{m n} m_{e}}{3 h e^{2}}\left|\left\langle\psi_{m}^{(0)}|\mathrm{d}| \psi_{n}^{(0)}\right\rangle\right|^{2},
$$

com $m_{e}$ e $e$ a massa e a carga do elétron, respectivamente. O valor de $f$ depende apenas de propriedades internas da molécula e tipicamente, uma transição intensa terá um valor de $f$ compatível com 1 . Comparando a força do oscilador acima com a (3.74), vemos que $f$ é proporcional à potência absorvida. 


\subsection{Introdução à fluorescência}

Luminescência é a emissão de luz por uma substância eletronicamente excitada $^{[86]}$. Essa excitação eletrônica pode ter diversas origens, como campos elétricos, calor ou absorção de luz. Ao fenômeno de luminescência que segue absorção de luz damos o nome de fotoluminescência.

A diferença de massa entre os núcleos atômicos e os elétrons nos leva à aproximação adiabática discutida na Seção 3.1 e à constatação de que os elétrons se adaptam a mudanças nas posições do núcleos rapidamente, a ponto de os núcleos se moverem em um potencial efetivo gerado pela configuração eletrônica. Isso é válido tanto para o estado fundamental quanto para estados excitados. O efeito do movimento dos núcleos nesse potencial efetivo é o surgimento de conjuntos de níveis vibracionais para os núcleos, um conjunto para cada estado eletrônico, soluções da equação (3.3).

Pela mesma razão, as posições dos núcleos não reagem tão rapidamente a mudanças no estado eletrônico do sistema, de forma que se considerarmos um gráfico como o da Figura 3.2, que ilustra o potencial efetivo gerado pelos elétrons em função das coordenadas nucleares, as transições eletrônicas ocorrem verticalmente, ou seja, a energia do sistema se altera sem mudança nas coordenadas nucleares.

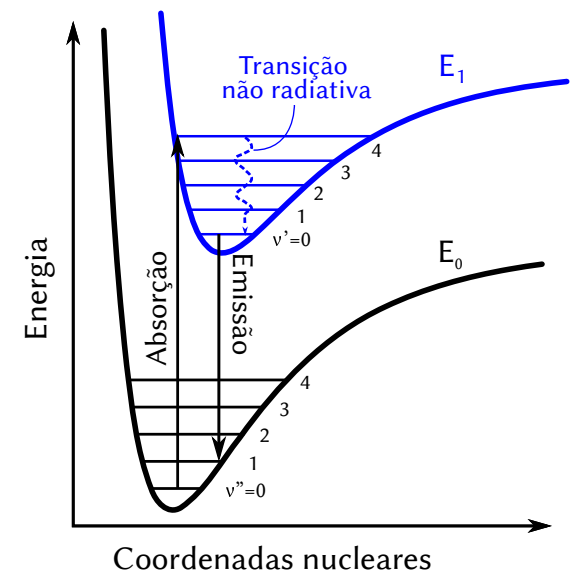

Figura 3.2: Ilustração do processo de fluorescência com curvas de potencial efetivo para o estado fundamental eletrônico $E_{0}$ e primeiro estado excitado. Note as transições verticais e a emissão de energia menor que a absorção.

Tipicamente, a absorção se dá na ordem de $1 \mathrm{fs}$ ou $10^{-15} \mathrm{~s}$, enquanto a molécula pode permanecer no estado excitado durante $100 \mathrm{ps}$ a $100 \mathrm{~ns}\left(10^{-10} \mathrm{~s} \mathrm{a}\right.$ $10^{-7} \mathrm{~s}$ ), tempo suficiente para a estrutura relaxar não radiativamente para $\mathrm{o}$ nível vibracional $v^{\prime}=0$ do perfil de energia do estado excitado eletrônico ${ }^{[86]}$. A emissão ocorre então do fundo do poço do estado excitado para algum nível 


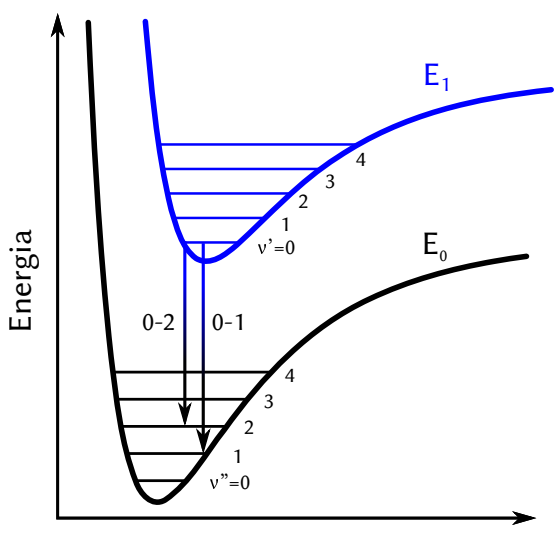

Coordenadas nucleares

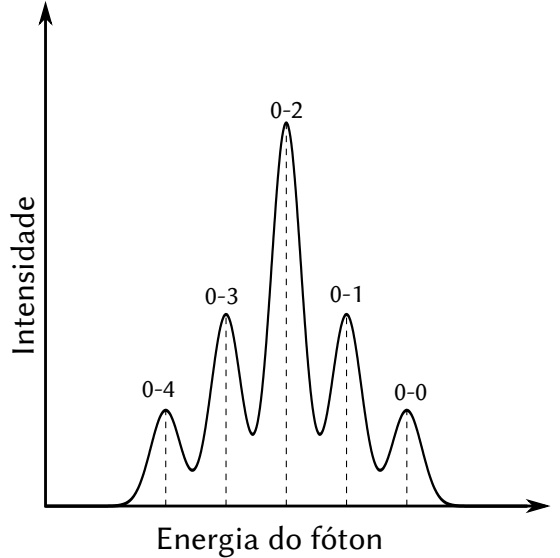

Energia do fóton

Figura 3.3: Estrutura vibrônica oriunda da probabilidade de transição para diversos níveis vibracionais do estado eletrônico final (esquerda). À direita, as linhas tracejadas indicam as transições observadas em estado gasoso. A curva cheia mostra o alargamento de espectro esperado em solução ${ }^{[86]}$.

vibracional do poço do estado fundamental. Este processo é conhecido como fluorescência.

A possibilidade de o sistema decair para mais de um estado vibracional dá origem à emissão de fótons com energia que diferem de $\hbar \omega^{\prime \prime}$, formando o que chamamos de estrutura vibrônica, apresentada na Figura 3.3. Damos às transições nomes que indicam os estados vibracionais envolvidos, de forma que uma transição 0-0 ocorre entre os níveis vibracionais fundamentais e uma transição 0-1 ocorre entre o nível vibracional mais baixo do estado excitado eletrônico e o nível $v^{\prime \prime}=1$ no estado fundamental eletrônico.

Pode ocorrer, enquanto o sistema vagueia pelo estado excitado, um cruzamento de estados de spin e o decaimento para um estado tripleto. Já que a probabilidade de decaimento do tripleto para o estado fundamental é menor, de forma que o tempo de vida nesse estado é maior, de $1 \mathrm{~ms}$ a $1 \mathrm{~s}$. Nesse caso, o processo é conhecido como fosforescência e está fora do escopo deste trabalho.

\subsection{Fotoluminescência: espectro semiempírico}

Como vimos, no processo de fluorescência o fóton é emitido quando a molécula se encontra no mínimo de energia vibracional do estado excitado eletrônico. Uma vez que com o ZINDO obtemos a energia de transição eletrônica vertical, é possível articular um processo em que partimos da geometria do estado excitado e calculamos as energias das transições eletrônicas para obter o espectro de emissão da molécula. 
A dinâmica molecular nos permite explorar o espaço de fase do sistema devido a sua ergodicidade, ou seja, a média temporal das configurações que o sistema adota ao longo de uma simulação de dinâmica molecular equivale a obter médias das configurações do espaço de fase com pesos proporcionais à probabilidade de certa geometria ser encontrada. Podemos, então, obter amostras das geometrias do estado excitado eletrônico de uma substância se utilizarmos um campo de forças clássico que reproduza a superfície de energia potencial efetiva nesse estado. Em particular, reparametrizar um campo de forças para reproduzir os comprimentos de ligação, ângulos, torções e frequências de oscilação da molécula do estado excitado é uma forma de obter essa superfície. Outra forma de obter essa estatística é levar em conta os estados vibracionais da molécula no estado excitado ${ }^{[8788]}$, mas esta abordagem, por se tratar de cálculo semiempírico, acaba tendo aplicabilidade limitada a sistemas de pequeno porte.

De posse de uma população representativa do estado excitado de uma molécula, podemos calcular as energias de transição eletrônica para cada uma delas. Em princípio, o cálculo ZINDO é realizado para uma molécula em uma dada geometria e o sentido da transição não é explícito. Entretanto, quando consideramos o espectro médio da amostra, o resultado reflete a estatística do estado excitado e reproduz o espectro de emissão daquela estrutura. 



\section{Parte II}

\section{Resultados e discussão}





\section{Capítulo 4}

\section{Mecanismo de suspensão seletiva de nanotubos em solução de polifluoreno}

Simular a fotofísica e o comportamento dinâmico dos compósitos de polifluoreno e nanotubos de carbono em solução exige um procedimento de diversas etapas, descritas neste capítulo, juntamente com os resultados.

Primeiramente, apresentamos uma visão geral dos desenvolvimentos no processo de suspensão seletiva dos nanotubos em soluções de PFO e descrevemos a estratégia adotada para compreender esse fenômeno.

A seguir, mostramos como o campo de forças CVFF ${ }^{[89]}$ (Consistent-Valence Forcefield, campo de força de valência consistente) foi adaptado para os propósitos deste trabalho.

Na Seção seguinte, descrevemos simulações de dinâmica molecular utilizando esse campo de força reparametrizado para comparar a estabilidade de diversas conformações de $\mathrm{PFO}$ e nanotubos de carbono, tanto na presença quanto na ausência de solvente.

Finalmente, mostramos como obtemos o espectro de luminescência de uma amostra simulada de PFO e como ela se compara a resultados experimentais.

\subsection{Estado atual}

Adrian Nish, Robin Nicholas e colaboradores observaram ${ }^{[28]}$ que polímeros baseados no fluoreno podem suspender seletivamente nanotubos em solução de tolueno. Em seu trabalho, dispersaram nanotubos em soluções de derivados do polifluoreno em tolueno através do processo de sonicação, que consiste em submeter a solução à agitação causada por ultrassom emitido por um sonda ou 
um banho de imersão. Em seguida, as amostras foram centrifugadas para isolar os tubos suspensos. Com essas suspensões os autores prepararam mapas de excitação de fotoluminescência (PLE, photoluminescence excitation) [53 e Seção 2.2.5] e espectros de absorção a fim de identificar as espécies de nanotubos suspensas e sua população relativa. Observaram que o poli[9,9-dioctilfluorenil-2,7-diil] (PFO ou PF8), representado na Figura 4.1, é o derivado de polifluoreno que rende suspensões com a distribuição mais estreita de ângulos quirais, concentradas em $\theta \gtrsim 25^{\circ}$ e diâmetros de $0,8 \mathrm{~nm}$ a $1,0 \mathrm{~nm}$.

Com esse resultado em mãos, Nish e colaboradores recorreram à mecânica molecular para calcular a energia de ligação entre os polímeros e os nanotubos e chegaram a um modelo em que as cadeias de polímeros se alinham com o eixo do tubo e o número de cadeias aderidas está ligado à circunferência dos tubos. Em particular, os tubos com diâmetro de $0,5 \mathrm{~nm}$ a 1,1 nm tendem a ser recobertos por três cadeias.

Mais tarde, examinaram o papel do solvente no processo de seleção ${ }^{[33]}$. Para isto, repetiram o procedimento acima utilizando $\mathrm{PFO}$ e outros polímeros conjugados dissolvidos em tolueno, clorofórmio, xileno e tetra-hidrofurano (THF). Os dados de absorção mostram uma absorbância da suspensão de nanotubos em PFO e tolueno cerca de quatro vezes maior que daqueles suspensos em $\mathrm{PFH}$ e tolueno. Isso leva a concluir que o $\mathrm{PFH}$ é bem menos eficiente em suspender nanotubos, além de menos seletivo, como vimos no trabalho anterior. Variando o solvente, os dados de absorção e PLE mostram que, enquanto o PFO em clorofórmio ou em THF leva a suspensões de nanotubos com maior absorbância, a seletividade é perdida, o que mostra a importância do tolueno na capacidade do PFO de suspender tubos de quiralidades e diâmetros específicos.

Em 2010, J. Gao e M. A. Loi realizaram medidas de absorção e fotoluminescência de nanotubos suspensos por cadeias de polímeros conjugados ${ }^{[32]}$. Em particular, observaram o comportamento da fotoluminescência dos nanotubos de forma dependente do tempo, que lançou luz sobre a forma com que os nanotubos e os polímeros interagem. Outra medida importante do trabalho consistiu no espectro de fotoluminescência dos polímeros que envolvem o tubo e a diferença entre os polímeros livres em solução ou enovelados com os tubos. Esse tipo de medida permite obter informações sobre a conformação da cadeia polimérica, uma vez que o espectro de fluorescência de polímeros conjugados é fortemente dependente de sua geometria. Devido a sua complexidade, esse tipo de medida é pouco explorado na literatura de nanotubos, mas permite compreender mais profundamente o mecanismo que rege a seletividade desses polímeros.

Neste trabalho, desenvolvemos um método para calcular o espectro de luminescência de cadeias de PFO interagindo com nanotubos de carbono em solução de tolueno. Para isto foi necessário estudar o comportamento dinâmico do polímero em seu estado excitado para então calcular o espectro de emissão 
médio de várias amostras da estrutura ao longo da simulação, para obter um espectro médio, representativo da dinâmica.

\subsection{Adaptação do campo de força}

Como visto na Seção 3.6, para calcularmos o espectro de emissão utilizando métodos semiempíricos é necessário partir da geometria do estado excitado. Campos de força, entretanto, são parametrizados para reproduzir a geometria molecular no estado fundamental eletrônico. Por isso é necessário alterar parâmetros do campo de força para reproduzir a geometria do estado excitado.

Partimos da molécula de di[9,9-dimetilfluoreno], ilustrada nas Figs. 4.1. Substituímos os radicais octil por metil para reduzir a complexidade dos cálculos nesta fase. Comparamos a geometria do estado fundamental, calculada utilizando teoria do funcional da densidade com o funcional híbrido B3LYP ${ }^{[84]}$ (vide eq. (3.56)) e a base gaussiana 6-31G(d), com a geometria do estado excitado calculada através de um método de interação de configurações envolvendo todos os determinantes de Slater simplesmente excitados (CI-Singles) no contexto de Hartree-Fock-Roothaan, utilizando a mesma base.

Comparamos essas duas estruturas com a calculada usando o campo de força CVFF, adotando as cargas atômicas obtidas a partir do cálculo DFT anterior. A Figura 4.1 mostra os tipos atômicos adotados no modelo. O pentágono no centro da estrutura é formado por quatro átomos de carbono tipo c5 (carbono $s p^{2}$ pertencente a um anel com 5 átomos) e um c (carbono $s p^{3}$ ligado a quatro átomos de carbono).

Vemos na Tabela 4.1 que a ligação $B$, o lado do pentágono oposto ao carbono que conecta os radicais, está muito curta em relação ao calculado para o estado excitado. As outras ligações c5-c5 $(L)$ são mais longas que o resultado do cálculo $a b$ initio. Dessa forma, alterar unicamente o valor de equilíbrio dessa ligação afetaria a geometria da molécula de forma indesejada. Para contornar

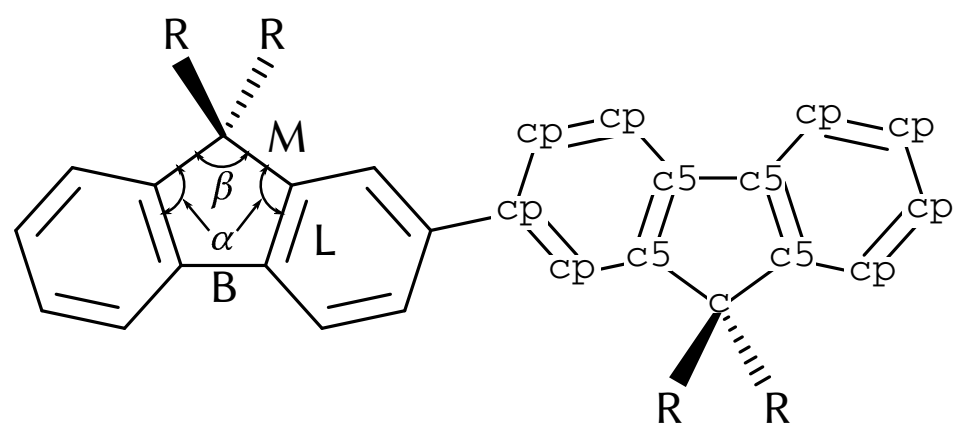

Figura 4.1: Estrutura do difluoreno com os tipos atômicos utilizados no campo de força CVFF. 
Tabela 4.1: Dimensões relevantes na estrutura do difluoreno. B,L,M: comprimentos de ligação, em Å, conforme Fig. 4.1, $\alpha, \beta$ : ângulos planos, em graus, como na Figura 4.1.

\begin{tabular}{cccccc}
\hline Método & B & L & M & $\alpha$ & $\beta$ \\
\hline DFT - B3LYP & 1,467 & 1,409 & 1,529 & 110,8 & 101,2 \\
CI & 1,434 & 1,418 & 1,528 & 110,3 & 100,9 \\
CVFF & 1,384 & 1,431 & 1,576 & 111,5 & 97,1 \\
CVFF-c5 & 1,433 & 1,446 & 1,519 & 109,6 & 103,1 \\
\hline
\end{tabular}

este problema, alteramos uma série de parâmetros, com o objetivo de aumentar os ângulos internos do pentágono da estrutura. Os termos modificados em relação ao CVFF original, para criar o que chamaremos de CVFF-c5, foram:

- o termo de intensidade $D_{\mathrm{c5}, \mathrm{c5}}$ do potencial de Morse (eq. (3.7)) entre dois átomos do tipo c5, alterado de 70,0 $\mathrm{kcal} \mathrm{mol}^{-1}$ para $110,0 \mathrm{kcal} \mathrm{mol}^{-1}$;

- o termo de intensidade $H_{\mathrm{c}, \widehat{c 5, c 5}}$ do potencial harmônico (eq. (3.8)) para o ângulo centrado em um átomo c5 envolvendo em uma extremidade um átomo c5 e em outra um c ( $\alpha$ na Figura 4.1). A rigidez dessa ligação foi alterada de $120,0 \mathrm{kcal} \mathrm{mol}^{-1} \mathrm{rad}^{-2}$ para $145,0 \mathrm{kcal} \mathrm{mol}^{-1} \mathrm{rad}^{-2}$;

- criado novo termo de ângulo entre átomos c5 centrado num átomo c. $\theta_{c 5, c, c 5}^{*}=180,0^{\circ}$ e $H_{c 5, c, c 5}=135,0 \mathrm{kcal} \mathrm{mol}^{-1} \mathrm{rad}^{-2}$. Este termo foi criado com a intenção de aumentar o ângulo $\beta$ na Figura 4.1 e enrijecer a estrutura do pentágono.

Uma vez que o tipo atômico c5 não aparece em outros compostos envolvidos neste trabalho, restringimos as alterações no campo de força a termos que incluem o c5 em sua definição. Alterar o mínimo de parâmetros possível também foi uma preocupação nesta etapa, já que a consistência dos parâmetros é algo delicado e a força em cada átomo é resultante de várias contribuições.

É importante agora verificar a eficácia desse novo campo de forças para reproduzir o espectro do fluoreno em estado excitado nas condições em que o restante das simulações será realizado. Calculamos, então, o comprimento de onda da transição de menor energia permitida por dipolo, $\lambda_{\max }$, de cada uma das quatro geometrias. Os resultados estão na Tabela 4.2, com as dimensões relevantes ilustradas na Fig. 4.2. Observamos que o valor de $\lambda_{\max }$ da estrutura calculada com o campo força CVFF - c5 é bem próximo daquele do estado excitado calculado com CI, apesar da geometria e da conjugação das ligações A-F não estar perfeitamente reproduzida.

Cabe salientar que a estrutura do polifluoreno obtida com o campo de forças CVFF-c5 não deve interagir com o nanotubo de forma muito diferente da cadeia 
Tabela 4.2: Dimensões relevantes na estrutura do difluoreno. A-F: comprimentos de ligação, em $\AA$, conforme Fig. 4.2, $\varphi$ : ângulo de torção, em graus, tal que $0^{\circ}$ corresponde à estrutura plana anti, como na Figura 4.2 .

\begin{tabular}{lcccccccc}
\hline \multicolumn{1}{c}{ Método } & $\mathrm{A}$ & $\mathrm{B}$ & $\mathrm{C}$ & $\mathrm{D}$ & $\mathrm{E}$ & $\mathrm{F}$ & $\varphi$ & $\lambda_{\max }$ \\
\hline DFT - B3LYP & 1,397 & 1,467 & 1,396 & 1,394 & 1,408 & 1,484 & 37,9 & 334,6 \\
CI & 1,400 & 1,434 & 1,408 & 1,362 & 1,440 & 1,423 & 9,8 & 382,7 \\
CVFF & 1,441 & 1,384 & 1,424 & 1,395 & 1,440 & 1,422 & 30,0 & 391,6 \\
CVFF-c5 & 1,428 & 1,433 & 1,414 & 1,397 & 1,440 & 1,413 & 32,1 & 378,1 \\
\hline
\end{tabular}

modelada com o campo de forças original CVFF, uma vez que os termos de van der Waals não foram modificados. Além disso, a flexibilidade da cadeia, governada pela torção $\phi$, e o comprimento do polímero não sofreram modificações relevantes. Dessa forma, esperamos que o comportamento em larga escala da cadeia modelada no estado excitado seja semelhante ao daquela modelada no estado fundamental.

Com esses resultados em mãos e o campo de forças CVFF-c5 definido, partiremos para as etapas seguintes do trabalho.

\subsection{Dinâmica molecular}

Como discutido na Seção 3.6, devemos tomar médias temporais dos espectros individuais para melhor reproduzir resultados experimentais, uma vez que as medidas são tomadas ao longo de um certo tempo de exposição e os resultados de fato refletem uma média temporal (e de ensemble) da configuração das moléculas. Por isso, devemos realizar simulações de dinâmica molecular para obter uma série temporal das estruturas em movimento. Também é importante comparar

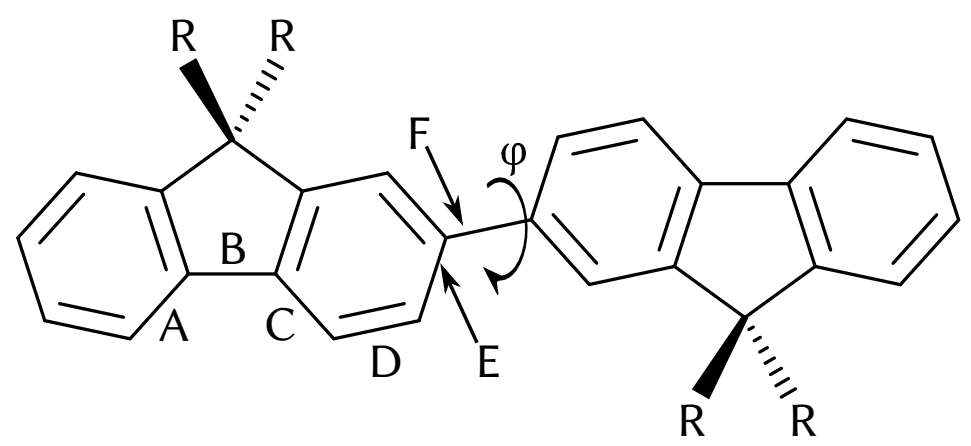

Figura 4.2: Estrutura do difluoreno com as dimensões relevantes destacadas. No caso do $\mathrm{PFO}, \mathrm{R}=\mathrm{C}_{8} \mathrm{H}_{17}$, no caso de $\mathrm{PFM}, \mathrm{R}=\mathrm{CH}_{3}$. 
a energia interna das estruturas para obter informações sobre sua estabilidade e população relativa em uma solução.

Realizamos simulações de dinâmica molecular em sistemas compostos de nanotubos de carbono e cadeias de $\mathrm{PFO}$ em condições comparáveis às experimentais. Como os trabalhos de Nish, Hwang e colaboradores ${ }^{[28 ; 33]}$ mostram que o PFO apresenta grande seletividade para nanotubos de diâmetro de $0,75 \mathrm{~nm}$ a $1,05 \mathrm{~nm}$ e ângulo quiral próximo de $30^{\circ}$, fizemos os estudos com tubos do tipo $(7, n)$ e $(8, n)$, com $n=4,5,6,7$, cujas propriedades geométricas se encontram na Tabela 4.3.

Tabela 4.3: Nanotubos considerados na dinâmica molecular

\begin{tabular}{ccc}
\hline$(n, m)$ & Diâmetro $(\AA)$ & Ângulo quiral \\
\hline$(7,4)$ & 7,5 & 21,1 \\
$(7,5)$ & 8,2 & 24,5 \\
$(7,6)$ & 8,8 & 27,5 \\
$(7,7)$ & 9,5 & 30,0 \\
$(8,4)$ & 8,3 & 19,1 \\
$(8,5)$ & 8,9 & 22,4 \\
$(8,6)$ & 9,5 & 25,3 \\
\hline
\end{tabular}

No mesmo trabalho ${ }^{[28]}$ os autores calculam que em torno de tubos dessa faixa de diâmetro alinham-se três cadeias de PFO, dadas as restrições de tamanho das caudas de alquila em comparação com a circunferência do nanotubo. Por isso consideramos casos em que três cadeias interagem com cada nanotubo, em duas conformações: a) alinhadas com o eixo do tubo, semelhantes ao mostrado no artigo de Nish et al. ${ }^{[28]}$ ou b) fazendo uma hélice em torno do tubo, de modo a maximizar os contatos entre as caudas de alquila de cadeias vizinhas. Exemplos dessas duas conformações encontram-se na Fig. 4.3.

Uma vez que tanto a cadeia principal do PFO quanto a superfície do nanotubo apresentam alta densidade de elétrons $\pi$, essas estruturas podem interagir através de interações $\pi-\pi$ semelhantes às envolvidas no empilhamento de folhas de grafeno, levando a um alinhamento dos anéis aromáticos do polímero com uma fileira de anéis do nanotubo. Isso nos leva a considerar uma estrutura em que os anéis da cadeia principal do polímero estejam aproximadamente paralelos à superfície do nanotubo. Levando em conta a existência da fase $\beta$ do PFO em tolueno, também podemos conjecturar uma estrutura helicoidal que se forma quando uma fita de $\beta$-PFO se enrola em torno de um nanotubo sem alterar a interdigitação ${ }^{[35]}$ dos radicais octil.

Inicialmente, devemos comparar a estabilidade relativa entre a cadeia de PFO disposta de forma helicoidal e paralela ao eixo do tubo. A energia potencial do 


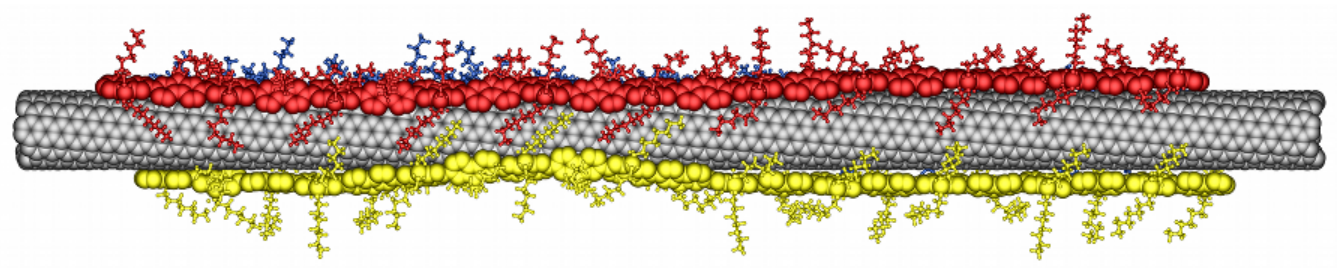

(a) Cadeias de PFO alinhadas com o eixo de um nanotubo $(8,6)$

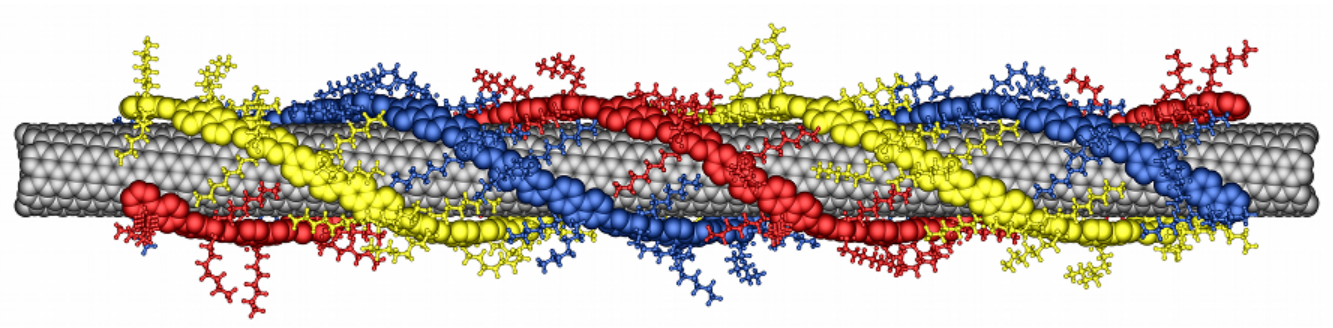

(b) Cadeias de PFO enoladas em hélice em torno de um nanotubo $(8,6)$

Figura 4.3: Duas conformações de PFO sobre nanotubos consideradas neste trabalho. Nanotubo em cinza. Cadeias de PFO em amarelo, vermelho e azul. Para facilitar a visualização, moléculas de tolueno não são representadas.

sistema dá informações a respeito disso e será o objeto inicial de nosso estudo. Uma vez que buscamos informações a respeito do comportamento dos sistemas em solução e à temperatura ambiente, uma comparação da energia de potencial mínima dos sistemas otimizados não é suficiente, por isso devemos proceder a simulações de dinâmica molecular à temperatura ambiente.

\subsubsection{Preparação das estruturas}

Preparamos as estruturas envolvendo oito tubos: $(7, n)$ e $(8, n)$, com $n=$ 4, 5, 6, 7, cada um envolvido por três cadeias de polifluoreno. Construímos cada cadeia de PFO com 21 monômeros. Consideramos duas conformações para as cadeias poliméricas: em hélice ou estirada. As simulações seguiram o procedimento descrito a seguir e ilustrado na Figura 4.4.

Procedemos então às simulações de dinâmica molecular em vácuo e na presença de tolueno, utilizando o campo de forças CVFF-c5. Devido às dimensões do sistema, uma simulação em uma caixa periódica preenchida com solvente seria inviável dada a infraestrutura computacional disponível, além de poder dar origem a configurações helicoidais na forma de artefatos da estrutura periódica ${ }^{[90 ; 91]}$ portanto optamos em posicionar uma camada de moléculas de tolueno em torno das estruturas. Isso diminui drasticamente o número de átomos envol- 


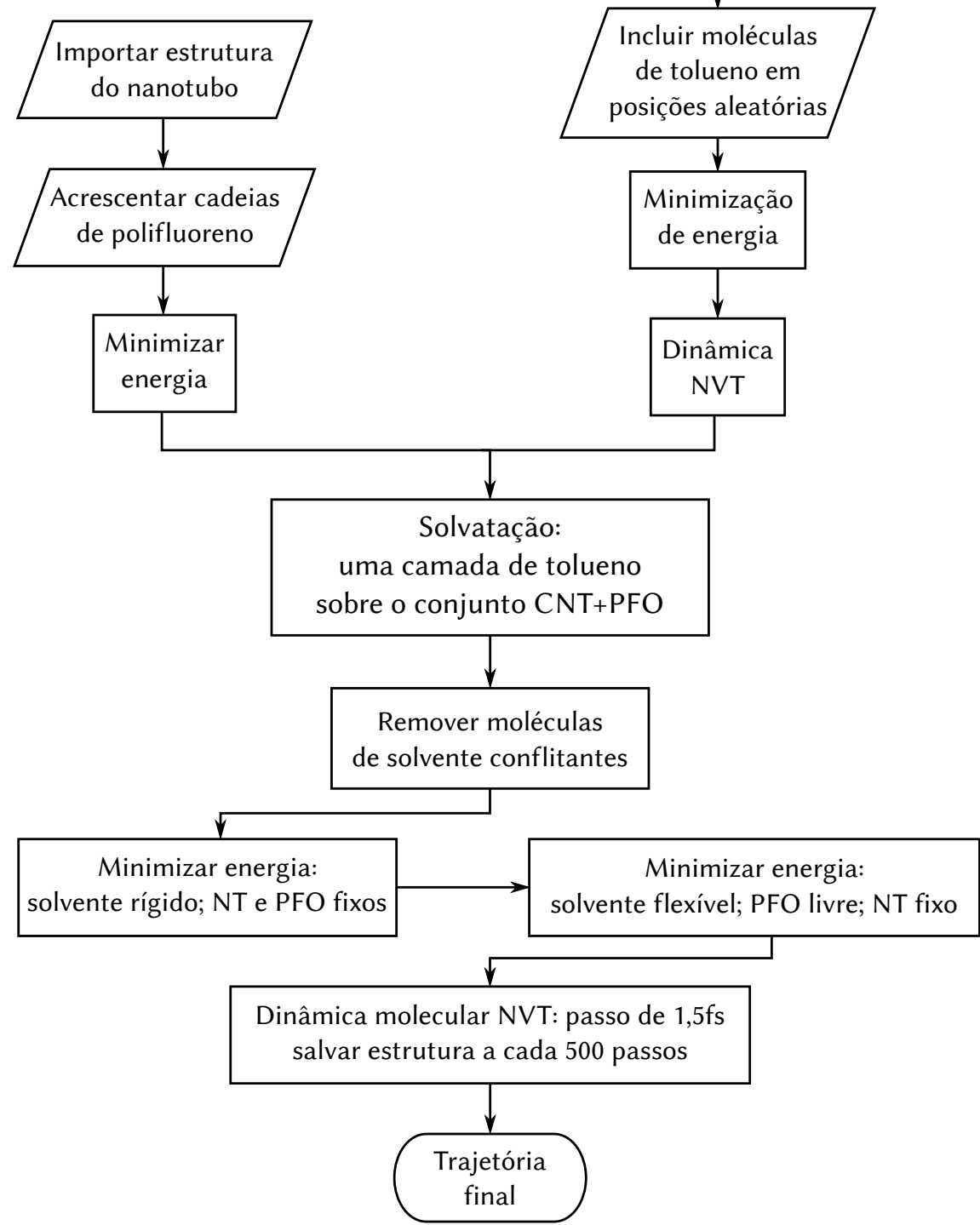

Figura 4.4: Fluxograma da preparação e simulação dos sistemas NT + PFO. Em todo o procedimento utilizamos o campo de forças CVFF-c5 e a mesma caixa de tolueno 
vidos na simulação enquanto permite levar em conta o efeito das moléculas de tolueno na interação tubo-PFO.

Para criar as camadas de solvatação, preenchemos uma caixa periódica com tolueno, adicionando moléculas aleatoriamente até atingir uma densidade de $0,86 \mathrm{~g} \mathrm{~cm}^{-3}$, compatível com a densidade do tolueno líquido à temperatura ambiente. Em seguida, minimizamos a energia do sistema utilizando o campo de forças CVFF e em seguida agitamos a caixa através de dinâmica molecular no ensemble canônico $(N V T)$ a $300 \mathrm{~K}$ por tempo suficiente para que a energia potencial do sistema oscilasse em torno de um valor médio constante.

Transferimos amostras dessa caixa para as estruturas de NT+PFO, de modo a formarem uma camada com espessura suficiente para cobrir os radicais octil do PFO, como na Fig. 4.5. Em seguida, minimizamos a energia do sistema com o conjunto NT+PFO fixo e cada molécula de tolueno rígida, porém livre para se deslocar. Depois, minimizamos energia do sistema com o solvente e os polímeros livres. As coordenadas atômicas do nanotubo, entretanto, foram mantidas fixas durante todo o processo para evitar que o sistema como um todo se deslocasse pelo espaço.

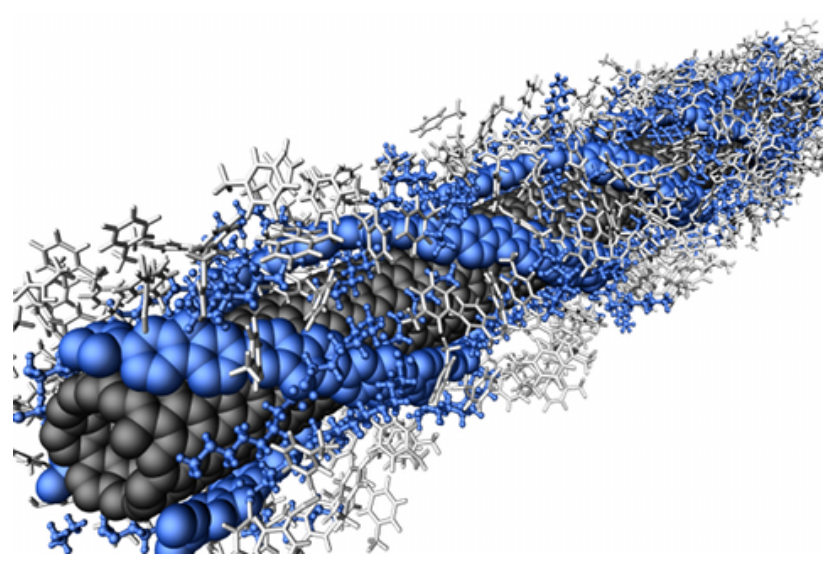

Figura 4.5: Exemplo de sistema nanotubo + PFO envolto por uma camada de tolueno. Nanotubo em cinza escuro, PFO em azul, tolueno em cinza claro.

Submetemos as estruturas preparadas desta forma a dinâmica molecular no ensemble canônico (NVT) com a temperatura regulada pelo termostato de NoséHoover ${ }^{[92]}$ a $300 \mathrm{~K}$ e passo de integração de 1,5 fs, mantendo fixas as coordenadas dos átomos do nanotubo e livres as demais. As coordenadas atômicas foram salvas a cada 500 passos $(0,75 \mathrm{ps})$. 


\subsubsection{Energia de interação}

Uma vez que buscamos conhecer a estrutura mais estável do polifluoreno em torno dos nanotubos em solução, devemos levar em conta os aspectos dinâmicos do sistema, efeitos de temperatura e diferenças de volume do sistema. Por isso, comparamos a energia potencial média ao longo de 50 ps de dinâmica molecular com o mínimo de energia de cada sistema otimizado com o mesmo campo de forças:

$$
\Delta E=E_{300 \mathrm{~K}}-E_{0} .
$$

Em busca de comportamentos sistemáticos, construímos gráficos de $\Delta E$ em função do diâmetro e do ângulo quiral, exibidos na Fig 4.6. Podemos observar que as cadeias de polímero enrolando-se em hélice em torno dos nanotubos apresentam mais baixa energia de ligação que as cadeias alinhadas com o eixo dos mesmos tubos. Isso indica que é mais provável, em solução, que as cadeias envolvam os nanotubos em forma de hélice.

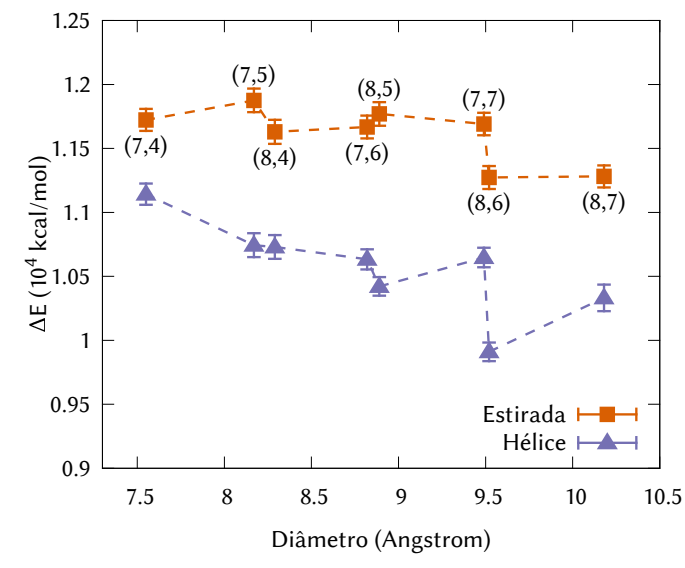

(a) $\Delta E$ em função do diâmetro do tubo

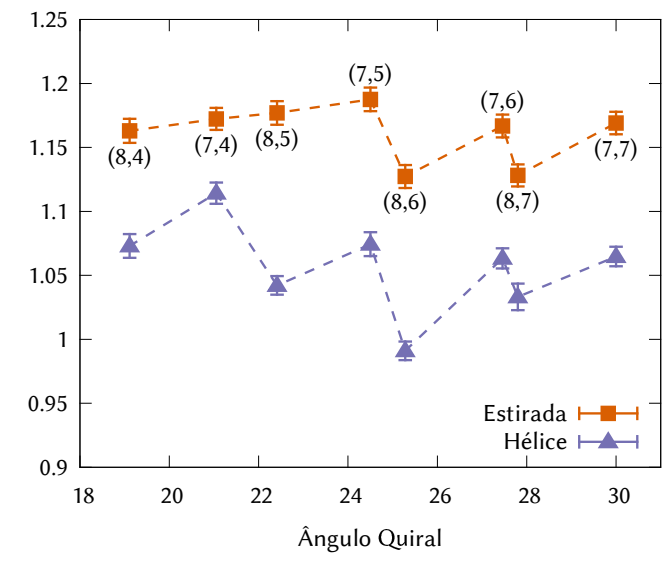

(b) $\Delta E$ em função do ângulo quiral

Figura 4.6: Energias de ligação $(\Delta E)$ em função do diâmetro e do ângulo quiral. Quadrados vermelhos: cadeia estirada sobre o tubo. Em triângulos azuis, cadeia em hélice. As linhas entre os pontos têm apenas função de guiar os olhos.

A Figura 4.7 ilustra um fenômeno capaz de justificar esse comportamento. Nela podemos comparar a forma com que os radicais octil de cadeias vizinhas se encaixam interdigitados, como se fossem um zíper, na configuração helicoidal. Por razões geométricas, isso não acontece tão bem com as cadeias alinhadas: o comprimento dos radicais não é necessariamente compatível com a circunferência dos tubos e por isso a interdigitação não é favorecida, levando a distorções na cadeia e espaços vazios, como na Figura 4.7(a). Isso vai ao encontro da hipótese 
discutida anteriormente, com base no papel da fase $\beta$ do PFO e da interdigitação dos radicais ${ }^{[35]}$.

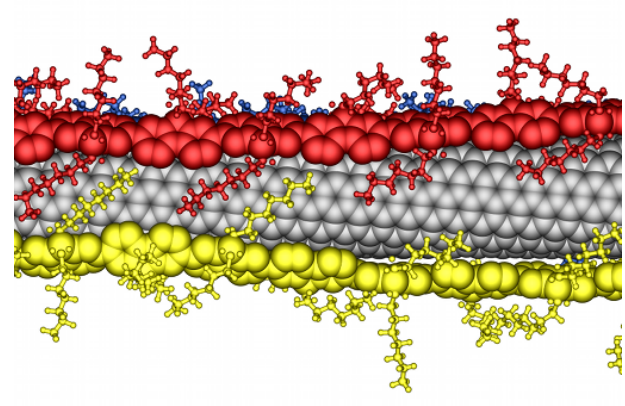

(a) Cadeias alinhadas com o eixo do tubo

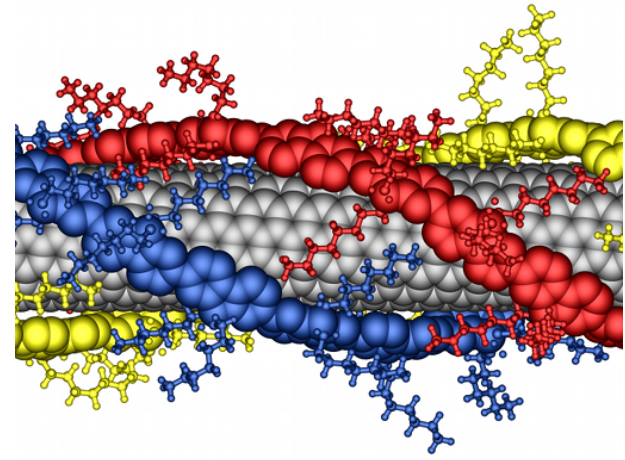

(b) Cadeias enoladas em hélice

Figura 4.7: Detalhe de duas conformações de PFO sobre um nanotubo $(8,6)$.

Também notamos na Fig. 4.6 que o nanotubo $(8,6)$ é o mais energeticamente favorável a acomodar cadeias de $\mathrm{PFO}$ ao seu redor. Isso é compatível com a observação experimental de que esse tubo é seletivamente suspenso em soluções de PFO em tolueno ${ }^{[28 ; 36]}$ a ponto de ser a espécie mais abundante após o processo de suspensão, mesmo que não componha a maioria da população original em amostras HiPCO ou CoMoCAT. O alinhamento dos anéis aromáticos das cadeias e dos radicais com a hélice do nanotubo quiral parece ser responsável por essa preferência.

\subsection{Cálculo de espectros de emissão}

Para calcular os espectros de emissão das cadeias de polifluoreno, executamos a dinâmica molecular nos sistemas nanotubo+PFO ao longo de 800 ps e utilizamos os últimos 50 ps para a tomada de dados. Deste intervalo, selecionamos 25 configurações, levando em conta a energia potencial média do período e a função de autocorrelação de velocidade. Assim, partimos de uma configuração com energia potencial próxima da média dos últimos 50 ps de simulação e selecionamos configurações periodicamente a cada $1,5 \mathrm{ps}$, intervalo que apresentava a mínima autocorrelação de velocidades.

Cada configuração deu origem a três estruturas de cadeias de PFO, de forma que temos 75 estruturas de que podemos tomar o espectro de emissão e obter um espectro médio. Cada estrutura foi isolada e os radicais octil foram substituídos por radicais metil, para reduzir o número de átomos da simulação, uma vez que 


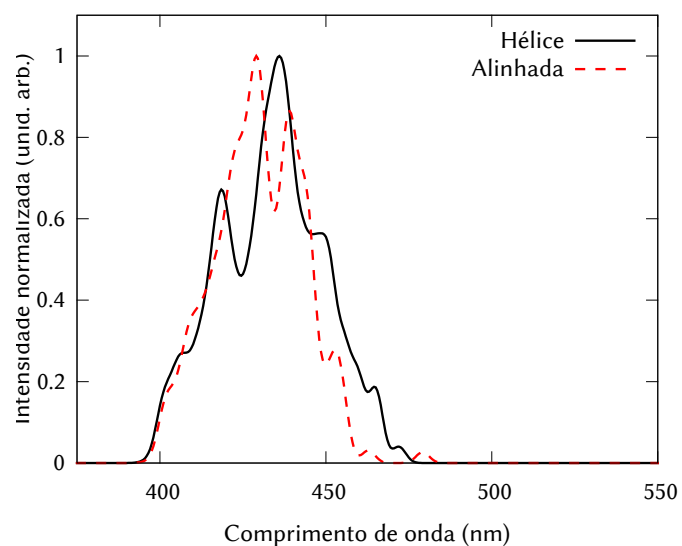

(a) $(7,4)$

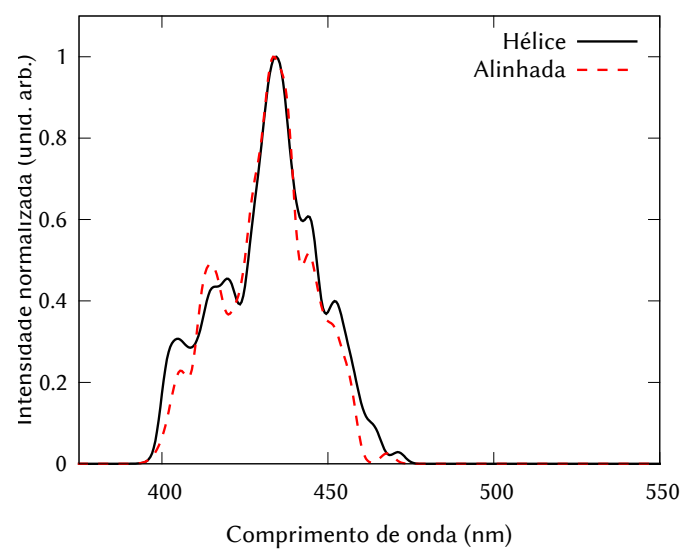

(c) $(7,6)$

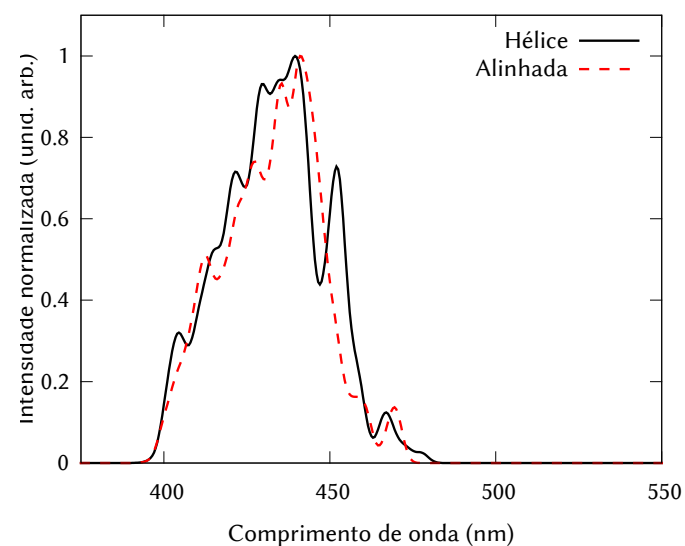

(b) $(7,5)$

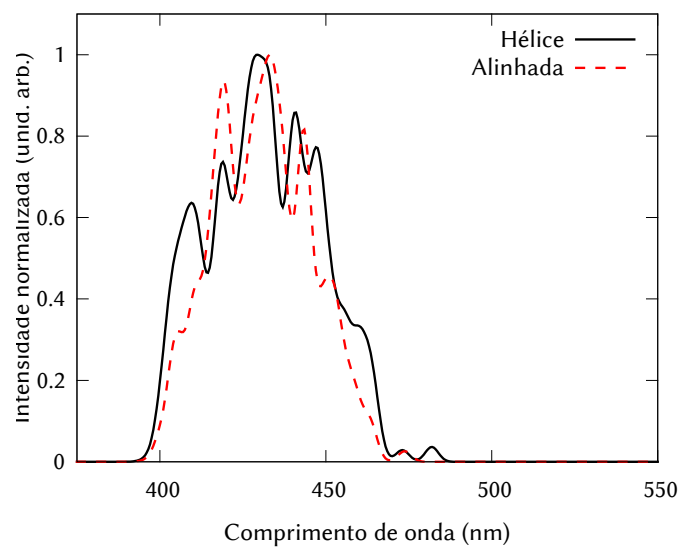

(d) $(7,7)$

Figura 4.8: Espectros de emissão calculados através do método ZINDO partindo de estruturas de PFO próximas ao estado excitado em torno e tubos da série $(7, n)$. Médias de 25 configurações de cada uma das três cadeias. Em preto: cadeias em hélice, em vermelho tracejado, cadeias estiradas sobre o nanotubo.

orbitais centrados nas cadeias laterais não participam do espectro de absorção na região UV-visível.

Em seguida, realizamos cálculos ZINDO/S sobre estas estruturas, buscando 30 transições envolvendo os 200 mais altos estados ocupados e os 200 mais baixos desocupados. Cálculos envolvendo mais estados não mostraram resultados diferentes.

De posse dos comprimentos de onda e das forças de oscilador das transições, obtivemos um espectro médio somando gaussianas de $2 \mathrm{~nm}$ de largura, centradas nos comprimentos de onda das transições e com altura igual à força 


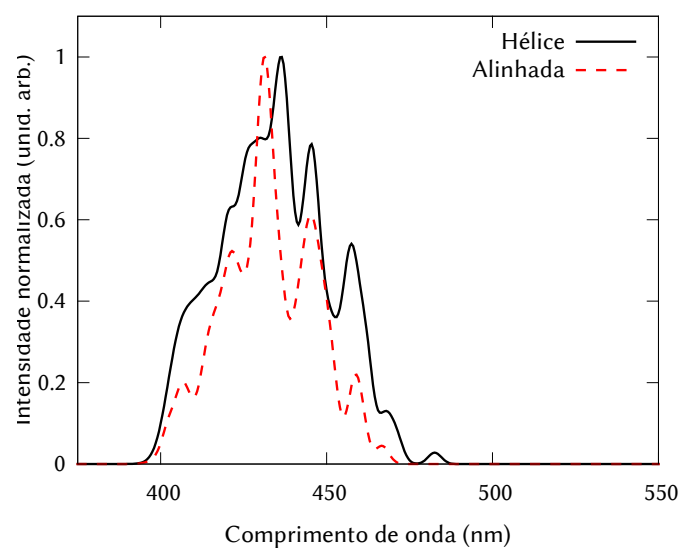

(a) $(8,4)$

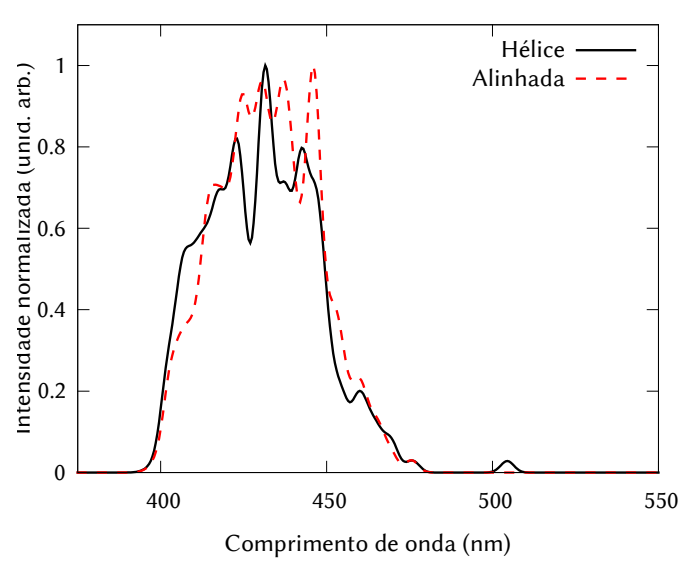

(c) $(8,6)$

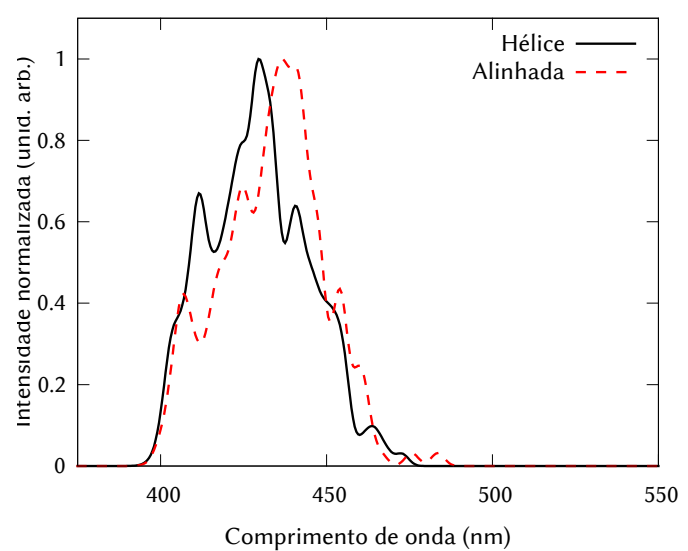

(b) $(8,5)$

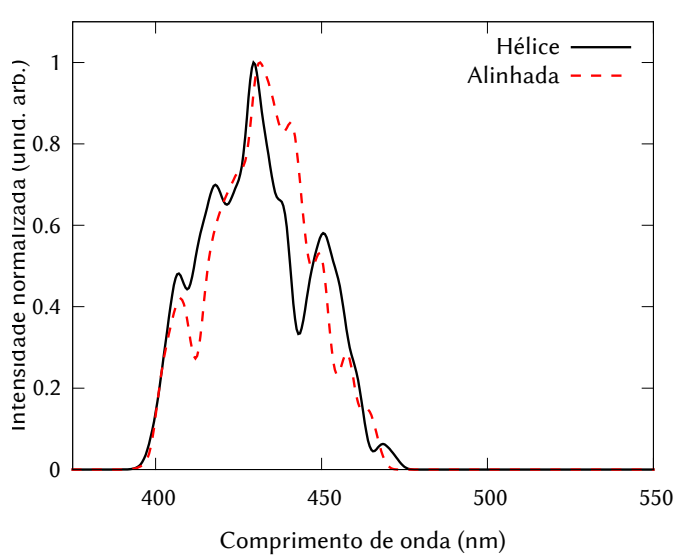

(d) $(8,7)$

Figura 4.9: Espectros de emissão calculados através do método ZINDO partindo de estruturas de PFO próximas ao estado excitado em torno de tubos da série $(8, n)$. Médias de 25 configurações de cada uma das três cadeias. Em preto: cadeias em hélice, em vermelho tracejado, cadeias estiradas sobre o nanotubo.

do oscilador, para levar em conta efeitos de alargamento de banda nos dados experimentais ${ }^{[86]}$. Isso nos leva aos gráficos das Figuras 4.8 e 4.9.

Uma vez que o método ZINDO procura apenas pelas transições permitidas, sem levar em conta se se trata de emissão ou absorção, e que durante a vibração resultante da dinâmica molecular podemos encontrar as unidades de PFO tanto em geometrias que reproduzem o estado excitado quanto o fundamental, a simulação nos retorna um espectro misto de absorção e emissão. Para eliminar a região referente ao espectro de absorção, aplicamos um filtro suave, semelhante à distribuição de Fermi-Dirac, que elimina os comprimentos de onda menores, 
em nm:

$$
f(\lambda)=\frac{1}{e^{\frac{400-\lambda}{1.5}}+1} .
$$

Realizamos o mesmo procedimento com três cadeias de polifluoreno estiradas, livres para interagir em uma caixa de tolueno. Utilizando os mesmos critérios de seleção de conformações e cálculo do espectro, chegamos ao resultado apresentado na Fig. 4.10

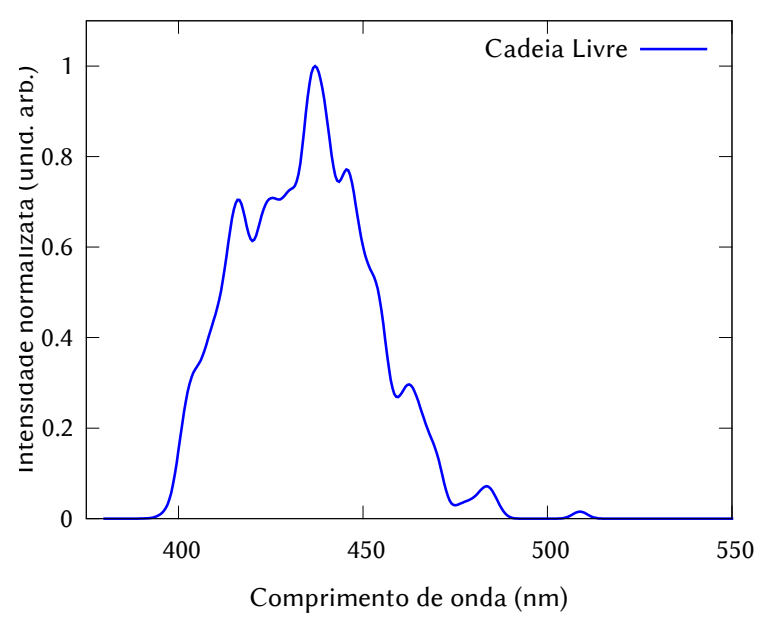

Figura 4.10: Espectro do PFO livre em tolueno.

Nos gráficos das Figuras 4.8, 4.9 e 4.10 é possível notar que utilizar amostras da molécula de interesse em diferentes instantes da simulação nos permite reproduzir a estrutura vibracional do espectro de emissão. Ele aparece como bandas espaçadas igualmente em torno de um pico principal. A dinâmica molecular produz amostras da molécula em diferentes conformações, cada uma levando a um espectro ligeiramente diferente. As contribuições dos diferentes espectros se somam e as transições mais prováveis se acumulam nas regiões que formam o espectro vibracional. Esse resultado é interessante pois mostra que este método nos dá acesso a informações inicialmente indisponíveis através da abordagem usual. Também é um sinal de que reproduzimos as condições experimentais, em que de fato se toma o espectro da média temporal das conformações adotadas pela molécula.

\subsubsection{Comparação com resultados experimentais}

Agora, vamos comparar estes resultados com medidas realizadas em dispersões de nanotubos e PFO em tolueno. Essas medidas foram realizadas pelo grupo de M. A. Loi, da Universidade de Groningen, nos Países Baixos, com 
quem colaboramos na realização deste trabalho. Em um trabalho recente ${ }^{[32]}$, o grupo realizou medidas de fotoluminescência utilizando nanotubos sintetizados através do método CoMoCAT ${ }^{[21]}$, que tem como espécies mais abundantes os nanotubos $(6,5)$ e $(7,5)^{[22]}$. Uma vez que nanotubos $(6,5)$ não são dispersados abundantemente por PFO, o nanotubo $(7,5)$ é a espécie mais abundante na suspensão. Apresentamos, portanto, esse resultado ao lado de nossos cálculos para esse nanotubo na Fig. 4.11.

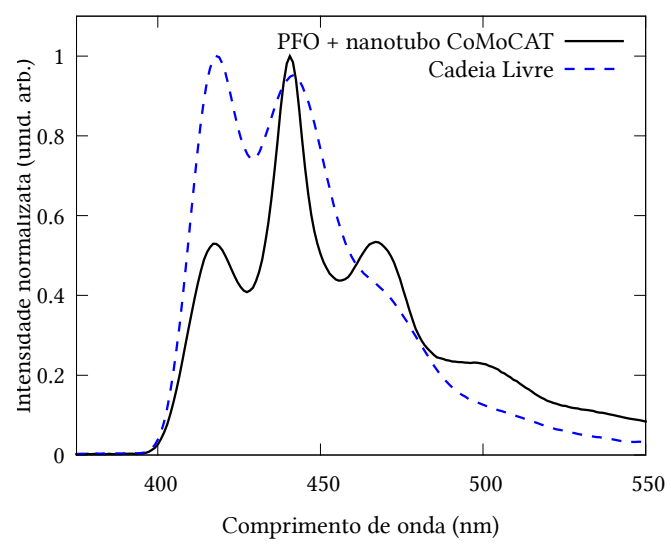

(a) Fotoluminescência do PFO livre (azul tracejado) e interagindo com nanotubos CoMoCAT (preto), conforme medido em ${ }^{[36]}$.

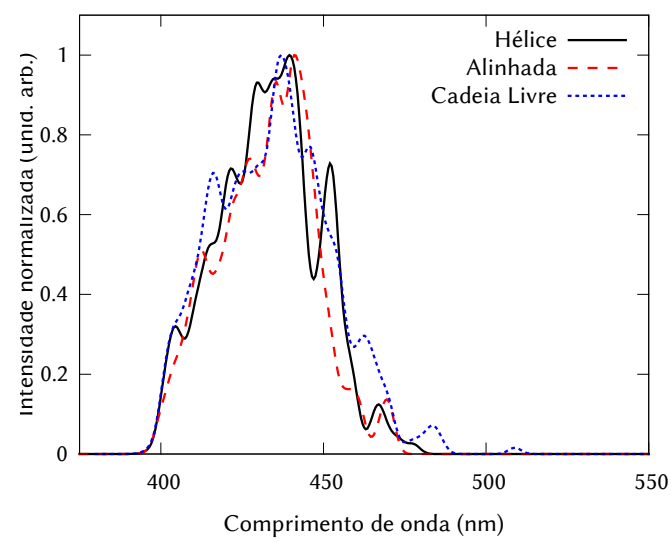

(b) Espectro simulado com dinâmica molecular + ZINDO. Cadeia livre: azul pontilhado, cadeia em hélice: preto, cadeias alinhadas: vermelho tracejado.

Figura 4.11: Comparação entre espectros de fotoluminescência do PFO interagindo com nanotubos CoMoCAT e espectros simulados de PFO interagindo com nanotubos $(7,5)$.

Espera-se que cadeias de PFO tenham menos liberdade de movimento quando envolvem nanotubos de carbono. A estrutura regular do nanotubo e a geometria helicoidal também levam a uma estrutura mais ordenada da cadeia polimérica. Esses dois fenômenos afetam a estrutura vibrônica ${ }^{[32 ; 36]}$. Em particular, observamos um aumento do pico próximo a $460 \mathrm{~nm}$ na Figura 4.11(a) quando o polímero envolve o nanotubo, em comparação com o polímero livre. Esse fenômeno também é observado nos espectros simulados da Fig. 4.11(b), com o pico próximo aos $450 \mathrm{~nm}$ bem mais pronunciado nas estruturas em hélice. Isso pode ser interpretado como um indício de que os polímeros observados na dispersão de nanotubos devem de fato estar enrolados sobre eles.

É possível observar nos resultados experimentais da Fig. 4.11(a) que o espectro do polifluoreno se estende para comprimentos de onda mais longos que $480 \mathrm{~nm}$, enquanto os espectros simulados não exibem fotoluminescência relevante além dessa região. Esse é um efeito do comprimento das cadeias que, 
no experimento, são mais longas que as simuladas. Uma vez que o PFO é um polímero conjugado, os estados envolvidos na luminescência são altamente deslocalizados e, quanto menor a localização desses orbitais, menor sua energia e, consequentemente, maior o comprimento de onda emitido. O comprimento da cadeia simulada, de 21 unidades, não é suficiente para produzir emissão de comprimento de onda maior que cerca de $480 \mathrm{~nm}$ com intensidade significativa. Entretanto, as características de interesse do espectro encontram-se na região de maior energia e são reproduzidas pela simulação.

Os resultados da Seção 4.3.2 indicam que, do conjunto de espécies consideradas, o tubo $(8,6)$ é o que apresenta maior afinidade com o PFO em hélice. Discussões sobre esse resultado levaram o grupo de $M$. A. Loi a repetir o experimento ${ }^{[36]}$ utilizando nanotubos produzidos pelo método de conversão de $\mathrm{CO}$ a alta pressão (HiPCO), que produz nanotubos de maior diâmetro que o CoMoCAT, de forma que a espécie mais abundante na suspensão é a $(8,6)^{[28]}$. O resultado se encontra na Fig. 4.12. Nela, observamos que a presença do tubo $(8,6)$ na amostra

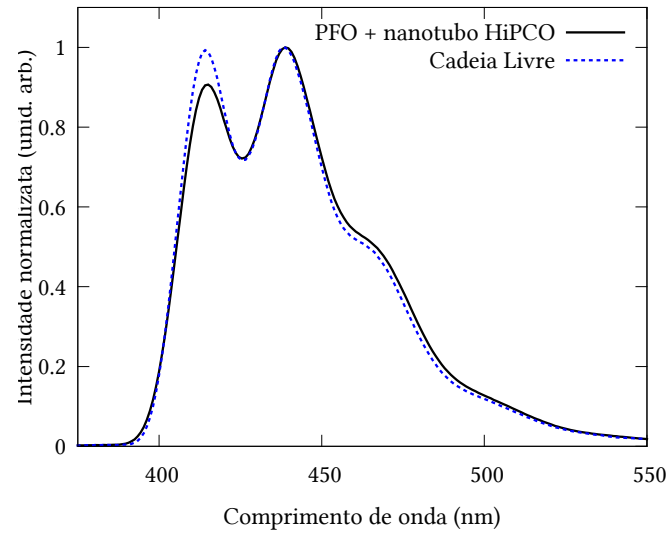

(a) Fotoluminescência do PFO livre (azul tracejado) e interagindo com nanotubos $\mathrm{HiPCO}$ (preto), conforme medido em ${ }^{[36]}$.

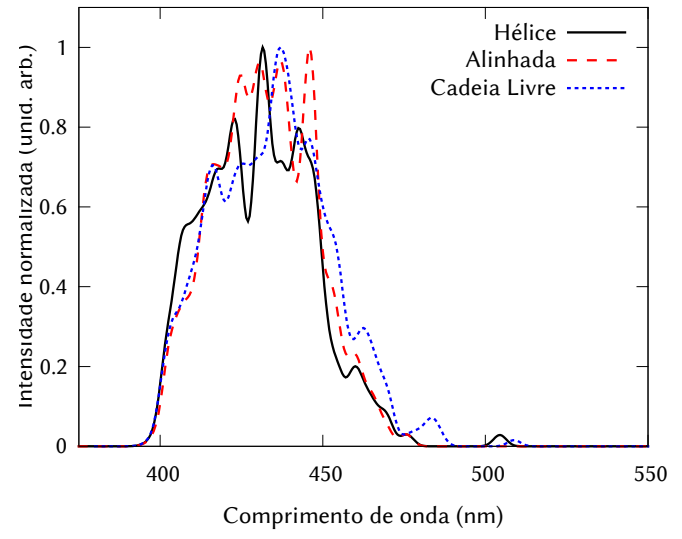

(b) Espectro simulado com dinâmica molecular + ZINDO. Cadeira livre: azul pontilhado, cadeia em hélice: preto, cadeias alinhadas: vermelho tracejado.

Figura 4.12: Comparação entre espectros de fotoluminescência do PFO interagindo com nanotubos HiPCO e espectros simulados de PFO interagindo com nanotubos $(8,6)$.

não modifica tão drasticamente o espectro quanto no caso anterior, apenas uma redução no primeiro pico, referente à transição $(0-0)$. Isso também é observado no espectro simulado do PFO em hélice sobre o tubo $(8,6)$. A pequena diferença entre o espectro de tolueno livre e na presença de tubos HiPCO é um indício de que a cadeia deve estar mais relaxada em torno desses tubos que em outros, enquanto a redução no pico referente à transição $(0-0)$ denuncia certa rigidez 
da cadeia, justificável pela torção entre os monômeros necessária para formar a hélice.

Quando comparamos espectros de soluções de PFO de diferentes massas moleculares ${ }^{[36]}$, medidas realizadas pelo grupo de M. A. Loi e exibidas na Fig. 4.13, observamos um fenômeno semelhante, com a redução da intensidade do pri-

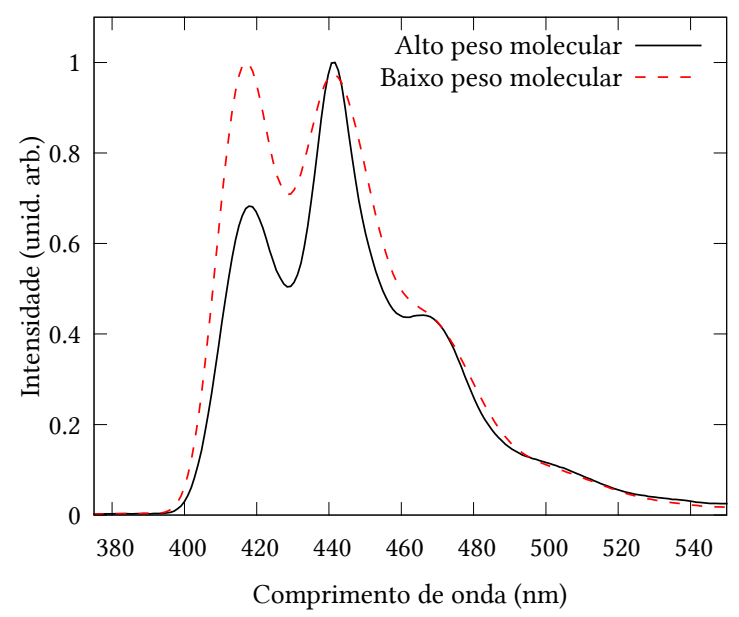

Figura 4.13: Espectros de fotoluminescência de amostras de PFO de peso molecular alto e baixo em solução de tolueno, conforme medido em ${ }^{[36]}$.

meiro pico para cadeias de massa molecular mais alta. As cadeias mais longas tendem a se enovelar e emaranhar, aumentando a desordem na estrutura polimérica. Isso restringe as torções acessíveis à estrutura de forma semelhante ao que faz a conformação helicoidal.

Finalmente, temos resultados que apontam em conjunto para uma conformação helicoidal das cadeias poliméricas em torno dos nanotubos: a semelhança dos espectros de emissão das dispersões de SWNT+PFO com os espectros simulados das cadeias em hélice; a pequena diferença observada entre a luminescência de cadeias livres e envolvendo nanotubos HiPCO e reproduzida em simulação; a interdigitação dos radicais das cadeias repousando sobre a superfície do tubo, semelhante à fase $\beta$ observada em solução de tolueno ${ }^{[35]}$ e a semelhança entre os espectros de compósitos SWNT+PFO e PFO rico em fase $\beta$.

Neste trabalho também mostramos que o método descrito na Seção 3.6 é capaz de reproduzir o espectro de emissão de uma molécula, incluindo sua estrutura vibrônica, informações inacessíveis se realizarmos as simulações considerando apenas o estado fundamental das moléculas. 



\section{Capítulo 5}

\section{Efeito da cadeia lateral na seletividade}

Como visto, as cadeias laterais têm um papel importante no comportamento do polifluoreno, tanto livres em solução quando na presença dos nanotubos. Podemos então nos perguntar qual o comportamento de polifluorenos dotados de diferentes cadeias laterais - em particular, alquilas de diversos comprimentos - e como a dispersibilidade dos nanotubos é afetada por essas mudanças.

\subsection{Revisão experimental}

Experimentos recentes ${ }^{[66-68]}$ mostram que o comprimento das cadeias laterais de polímeros tem de fato efeito na seletividade da suspensão dos nanotubos. Tange e seus colaboradores ${ }^{[67]}$ observaram que é possível suspender nanotubos de diâmetro maior que $1,3 \mathrm{~nm}$ utilizando diferentes polímeros derivados de polifluoreno. Um deles, poli-[(9,9-dioctilfluorenil)-alt-benzotiadiazol], um copolímero que alterna uma unidade do PFO com uma unidade de um composto heterocíclico (Fig. 5.1(a)), é capaz de suspender, de maneira altamente seletiva, poucas espécies de nanotubos semicondutores de grande diâmetro, com destaque para o $(15,4)$. Os autores argumentam que a coincidência entre os níveis HOMO e LUMO do polímero e de alguns nanotubos pode contribuir para a seletividade dos polímeros em relação ao ângulo quiral dos NTs e sustentam essa hipótese com dados espectroscópicos.

Já o outro polímero testado pelo grupo, poli-(9,9-didodecilfluorenil), PF12, análogo ao PFO, mas com $\mathrm{C}_{12} \mathrm{H}_{25}$ como cadeia lateral (vide Fig. 5.1(b)), se mostrou bem menos seletivo. Com ele, os nanotubos semicondutores são suspensos indistintamente, tanto que o espectro de absorção da dispersão, na região que contempla os nanotubos semicondutores, apresenta uma forma semelhante à 
suspensão dos nanotubos em água e surfactante. Nanotubos metálicos, entretanto, não são observados suspensos por PF12. Esse comportamento é diferente do PFO, que exibe nítida preferência por tubos semicondutores de grande ângulo quiral $\left(\theta \gtrsim 25^{\circ}\right)$. Os autores atribuem ${ }^{[67]}$ essa diferença à solubilidade do PF12 em tolueno, que é maior que a do PFO devido à cadeia lateral mais longa. De fato, o PF12 não forma fase $\beta$ em tolueno. Nota-se, entretanto, que a absorbância reportada [67: Figura 1] (e, infere-se, a concentração de nanotubos) das suspensões com polímeros é de dez a doze vezes menor que aquela com surfactante, o que poderia levar a entender que os polifluorenos e seus derivados não seriam tão eficientes para suspender os nanotubos.

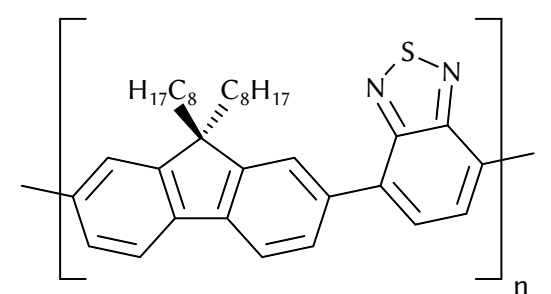

(a) P8BT

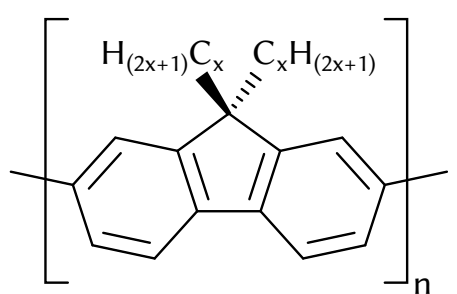

(b) PFO/PF8: $x=8$;

PF12: $x=12$<smiles>CCCCCCc1sc(CCCCC)cc1CC</smiles>

(c) P3DDT

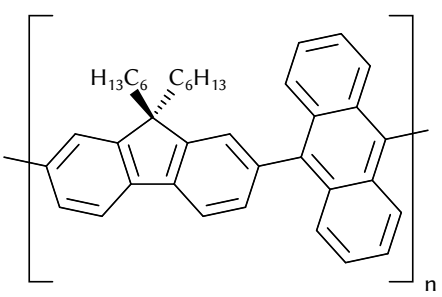

(d) PFH-A

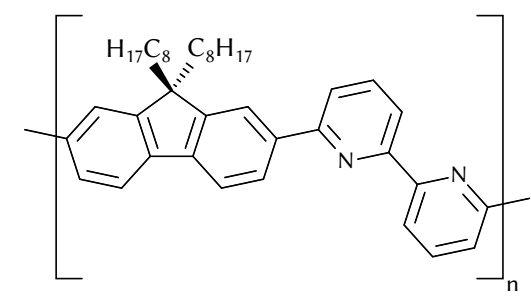

(e) PFO-BPy

Figura 5.1: Polímeros capazes de suspender nanotubos.

Em um trabalho envolvendo politiofenos com alquilas pendentes, o grupo de Z. Bao ${ }^{[66]}$ mostrou que poli-(3-alquiltiofeno)s (vide Fig. 5.1(c)) são capazes de suspender nanotubos de até cerca de $1,1 \mathrm{~nm}$ de diâmetro, apresentando forte seletividade por tubos semicondutores. Observaram também que a suspensão é mais eficiente com o P3DDT, dotado de radicais $\mathrm{C}_{12} \mathrm{H}_{25}$, e progressivamente menos efetiva à medida que se utilizam grupos pendentes mais curtos, como P3DT, com 10 carbonos na cadeia lateral, ou P3OT, com oito.

Ao interpretar esses resultados, os autores argumentam que parâmetros como o comprimento das alquilas, sua densidade e posicionamento ao longo da cadeia principal são fundamentais na interação entre o polímero e os nanotubos. Um cálculo geométrico simples apoia esse argumento: supondo duas cadeias poliméricas ligadas por alquilas completamente interdigitadas e enroladas em hélices 


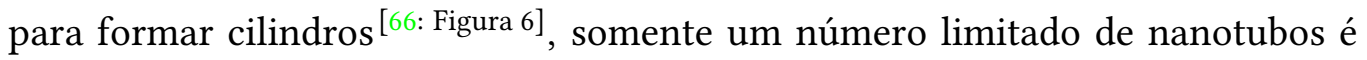
compatível com os diâmetros permitidos.

Outro argumento nesse trabalho ${ }^{[66]}$ a respeito do papel das alquilas é o efeito da temperatura em que se realiza a dispersão. Há um máximo de intensidade de absorção quando a dispersão dos tubos com P3DDT se dá a $50{ }^{\circ} \mathrm{C}$. Os autores observam a correlação entre a temperatura de dispersão e a temperatura de fusão das cadeias laterais. Argumentam também que a energia livre do polímero em solução pode ser manipulada através da temperatura, relativamente às energias livres do polímero em aglomerados ou aderido aos nanotubos e que apenas em uma certa faixa de temperatura a estabilidade relativa dessas três fases permite a suspensão dos tubos.

Kevin Mistry e colaboradores ${ }^{[68]}$ relataram sucesso em suspender nanotubos semicondutores de grande diâmetro utilizando dois copolímeros derivados

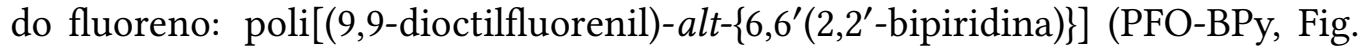
5.1(e)) e poli[(9,9-di-hexilfluorenil)-co-(9,10-antraceno)] (PFH-A, Fig. 5.1(d)). Um deles, PFH-A, é altamente seletivo por NTs semicondutores quase-armchair, com ângulo quiral entre $24,5^{\circ}$ e $26,7^{\circ}$, em particular aqueles em que

$$
q=(n-m) \bmod 3=2 \text {. }
$$

Nesse trabalho, argumenta-se que tanto a coincidência dos níveis eletrônicos entre polímero e nanotubo proposta por Tange ${ }^{[67]}$ quanto a interdigitação das cadeias laterais $^{[36 \text { e Seção } 4.4]}$ são insuficientes para explicar a seletividade e se sugere que a geometria que o PFH-A adota em torno dos tubos deve ser extremamente sensível à quiralidade, mas não se propõe um mecanismo para isso.

O grupo de M. A. Loi realizou experimentos semelhantes ${ }^{[9]}$, com derivados de polifluoreno dotados de cadeias laterais de diferentes comprimentos, de seis (PF6) a dezoito carbonos (PF18) (vide Fig. 5.1(b)). Os experimentos foram realizados com nanotubos sintetizados por dois métodos: HiPCO, com 1,0 nm de diâmetro médio, e jato de plasma (chamados $\mathrm{SO}$ ), com diâmetro médio de 1,4 nm, como mostra a Fig. 5.2. Amostras de cada família de nanotubos foram dispersas em tolueno na presença de cada um dos derivados de polifluoreno. Os espectros de absorção de cada dispersão, dispostos na Figura 5.3, indicam um aumento da absorbância e, portanto, da dispersibilidade dos nanotubos na presença de polímeros com cadeia mais longa, se comparados com aqueles de cadeia lateral mais curta.

Os resultados sugerem também que o PFO (ou PF8) é incapaz de suspender nanotubos maiores que $1,0 \mathrm{~nm}$ de diâmetro, assim como o PF6. Já os polímeros PF12, PF15 e PF18 suspendem nanotubos com diâmetro de 1,4 nm, com variada eficiência. Há, portanto, uma correlação entre o diâmetro dos nanotubos suspensos e o tamanho da cadeia lateral do polímero. 


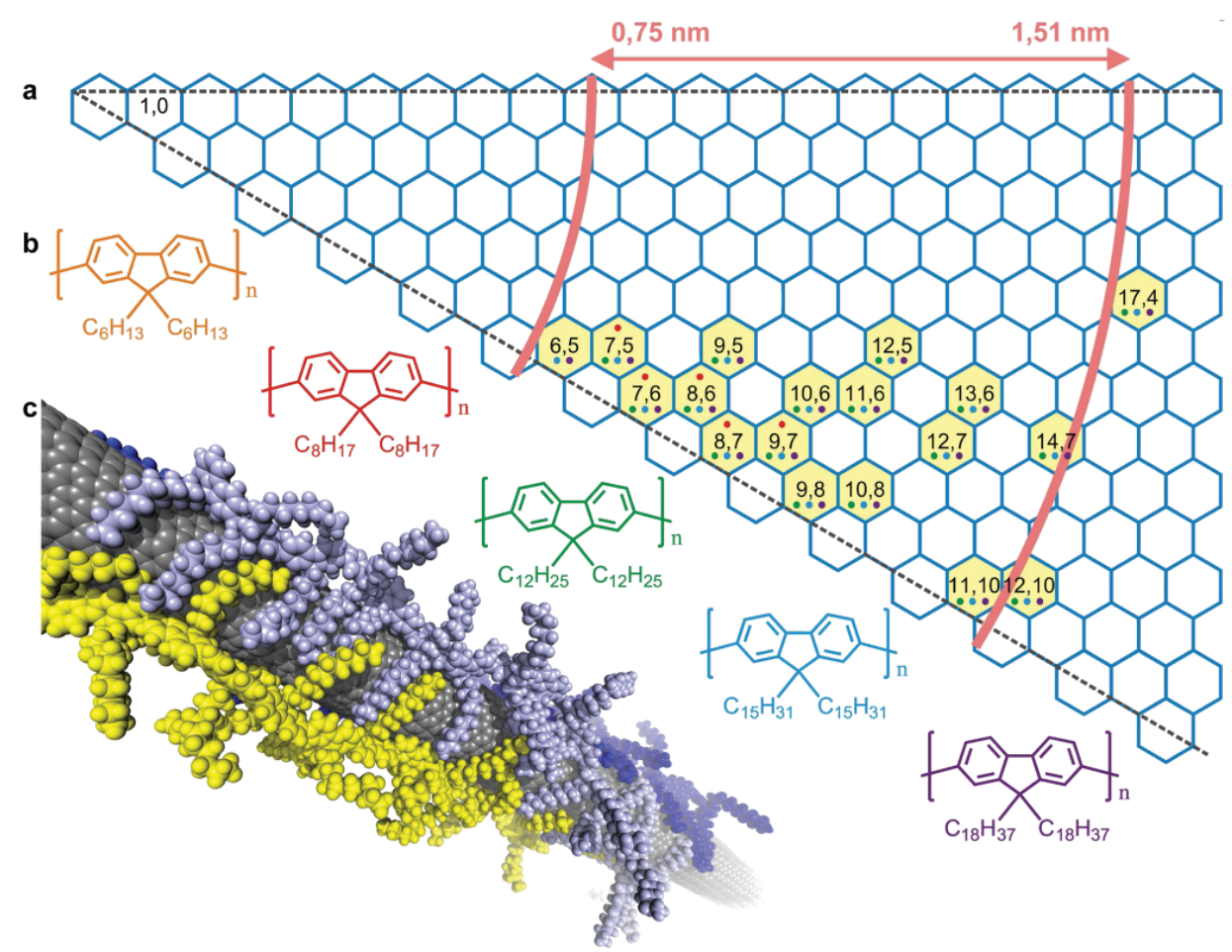

Figura 5.2: Nanotubos suspensos por diferentes cadeias de polifluoreno destacados em amarelo. Os derivados de polifluoreno capazes de suspender cada nanotubo estão representados por pontos com cores correspondentes a sua estrutura em (b). Em (c), estrutura do PF12 em torno de um tubo $(12,10)$. Figura de W. Gomulya et al. ${ }^{\left[{ }^{[}\right.}$

Em particular, a absorbância dos nanotubos suspensos com polifluorenos de cadeia longa chama a atenção, por ser de duas a três vezes maior que aquela dos tubos suspensos por surfactante (o que não ocorre nos tubos menores, para os quais a relação é inversa). Isso é indicativo de que os polímeros seriam mais eficientes do que o SBDS para suspender os NTs de grande diâmetro. Embora isso não seja compatível com os resultados de Tange et al ${ }^{[67]}$, seu próprio argumento pode ser usado pra justificar esse comportamento: tubos maiores, por terem a parede mais plana e serem menos rígidos, têm uma área de contato maior com os vizinhos quando em feixe, o que aumenta a interação de van der Waals entre eles e dificulta seu isolamento pelo surfactante. O polifluoreno, entretanto, interage não apenas com a superfície do tubo, mas também com outras cadeias poliméricas. Nesse cenário, um tubo que se aproxime de outro recoberto por polifluorenos pode não ser capaz de deslocar os polímeros tão facilmente quanto se fossem moléculas de surfactante e isso dificulta o reagrupamento e precipitação dos tubos. 


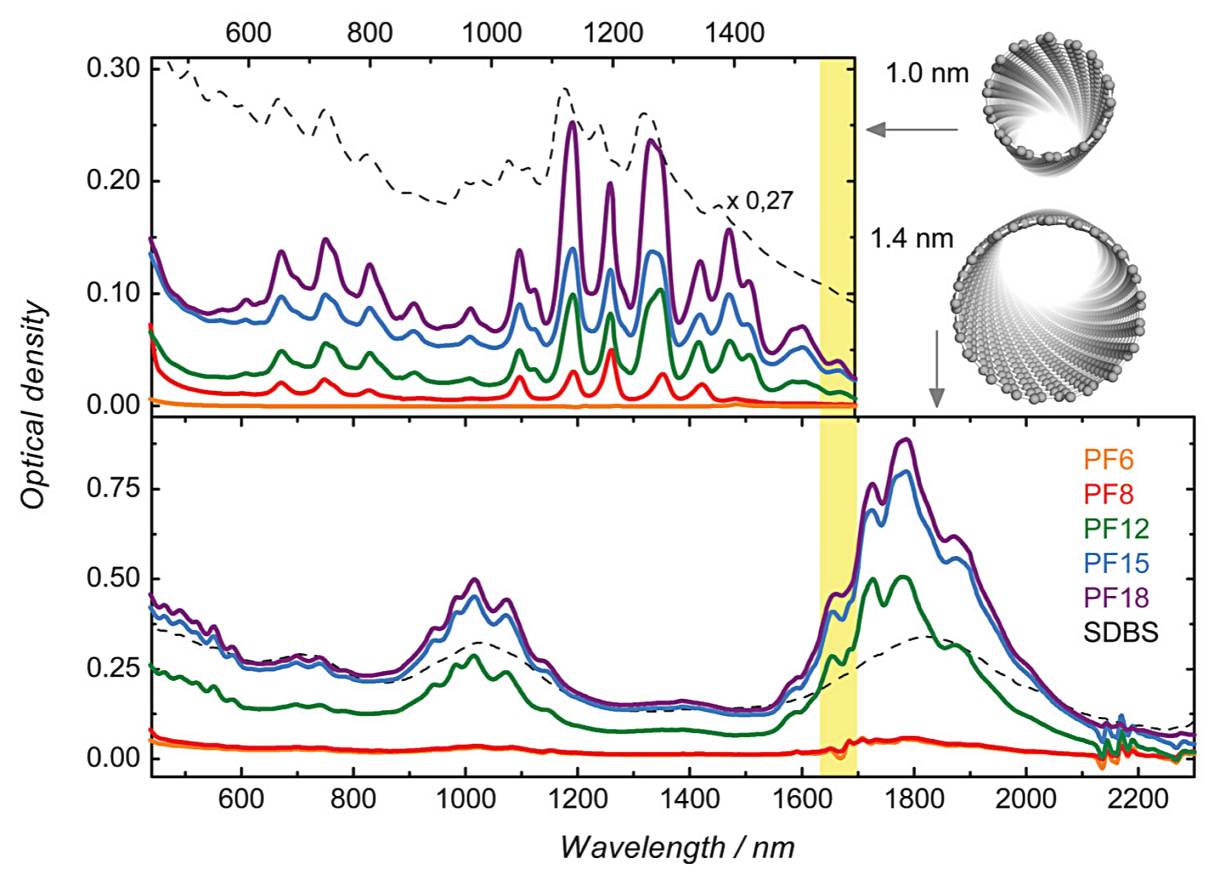

Figura 5.3: Energias de absorção de suspensões de nanotubos com diferentes polifluorenos Painel superior, nanotubos HiPCO, com diâmetro típico de 1,0 nm. Painel inferior, nanotubos SO, com diâmetro típico de 1,4 $\mathrm{nm}$. As linhas cheias coloridas representam os diferentes polifluorenos, de acordo com a legenda no painel inferior. A linha tracejada representa a amostra original suspensa com SDBS. Figura de W. Gomulya et al. ${ }^{[9]}$

Medidas de fotoluminescência das amostras reforçam esse resultado. Em particular, o rendimento de fotoluminescência, que pode ser aproximado como a razão entre a intensidade da fotoluminescência e a absorbância, é um indicador da qualidade da suspensão: quanto mais individualizados estiverem os nanotubos, menos rotas de decaimento não-radiativo estão disponíveis para o elétron excitado e menor é a chance de extinção (quenching) da luminescência do tubo. A análise desses dados nos leva a entender que o PF12 é o polímero que mais eficientemente suspende os nanotubos HiPCO.

\subsection{Simulação}

Buscamos compreender esse comportamento através de mais uma série de simulações de dinâmica molecular. Consideramos moléculas de polifluoreno dotadas de diferentes cadeias laterais: de 8,12, 15 e 18 carbonos e quatro geometrias 
de nanotubos: $(14,7),(12,10),(12,7)$ e $(10,9)$ que formam pares com diâmetro semelhante e quiralidade distinta, como se vê na tabela 5.1 .

Tabela 5.1: Nanotubos considerados na dinâmica de impulso

\begin{tabular}{ccc}
\hline$(n, m)$ & Diâmetro $(\AA)$ & Ângulo quiral \\
\hline$(14,7)$ & 14,5 & 19,1 \\
$(12,10)$ & 14,9 & 27,0 \\
$(12,7)$ & 13,0 & 21,4 \\
$(10,9)$ & 12,9 & 28,3 \\
\hline
\end{tabular}

Consideramos também duas orientações da cadeia principal: com os anéis aromáticos paralelos $(P)$ à superfície do tubo ou perpendiculares $(T)$ a ela (vide Fig. 5.4), já que polifluorenos com cadeias laterais diferentes de octil não apresentam fase $\beta$ e portanto têm, em princípio, mais liberdade para se posicionar sobre o tubo.

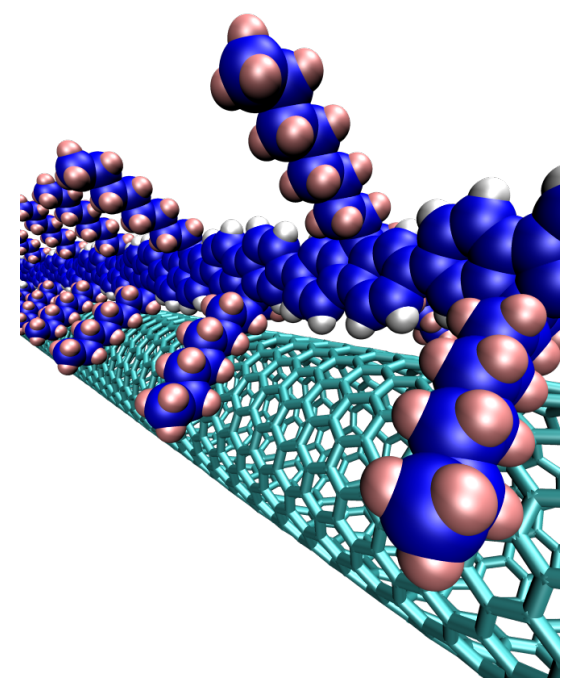

(a) Configuração $T$

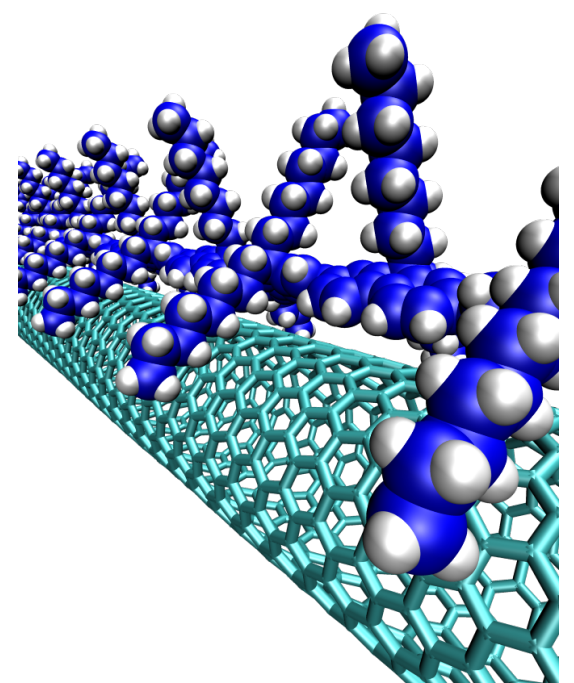

(b) Configuração $P$

Figura 5.4: Conformações $T$ e $P$. Em bastões cinzentos, o nanotubo. Em azul e branco, polifluoreno.

A diferença entre essas orientações está na posição dos orbitais $\pi$ do polímero em relação ao nanotubo e na orientação das cadeias laterais de cada unidade de fluoreno. No caso da cadeia principal paralela $(P)$ à superfície do tubo, os orbitais $\pi$ do fluoreno e do nanotubo podem interagir mais fortemente, através do empilhamento $\pi$, e cada unidade do polímero terá uma cadeia lateral 
próxima ao tubo e outra inicialmente afastada dele. Já na orientação $T$, os anéis aromáticos do fluoreno e do nanotubo estão perpendiculares entre si, minimizando a sobreposição dos orbitais $\pi$, de maneira análoga à interação de pares de moléculas aromáticas como o naftaleno ${ }^{[93]}$ e o pentaceno. Nesse caso, as cadeias laterais de cada monômero hora se encontram ambas sobre a superfície do tubo, hora orientadas ambas inicialmente na direção oposta à do tubo.

Temos, finalmente, 32 configurações para simular: quatro nanotubos, com quatro polímeros em duas orientações. Cada uma das simulações foi realizada no pacote Cerius ${ }^{2}$, utilizando o campo de forças CVFF - c5 descrito na Seção 4.2, de acordo com o seguinte algoritmo, ilustrado na Figura 5.5:

1. Configuração incial: Um nanotubo isolado, em vácuo, num espaço ilimitado, sem condições periódicas de contorno

2. Inserção da primeira cadeia: Posiciona-se uma cadeia do polímero de interesse, com 16 unidades de comprimento, paralela ao eixo tubo na conformação $T$ ou $P$, segundo cada caso, a $1 \mathrm{~nm}$ de distância da superfície.

3. Velocidade inicial: Atribui-se à cadeia uma velocidade inicial de $1 \AA \mathrm{ps}^{-1}$, radial em relação ao tubo, no sentido do eixo. Aos átomos do tubo, atribuem-se velocidades aleatórias de acordo coma distribuição de MaxwellBoltzmann a $300 \mathrm{~K}$

4. Dinâmica de impulso: 1000 passos de dinâmica NVE, mantendo constantes o número de partículas, o volume da caixa e a energia total do sistema.

5. Minimização de energia: até que a força quadrática média seja inferior a $0,1 \mathrm{kcal} \mathrm{mol}^{-1} \AA^{-1}$

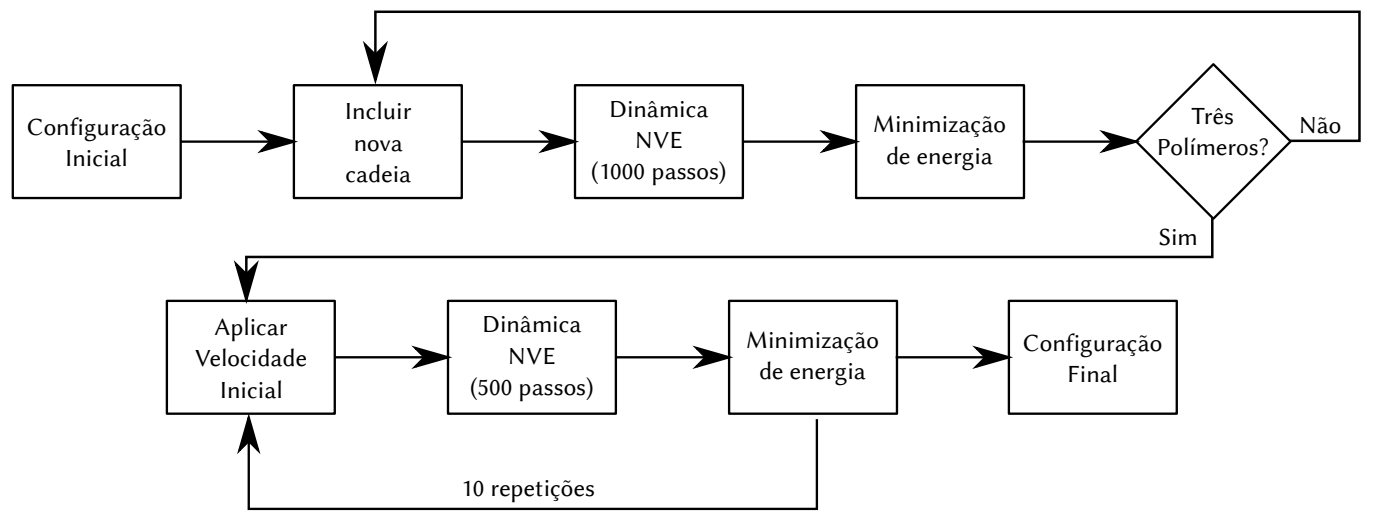

Figura 5.5: Fluxograma da simulação de dinâmica de impulso 
6. Adição de novas cadeias: repete-se os passos de 2 a 5 com duas novas cadeias, cada uma posicionada a $120^{\circ}$ da cadeia anterior.

7. Acomodação das cadeias: 500 passos de dinâmica $N V E$, seguidos de minimização de energia nos mesmos parâmetros, dez repetições

8. Análise dos resultados: Após a última etapa de minimização, calcula-se a energia de ligação e a superfície de contato.

Essa abordagem, chamada de dinâmica de impulso, permite que as cadeias se posicionem na conformação de energia de ligação mais intensa de maneira rápida, enquanto ainda dá às moléculas a liberdade de sobrepor barreiras que limitam o espaço de fase disponível aos polímeros.

\subsection{Resultados da dinâmica}

Vemos na Figura 5.6 as conformações adotadas pelo polifluoreno em torno de um nanotubo $(14,7)$ ao fim da dinâmica de impulso. A figura foi elaborada com base na superfície acessível ao solvente, calculada pelo algoritmo de Connolly ${ }^{[94]}$, que considera o solvente como uma esfera (chamada sonda) que rola sobre a superfície formada pelas esferas de van der Waals da molécula, gerando uma superfície suave que representa a distância mínima da molécula em que o centro da sonda pode se encontrar. Neste caso, consideramos o diâmetro da sonda compatível com a molécula de tolueno.

À medida que o tamanho da cadeia lateral aumenta, observamos que também aumenta a área do nanotubo coberta pelo polímero e inacessível ao solvente. Uma área muito grande exposta ao solvente permitiria a adesão de outro nanotubo e, consequentemente, o reagrupamento e precipitação do conjunto, reduzindo a eficácia da suspensão.

Em particular, vemos que a cadeia lateral do PF12 (Fig. 5.6-A) é muito curta para recobrir toda a superfície do tubo $(14,7)$ com apenas três cadeias, ao mesmo tempo que a área exposta do tubo (circulada em vermelho na figura) não comporta uma quarta cadeia aderida firmemente ao tubo. Isso acabaria por deixar aquela área do tubo exposta ao solvente e, com isso, a outros nanotubos em situação similar.

Há uma tendência das cadeias laterais se alinharem e interdigitarem, de forma análoga ao que observamos antes com o PFO. Isso faz com que os polímeros se acumulem em um dos lados do tubo se seus grupos pendentes não forem suficientemente logos e isso é o que leva à exposição de uma área contínua do tubo enquanto outro lado pode se encontrar densamente recoberto. 

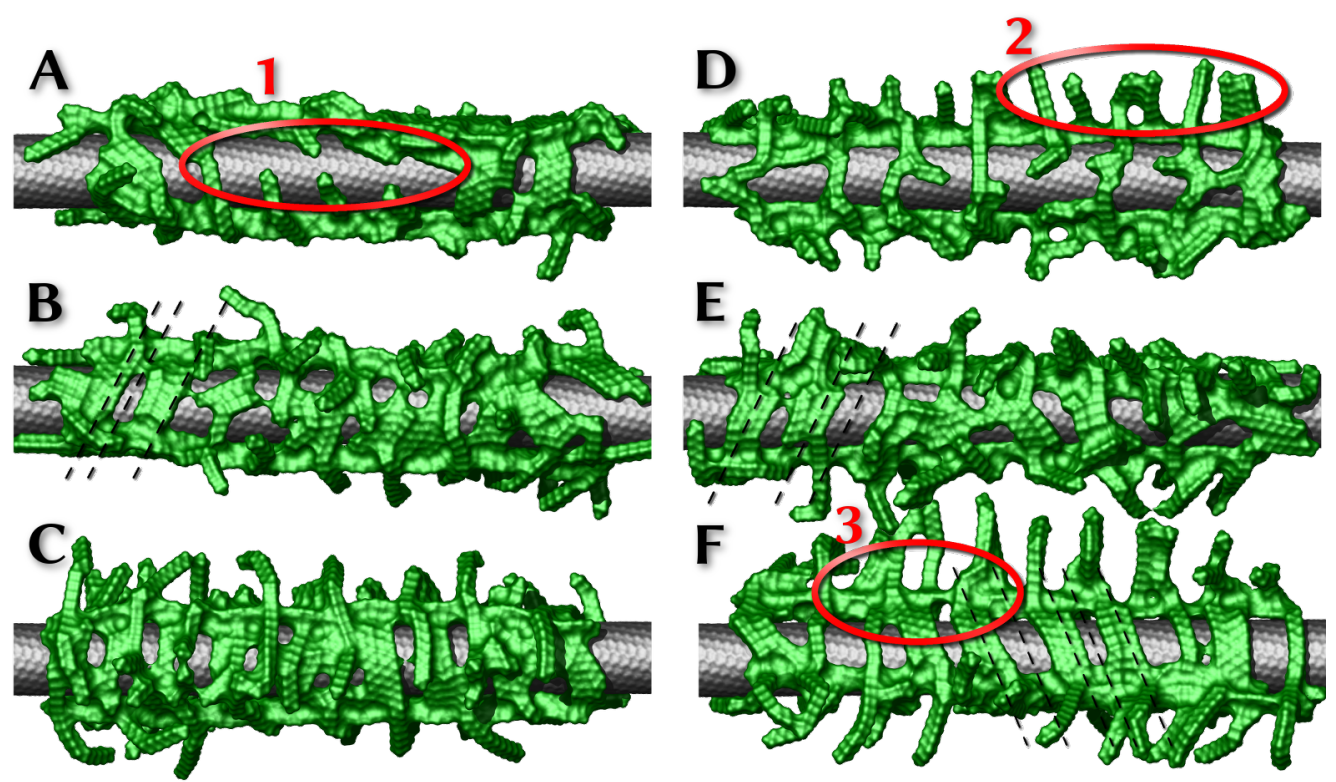

Figura 5.6: Estruturas de polifluoreno em torno de nanotubo $(14,7)$ após dinâmica de impulso Coluna da esquerda, estruturas $P$ (vide Fig. 5.4). Coluna da direita: estruturas $T$. De cima para baixo, PF12, PF15 e PF18. Figura publicada originalmente na referência 9.

Outro fenômeno que se dá com as alquilas laterais é que elas tendem a se alinhar com os padrões de zigue-zague do tubo, segundo sua quiralidade. Destacamos isso na Fig. 5.6 na forma de linhas tracejadas indicando a orientação das alquilas e das ligações no tubo.

Caso a cadeia lateral seja muito longa se comparada à circunferência do tubo, a estrutura de zíper pode forçar a cadeia principal do polímero a se afastar do nanotubo, criando um espaço que pode acomodar moléculas de solvente. Este fenômeno está ilustrado na Figura 5.6-F, na região destacada com o círculo vermelho de número três. Isso pode ocorrer por duas razões: Ou o espaço entre as alquilas não é suficiente para acomodar uma nova cadeia polimérica e ela acaba por se depositar sobre as alquilas das vizinhas, formando duas camadas de polímero sobre o tubo; ou a estrutura de zíper das cadeias laterais forma um cilindro de diâmetro maior que o suficiente para acomodar apenas o nanotubo em seu interior e se produz um hiato que permite a entrada do solvente. Em ambos os casos, a presença do solvente reduz a energia de ligação entre o tubo e o polímero e pode levar ao desprendimento de uma ou mais cadeias. Nesse caso, o espaço deixado pela molécula que se desprende é análogo ao descrito anteriormente para o caso de alquilas curtas e poderia levar à precipitação do tubo. 


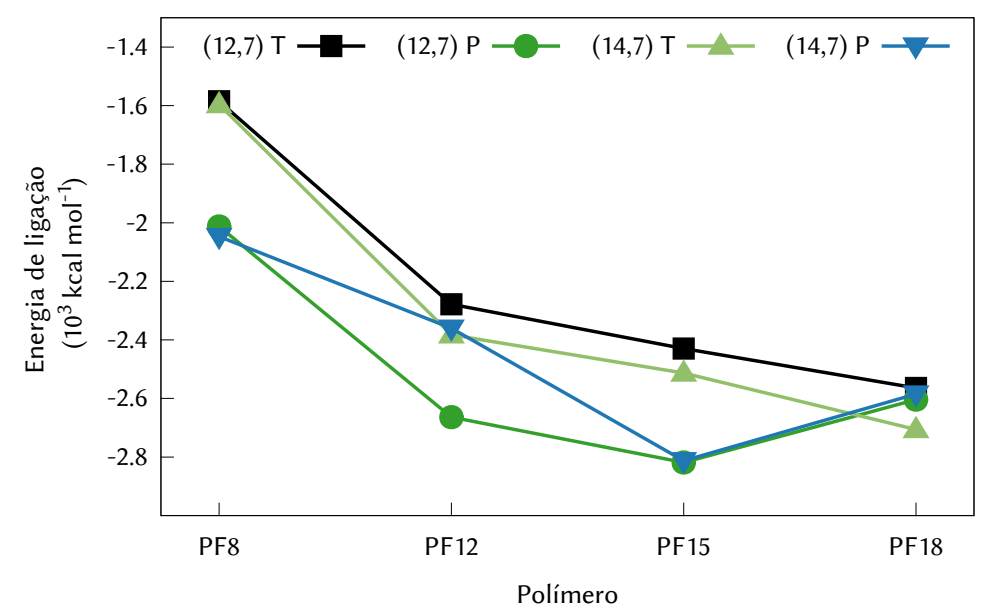

Figura 5.7: Energias de ligação entre polifluorenos e nanotubos, normalizada em relação ao comprimento do tubo recoberto por cadeias de polímero.

As energias de ligação dos sistemas colaboram para esse entendimento. Exibida na Figura 5.7 para os tubos $(12,7)$ e $(14,7)$, a energia de ligação foi calculada como a diferença de energia potencial entre o composto e a soma das partes individuais, normalizada pelo comprimento dos polímeros que recobrem o tubo:

$$
E_{\text {ligação }}=\frac{E_{\text {híbrido }}-\left(E_{\text {tubo }}+3 \times E_{\text {polifluoreno }}\right)}{L_{\text {polímero }}},
$$

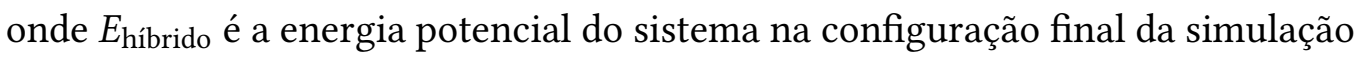
de dinâmica de impulso e $E_{\text {tubo }}$ e $E_{\text {polifluoreno são calculados com a molécula }}$ isolada e em seu mínimo de energia (conforme procedimentos da Seção 3.2.1). Desta maneira, a energia de ligação leva em conta tanto a interação entre os polímeros e o tubo quando dos polímeros entre si.

É possível observar dois comportamentos distintos para a energia de ligação. No caso do polifluoreno na configuração $T$, com os anéis aromáticos perpendiculares à superfície do tubo, notamos um comportamento monotônico decrescente, enquanto os polímeros com os anéis aromáticos paralelos ao tubo $(P)$ exibem um valor mínimo na energia de ligação. Apesar disso, à medida que o comprimento da cadeia lateral aumenta, a diferença entre as orientações dos polímeros diminui, denunciando a dominância do papel dos grupos pendentes na interação, que acabam por mascarar a vantagem que o empilhamento $\pi-\pi$ confere à conformação $P$ dos polímeros com alquilas mais curtas.

A redução da intensidade da ligação do PF18 em relação ao PF15 na conformação $T$ é efeito do afastamento da cadeia principal da superfície do tubo 
ilustrado na Figura 5.6-F, que leva a uma redução da superfície de contato entre os polímeros e o nanotubo.

A relação entre o comprimento da cadeia lateral e o diâmetro do tubo aparece na diferença entre energia de ligação do PF12 com o tubo $(12,7)$ e o $(14,7)$. O tubo menor permite que mais alquilas se interdigitem, o que aumenta a contribuição da interação das moléculas de polifluoreno entre si.

Em resumo, o papel das cadeias laterais na suspensão dos tubos pode ser compreendido através da cobertura que as alquilas formam sobre a superfície do tubo ao se interdigitarem. Deve haver concordância entre a circunferência do tubo e o comprimento das alquilas, de forma que um número inteiro de cadeias propicie a cobertura da maior área possível do tubo. À medida que o comprimento das cadeias laterais aumenta, sua interação com o tubo e com as cadeias vizinhas passa a ser mais significativa que aquela entre a cadeia principal e a superfície do tubo e elas passam a dominar o comportamento do sistema. Caso não haja concordância entre a circunferência do NT e as cadeias laterais, haverá áreas do tubo expostas ao solvente e, consequentemente, aos demais tubos que poderão se aderir ali e reagrupar, levando à precipitação do complexo. 



\section{Capítulo 6}

\section{Modelo granulado}

Explorar a conformação de moléculas complexas como polifluorenos ao redor de nanotubos de carbono em solução é um problema formidável, tanto em relação ao número de átomos envolvidos quanto em duração das simulações. O cálculo do espectro de emissão exige informação sobre as coordenadas atômicas com certa precisão e a simulação atomística é capaz de fornecer isso, com a contrapartida de ser computacionalmente custosa. Simulações atomísticas praticáveis, portanto, são acompanhadas de compromissos, como a extensão, limitada a poucos ns, e o número de partículas, na forma de camadas de solvatação enquanto critérios cuidadosos de escolha das condições iniciais (Seção 4.3.1) e análise da energia de interação (Seção 4.3.2) nos permitem realizar as simulações atomísticas em condições sensatas.

Por outro lado, o espaço de fase pode ser explorado mais amplamente através de simulações mais longas com a contrapartida de uma menor resolução nas interações e coordenadas atômicas. É possível, por exemplo, aumentar o passo de integração removendo as vibrações de mais alta frequência, como as ligações $\mathrm{C}-\mathrm{H}$, e substituí-las por restrições (constraints) que fixam a distância $\mathrm{C}-\mathrm{H}$ e a orientação dessa ligação em relação aos átomos vizinhos. Campos de força de átomos unidos - united-atom, UA - como o OPLS (Optimized Potentials for Liquid Simulations) ${ }^{[95]}$ e GROMOS-96 ${ }^{[73]}$, eliminam as frequências mais altas e reduzem a complexidade do sistema ao remover completamente átomos de hidrogênio do modelo e incorporar sua massa ao átomo pesado ligado a ele. Dessa forma, um grupo $\mathrm{CH}_{3}$ passa a ser representado por um "átomo" de carbono de massa 15 u m a, com carga e parâmetros de van der Waals próprios.

Também é possível reduzir a complexidade das moléculas com estratégias granuladas ou coarse-grained, que consistem em utilizar grãos ou beads para representar conjuntos de átomos a fim de reduzir o número de partículas na simulação e eliminar vibrações de alta frequência, em troca de uma resolução 
menor das coordenadas atômicas e simplificação das interações intermoleculares.

Há diversas ${ }^{[96]}$ implementações de campos de forças granulados, que diferem nas técnicas de parametrização e na forma com que os átomos são associados aos grãos, o mapeamento. Tipicamente desenvolvidos para sistemas biológicos, envolvem parâmetros para água ${ }^{[97]}$, lipídios ${ }^{[98 ; 99]}$, proteínas ${ }^{[100 ; 101]}$, ácidos nucleicos $^{[102]}$ e carboidratos ${ }^{[103]}$. Cada um desses campos de força foi parametrizado com um objetivo específico, seja reproduzir a densidade de solventes no estado líquido, reproduzir a função de distribuição de pares, estrutura em larga escala ou propriedades termodinâmicas. Os mesmos princípios podem ser aplicados a simulações em física de materiais ao parametrizar um campo de forças granulado tendo em vista reproduzir propriedades termodinâmicas, mecânicas ou macroscópicas das moléculas de interesse.

Em particular, o campo de forças MARTINI ${ }^{[101]}$ usa grãos para representar, cada um, três a quatro átomos pesados (elementos que não sejam hidrogênio). Isso permite passos de integração até 20 vezes maiores que aqueles de simulações atomísticas (10 fs a $40 \mathrm{fs}$ ) ao eliminar vibrações de alta frequência, com a vantagem de ser facilmente implementável em pacotes de dinâmica molecular existentes, como o GROMACS ${ }^{[104]}$.

Uma vez que perde-se resolução atômica na abordagem granulada, não é possível utilizá-la diretamente como fonte das geometrias para cálculo do espectro de emissão. Para recuperar a informação das coordenadas atômicas, utilizamos um procedimento conhecido como retromapeamento ou back mapping ${ }^{[105]}$. Nele, as coordenadas dos grãos servem como base para o posicionamento dos átomos e sessões curtas de dinâmica molecular com vínculos permitem que a estrutura atomística relaxe sem deixar de obedecer à conformação dos grãos.

Desta forma, a simulação granulada pode explorar o espaço de conformações e fornecer condições iniciais para simulações atomísticas mais precisas, como as apresentadas neste trabalho. As simulações atomísticas, por sua vez, fornecem as conformações para o cálculo do espectro de emissão, de forma que podemos obter uma amostragem mais representativa do estado do polímero nas condições experimentais.

\subsection{O campo de forças MARTINI}

Para implementar essa estratégia de amostragem, modelamos, com o grupo de S.-J. Marrink, na Universidade de Groningen, os componentes do sistema - polifluoreno, tolueno e nanotubo de carbono - utilizando o campo de forças MARTINI ${ }^{[101]}$, desenvolvido por esse grupo inicialmente para lipídios em solução aquosa e posteriormente estendido para proteínas, ácidos nucleicos e 
açúcares, com recentes aplicações em nanopartículas de carbono, como fulerenos $^{[106 ; 107]}$, grafeno ${ }^{[108 ; 109]}$ e nanotubos de carbono ${ }^{[110-112]}$.

No campo de forças MARTINI, os grãos interagem entre si tanto através de ligações químicas quanto através de interações não ligadas. As interações não-ligadas consistem em potenciais de Coulomb entre as cargas elétricas dos grãos e um termo de van der Waals, regido pelo potencial de Lennard-Jones como implementado no pacote Gromacs ${ }^{[104]}$, em que o parâmetro $\sigma_{i j}$ representa o tamanho efetivo da partícula:

$$
V_{\mathrm{vdW}}=\sum_{i j} 4 \epsilon\left[\left(\frac{\sigma_{i j}}{r_{i j}}\right)^{12}-\left(\frac{\sigma_{i j}}{r_{i j}}\right)^{6}\right] .
$$

Neste campo de forças se define quatro tipos principais de grãos: polares ou hidrofílicos $(\mathrm{P})$, apolares ou hidrofóbicos $(\mathrm{C})$, carregados $(\mathrm{Q})$ e não-polares $(\mathrm{N})$, que representam grupos parcialmente polares e apolares (como álcoois) ${ }^{[99]}$. Destes, apenas os grãos carregados (Q) portam carga elétrica, definida como um número inteiro de cargas elementares, para representar íons. Sob estes quatro tipos de sítios, há subtipos definidos de acordo com a capacidade de doar ou aceitar elétrons em ligações de hidrogênio ou para levar em conta diferentes níveis de hidrofobicidade. Assim, os grãos apolares são divididos em quatro tipos: C1, C2, C3, C4 e C5, do mais hidrofílico ao mais hidrofóbico.

Entre os diferentes tipos de grãos foram definidos dez níveis de interação, descritos de mais polar a menos polar e determinados pelo valor do parâmetro $\epsilon_{i j}$. O raio de van der Waals $\sigma_{i j}$ é fixo em $0,43 \mathrm{~nm}$ para grãos em anéis (identificados pela inicial S: SC1, SC4, SP4...) e 0,47 nm nos demais, de forma que ajustes na intensidade de interação são simplificados ao variar apenas a profundidade do poço $\epsilon_{i j}$.

As interações entre grãos ligados seguem as mesmas formas descritas na Seção 3.2, com termos de ligação, ângulos e torções próprias e impróprias. Não há, entretanto, parâmetros gerais definidos nesse campo de força, de forma que a topologia de cada molécula deve ser modelada independentemente, já que ela depende do mapeamento dos átomos para os grãos.

\subsection{Modelagem do tolueno}

Inicialmente, modelamos o solvente, tolueno, de forma análoga ao modelo MARTINI para o benzeno ${ }^{[101]}$, em que o anel aromático é representado por três grãos tipo SC4 distribuídos em um triângulo equilátero, como na Fig. 6.1(a). A distância entre os grãos é fixa, através de um vínculo, em $0,27 \mathrm{~nm}$. No caso do benzeno, cada grão tem massa de 26 unidades de massa atômica. Já no tolueno, um dos grãos tem massa 40 u m a para representar o radical metil. 


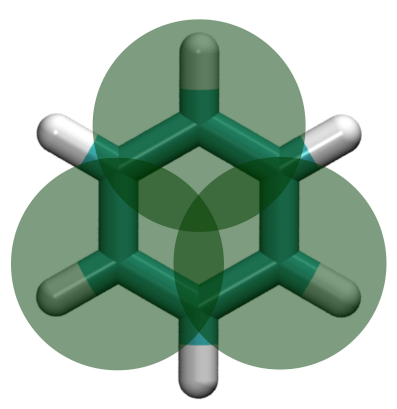

(a) Benzeno

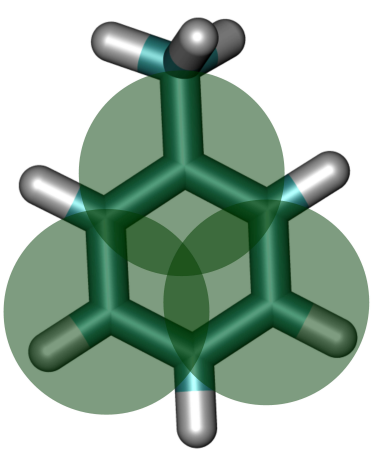

(b) Tolueno

Figura 6.1: Mapeamento dos grãos MARTINI: Em bastões cinzentos e brancos, a estrutura atomística. Esferas verdes representam os grãos

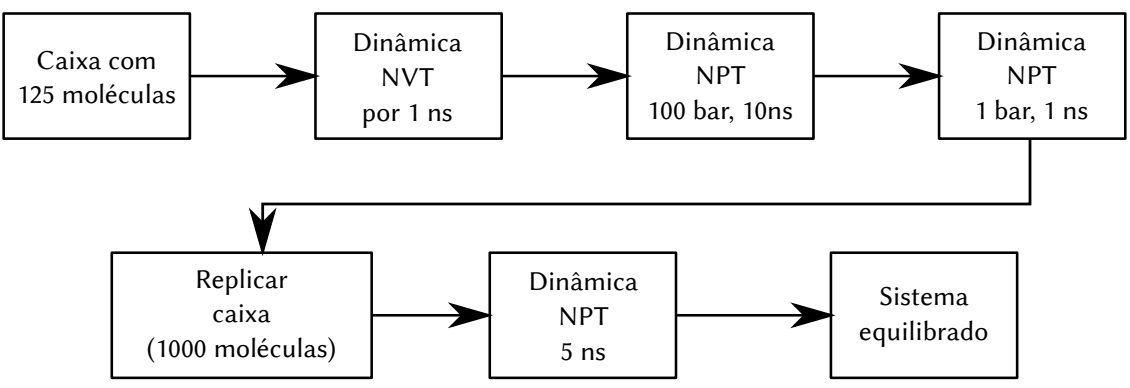

Figura 6.2: Procedimento para equilibrar uma caixa de solvente

Para testar a densidade do líquido obtido com este modelo de tolueno, seguimos o método utilizado por Caleman e colaboradores ${ }^{[113]}$ para avaliar campos de forças para líquidos, ilustrado na Figura 6.2. Construímos uma caixa com 125 moléculas, espaçadas $2 \mathrm{~nm}$ entre si, e deixamos relaxar por $1 \mathrm{~ns}$ mantendo constantes o volume da caixa e a temperatura a $300 \mathrm{~K}$. Em seguida, comprimimos a caixa por $10 \mathrm{~ns}$ a pressão constante de 100 bar para atingir a fase líquida. Após a compressão, deixamos o sistema relaxar por 1 ns a 1 bar. Formamos, então, uma caixa com 1000 moléculas replicando a caixa original nas três direções. Essa nova caixa passou por mais $5 \mathrm{~ns}$ de dinâmica nas mesmas condições de temperatura e pressão.

Dos últimos 500 ps dessa simulação, medimos a densidade a cada 2 ps para calcular a média, presente na Tabela 6.1. Pode-se ver que a densidade simulada é significativamente inferior tanto ao valor experimental quanto ao atomístico. Entretanto, essa diferença também aparece no modelo de benzeno e tentativas de 
alterar os parâmetros não-ligados de forma a reproduzir a densidade levaram ${ }^{\text {[101] }}$ à queda da qualidade dos dados de solubilidade, que é a propriedade de interesse na parametrização do campo de forças MARTINI.

Tabela 6.1: Densidades do tolueno e do benzeno, experimental e por simulações atomísticas (campo de forças OPLS/AA) e granuladas com o campo de forças MARTINI

\begin{tabular}{ccccc}
\hline $\begin{array}{c}\text { Densidade } \\
\left(\mathrm{kg} \mathrm{m}^{-3}\right)\end{array}$ & Experimental & Atomística & MARTINI & $\begin{array}{c}\text { MARTINI } \\
\text { Flexível }\end{array}$ \\
\hline Benzeno & $870^{[101]}$ & - & $720^{[101]}$ & - \\
Tolueno & $861,9^{[114]}$ & $872,0(2)$ & $837,9(13)$ & $870(4)$ \\
\hline
\end{tabular}

Passamos a investigar como a rigidez das ligações influencia na densidade. Para isto, substituímos os vínculos por ligações harmônicas, de $0,27 \mathrm{~nm}$ de comprimento e constante de mola $K_{i j}$ variável. Testamos cada modelo de tolueno de acordo com o procedimento da Figura 6.2. Com um valor de $K_{i j}=$ $5000 \mathrm{~kJ} \mathrm{~mol}^{-1} \mathrm{~nm}^{-2}$, obtivemos uma densidade de $870 \mathrm{~kg} \mathrm{~m}^{-3}$ e adotamos esses parâmetros no modelo definitivo do tolueno.

\subsection{Modelagem do nanotubo}

Entre as propriedades mais importantes de um nanotubo de carbono a serem reproduzidas em simulação encontram-se o diâmetro e o ângulo quiral. Para minimizar a perda de resolução dessas características, adotamos, como no trabalho de Patra e Král ${ }^{[111]}$, um mapeamento dois-para-um, em que cada grão representa dois átomos de carbono, como na Fig 6.3. Com este mapeamento, cada anel aromático do nanotubo é representado com três grãos SC4, de forma análoga ao benzeno.

Essa abordagem retém a estrutura e a simetria da rede hexagonal de grafeno que forma a superfície do tubo. Isso ocorre porque o mapeamento é equivalente a representar cada célula da rede de grafeno por um grão, em vez dos dois átomos da base. Dessa foma, as propriedades mecânicas e geométricas que dependem da rede são mantidas. Convém notar que, por representarem a rede hexagonal, a posição dos grãos em relação aos átomos que representam não afeta os resultados, uma vez que qualquer translação na rede representa uma rotação do tubo em torno de seu eixo e uma translação ao longo dele.

Neste trabalho, as propriedades mecânicas do nanotubo são de interesse secundário, por isso, em uma primeira abordagem, durante todas as simulações as coordenadas dos átomos foram mantidas fixas. Da mesma forma, os grãos no nanotubo são restritos a posições fixas no espaço e determinadas pela geometria 


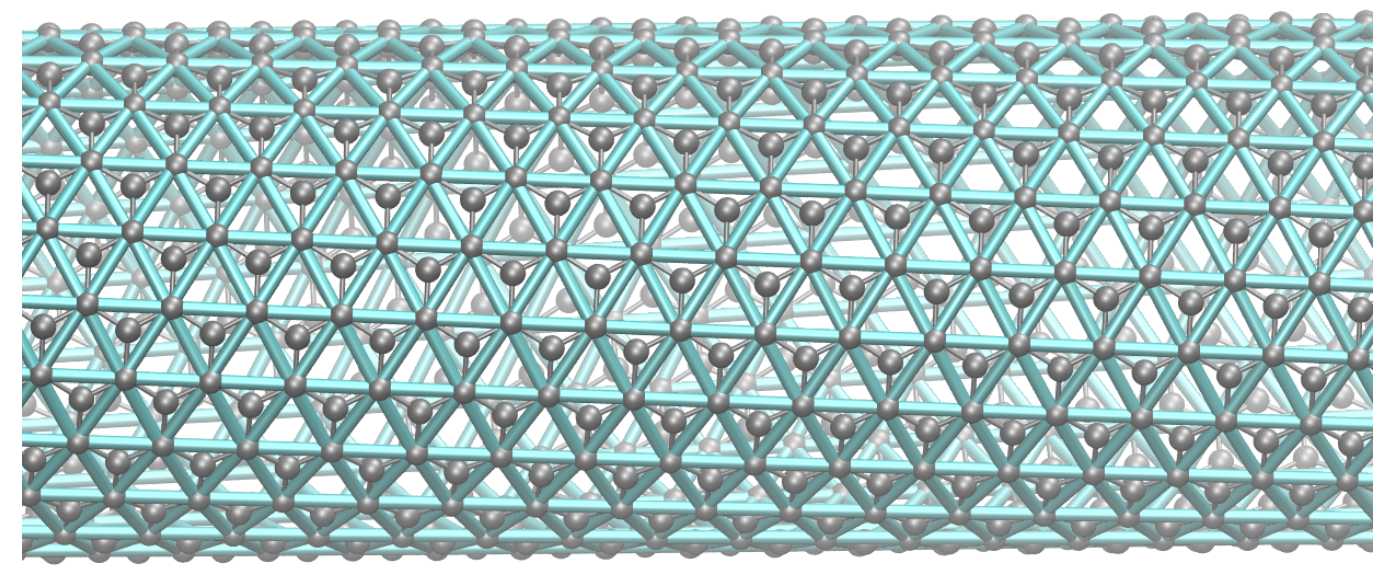

Figura 6.3: Mapeamento dos grãos em um nanotubo de carbono. Esferas ligadas por hastes: estrutura atomística. Bastões: estrutura granular. Note que cada grão se liga a seis vizinhos.

impostas pelos índices quirais que caracterizam o tubo. Assim, não são necessários termos de ligação, ângulo e torções impróprias para manter a estrutura do tubo.

\subsection{Modelagem do polifluoreno}

Para modelar o polifluoreno, dividimos a estrutura em duas partes: a cadeia principal, ou backbone, formada pelos núcleos aromáticos dos monômeros, e as cadeias laterais. Mapeamos as cadeias laterais, formadas por radicais octil, para dois grãos C1 cada, de forma análoga ao mapeamento MARTINI padrão para o octano (vide Fig. 6.4(a)). Os termos de ligação e ângulo entre os grãos foram herdados do mesmo modelo.

Mapeamos a cadeia principal de forma a reter elementos importantes da estrutura do polímero: o ponto de ancoragem das cadeias laterais (no átomo C9) e a ligação entre os monômeros (entre os átomos $\mathrm{C} 2$ e $\mathrm{C} 7$ ), com as respectivas torções preservadas. Uma vez que a cadeia principal é formada por anéis aromáticos, os grãos da cadeia principal são do tipo SC4, como no modelo de benzeno. A estrutura granular está representada nas Figuras 6.4(b) (mapeamento) e 6.4(c) (ligações). 


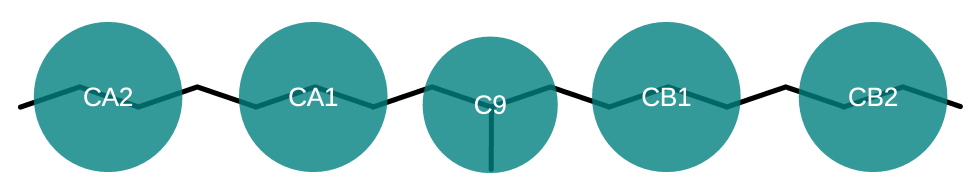

(a) Cadeias laterais

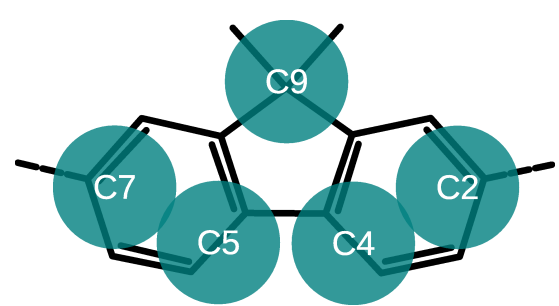

(b) Cadeia principal

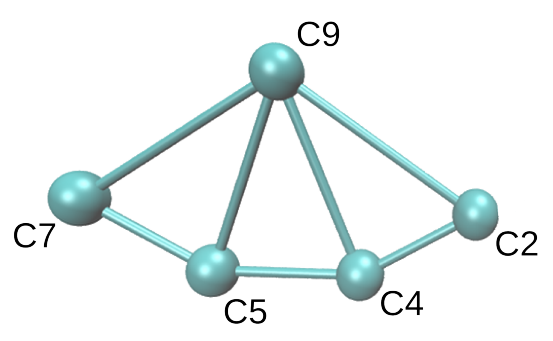

(c) Ligações na cadeia principal

Figura 6.4: Mapeamento dos grãos no modelo do polifluoreno. Hastes pretas representam a estrutura atomística. Esferas em ciano: grãos MARTINI.

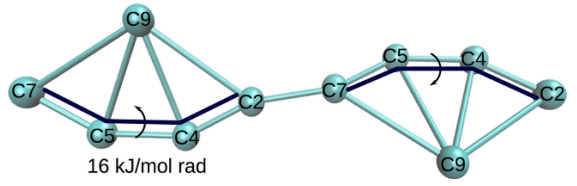

(a) $\mathrm{C} 2-\mathrm{C} 4-\mathrm{C} 5-\mathrm{C} 7$

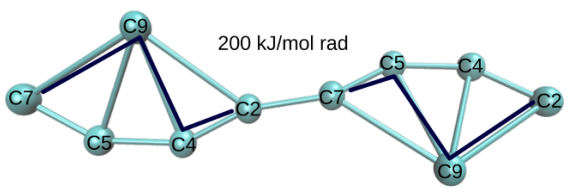

(c) $\mathrm{C} 2-\mathrm{C} 4-\mathrm{C} 9-\mathrm{C} 7$ e $\mathrm{C} 2-\mathrm{C} 9-\mathrm{C} 5-\mathrm{C} 7$

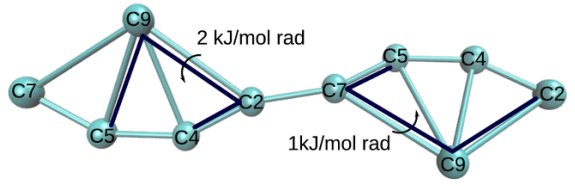

(b) $\mathrm{C} 4-\mathrm{C} 2-\mathrm{C} 9-\mathrm{C} 5$ e $\mathrm{C} 5-\mathrm{C} 7-\mathrm{C} 9-\mathrm{C} 2$

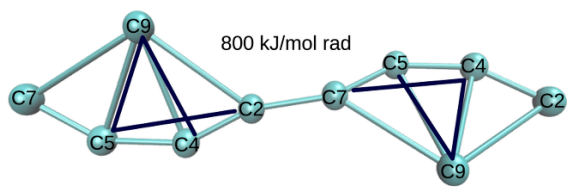

(d) $\mathrm{C} 2-\mathrm{C} 5-\mathrm{C} 9-\mathrm{C} 4$ e $\mathrm{C} 7-\mathrm{C} 4-\mathrm{C} 9-\mathrm{C} 5$

Figura 6.5: Torções para manter o núcleo na molécula planar.

Como vemos na Figura 6.4(c), o núcleo do monômero é formado por três triângulos que devem ser coplanares. As distâncias entre os grãos são mantidas fixas como vínculos. Durante a simulação espera-se, entretanto, que essa estrutura oscile em torno da conformação planar e é importante que o modelo granulado reproduza o comportamento médio da estrutura atomística. Por isso, definimos oito torções entre os grãos de uma unidade da cadeia principal, dispostas na Fig. 6.5. 
É fundamental que o modelo granulado reproduza o comportamento da cadeia polimérica como um todo e a interação entre unidades vizinhas tem um papel importante nisso. Em especial a torção entre os monômeros (Fig 6.6(a)) e o ângulo que cada unidade faz com a ligação entre ela e sua vizinha (Fig. 6.6(b)). Juntas, essas torções definem a flexibilidade do polímero.

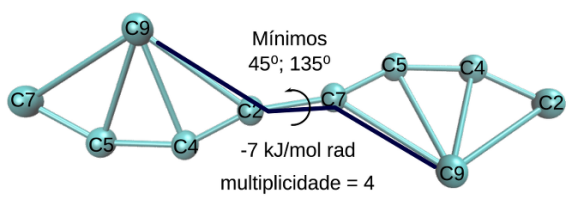

(a) Torção própria entre monômeros

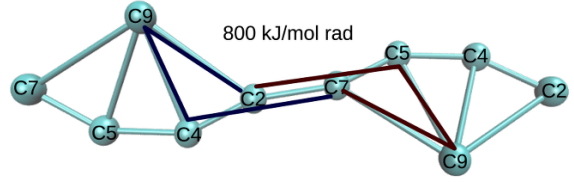

(b) Torção imprópria para manter os monômeros alinhados

Figura 6.6: Torções que determinam a flexibilidade da cadeia

No pacote Gromacs e no campo de forças MARTINI, as torções são descritas por um potencial periódico, de intensidade $k$, fase $\phi_{s}$ e multiplicidade $n$ :

$$
V_{\text {diedro }}=k\left[1+\cos \left(n \phi-\phi_{s}\right)\right] \text {. }
$$

Nos casos em que a torção tem a função de manter uma estrutura planar, a multiplicidade é 1 . No caso de uma estrutura que pode girar em torno de uma ligação, a multiplicidade está associada ao número de mínimos que o perfil de energia apresenta. Os parâmetros de força $k$ e fase $\phi_{s}$ devem ser determinados através de um processo heurístico que busca reproduzir a distribuição de ângulos diedros de uma simulação atomística de referência.

Iniciamos com uma simulação atomística de um dímero de fluoreno em vácuo, utilizando o campo de forças OPLS-AA ${ }^{[115]}$ - All-Atom Optimized Parameters for Liquid Simulations: Parâmetros otimizados para simulações de líquidos. A fim de isolar os efeitos das ligações da cadeia principal, substituímos as cadeias laterais por um grupo $\mathrm{CH}_{3}$. Inserimos a molécula em uma caixa de 3,3 nm de lado e, após uma fase de otimização de geometria, executamos uma simulação NVT com um termo de fricção para evitar que a molécula passasse a girar sem controle no vácuo.

A coleta de dados se deu ao longo de 10 ns de simulação, com as coordenadas atômicas armazenadas a cada 10 ps. Em seguida, convertemos a trajetória atomística em uma trajetória granulada: em cada quadro da trajetória, substituímos os grupos de átomos pelos grãos que os representam. Na trajetória convertida, medimos ângulos diedros descritos acima e preparamos um histograma de cada. Essas distribuições servirão de padrão para ajustar os parâmetros do modelo granulado do polifluoreno. 
Realizamos uma simulação semelhante utilizando o modelo granulado do fluoreno, com um conjunto inicial de parâmetros derivados de estruturas análogas já parametrizadas com o campo de forças MARTINI. Da trajetória resultante dessa simulação, calculamos as distribuições a serem comparadas com a referência, realizando ajustes nas constantes de força e fases de forma a reproduzir a média e largura distribuição de referência.

Após algumas iterações foi possível obter no modelo granulado distribuições compatíveis com a referência atomística, como podemos ver na Figura 6.7. En-

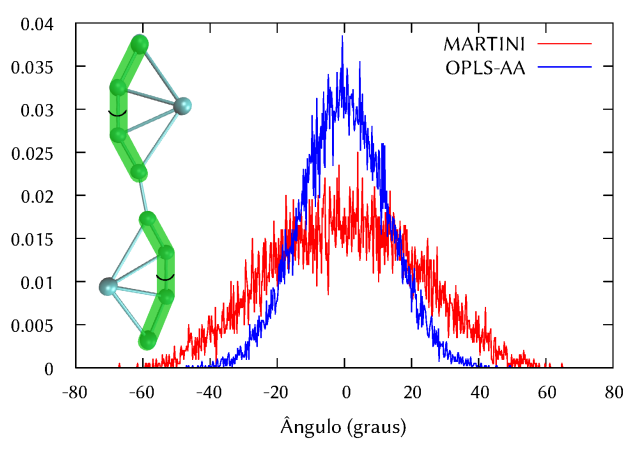

(a) Torção para manter o núcleo plano

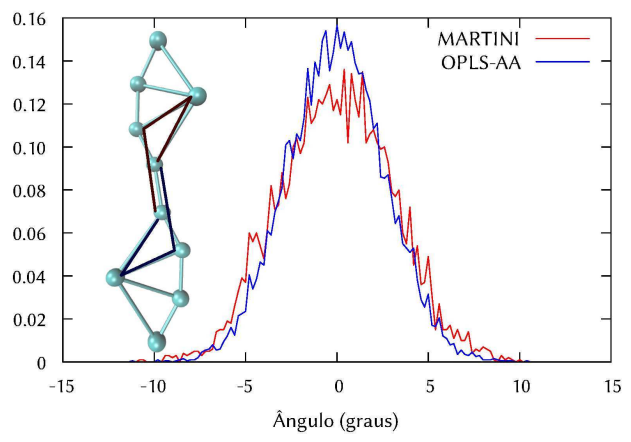

(c) Torção imprópria para manter os monômeros alinhados

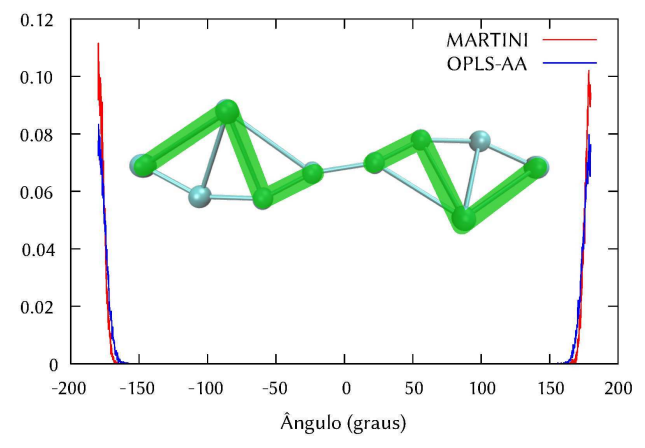

(b) Torção para manter o núcleo plano

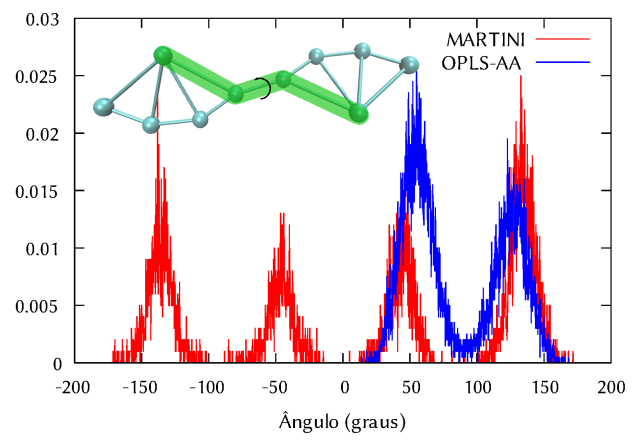

(d) Torção própria entre monômeros

Figura 6.7: Histogramas das torções. Em vermelho, modelo granulado. Em azul, referência atomística.

tretanto, algum esforço ainda deve ser dedicado à torção entre os monômeros (Fig. 6.7(d)) que, no caso da estrutura granulada, permite transições anti-para, que não se observa na referência atomística. Uma forma de solucionar essa discrepância é adicionar mais um termo de torção envolvendo esses átomos, mas de multiplicidade menor, de forma a criar uma barreira que penalize a transição. A introdução desse novo termo, entretanto, pode levar a artefatos que devem ser analisados cuidadosamente. 
Antes de realizarmos ajustes finos nos parâmetros, devemos testá-los em solução. A fim de aprimorar a estabilidade da estrutura, substituímos os vínculos das ligações por termos harmônicos como os da equação (3.6) (página 28). Determinamos, em vácuo, a distância de equilíbrio $r_{i j}^{*}$ e a constante de mola $K_{i j}$ das ligações através do mesmo processo heurístico utilizado para as torções. Realizamos o mesmo procedimento para os ângulos planos formados entre três átomos, como na equação (3.8).

Comparamos as distribuições de comprimentos de ligação, ângulos planos e ângulos de torção com um sistema equivalente, atomístico, modelado através do campo de forças OPLS-AA. Uma vez satisfeitos com o modelo do núcleo, acrescentamos as cadeias laterais, formadas pelos grãos CA1, CA2, CB1 e CB2 e otimizamos, pelo mesmo processo, os ângulos formados entre os grãos da cadeia lateral e os grãos do núcleo.

\subsection{Dinâmica molecular}

Aplicamos este modelo granulado para explorar as conformações adotadas pelo polifluoreno em torno de nanotubos de carbono de diferentes diâmetros, dentre as espécies estudadas no Capítulo 5. Experimentalmente, observa-se ${ }^{[9]}$ que o PFO é incapaz de suspender nanotubos de diâmetro da ordem de 1,2 nm. Portanto, preparamos caixas com nanotubos de $1,0 \mathrm{~nm}$ a $1,2 \mathrm{~nm}$ de diâmetro a fim de comparar o desempenho do modelo granulado de PFO com os resultados experimentais.

Adotamos condições periódicas de contorno ao longo do eixo do nanotubo, de forma a gerar um tubo infinito, o que previne a admissão de solvente no interior do tubo. Nas direções perpendiculares ao eixo, a célula unitária tem $10 \mathrm{~nm}$ de lado e as paredes formam um ângulo de 60 graus para dar origem a uma rede hexagonal, como na Figura 6.8. Essa geometria permite formar a caixa com a maior distância possível entre imagens ${ }^{[116 ; 117]}$ para um dado volume.

Preparamos caixas como essas contendo tubos $(6,5),(7,5),(7,7),(8,6),(12,10)$, $(13,8)$ e $(14,7)$, com três cadeias de PFO, em quatro condições: com as cadeias estiradas ou em hélice, como na Fig. 4.3 (página 63) e com a cadeia principal paralela ou perpendicular à superfície do tubo, como na Figura 5.4 (página 80). Isso resultou em 28 caixas, que submetemos a um processo de solvatação com tolueno, minimização de energia, dinâmica molecular NVT e NPT para equilibrar a temperatura e a pressão, antes de passarmos a simulações de dinâmica molecular NPT de produção, com duração de $1 \mu$ s. 


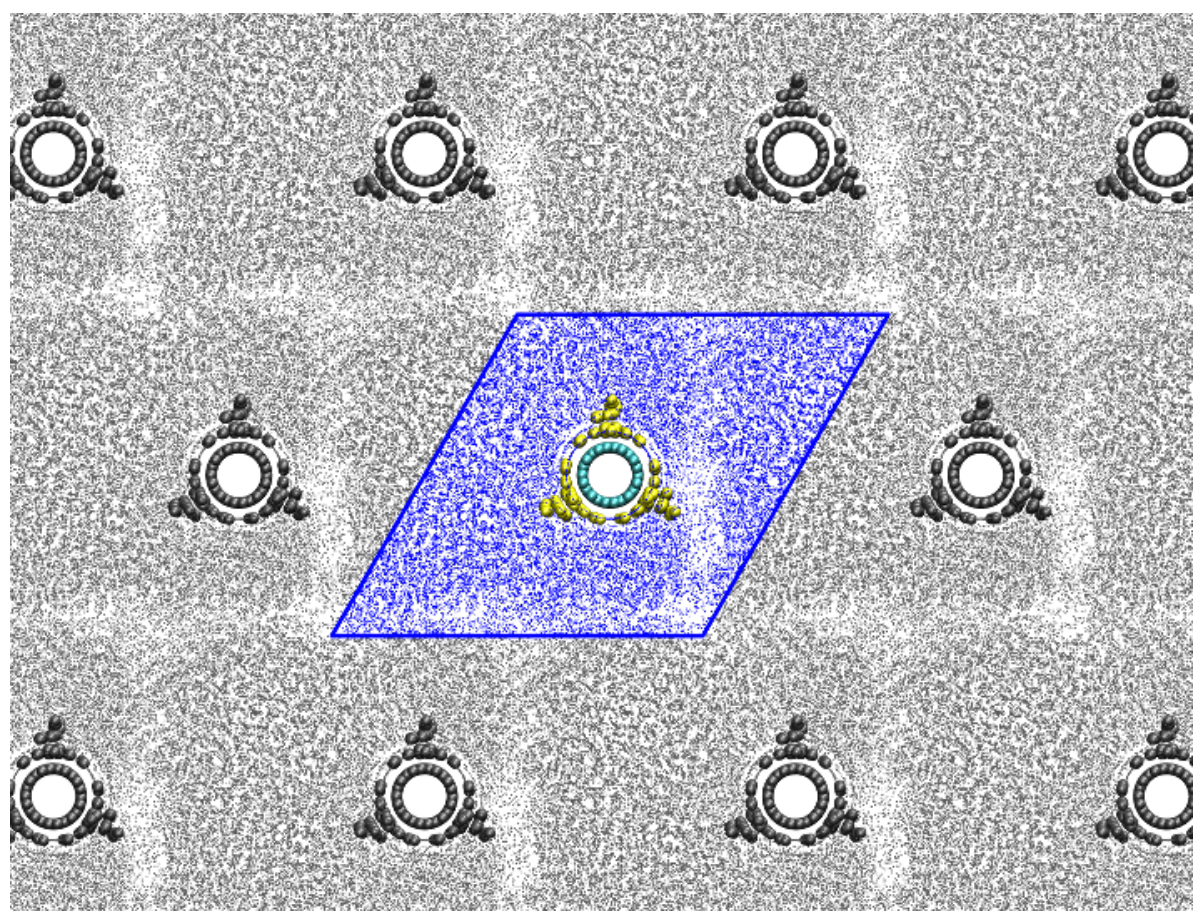

Figura 6.8: Configuração da caixa simulação do sistema NT + PFO em tolueno Em cinza claro, nanotubo $(13,9)$. Em amarelo, cadeias de PFO. Em azul, tolueno. As imagens periódicas da célula estão representadas em cinza escuro.

\subsubsection{Resultados}

Após $1 \mu$ s de dinâmica molecular NPT, observamos que as cadeias em hélice tendem a se desenrolar e adotar uma configuração linear, paralela ao eixo do tubo. Isso vai de encontro aos resultados das simulações da Seção 4.3, em que observamos um consistente favorecimento energético para a conformação helicoidal. Esse resultado nos leva a entender que o modelo granulado do PFO resulta em cadeias mais rígidas que a modelada com o campo de forças CVFF-c5. Dessa forma, os termos ligados do polifluoreno devem ser revistos, em particular aqueles que envolvem a ligação entre unidades vizinhas.

Além disso, como vemos na Fig. 6.9, o PFO tende a permanecer aderido ao tubo, mesmo àqueles de maior diâmetro, dependendo da orientação da cadeia principal. Esse resultado não é compatível com as observações experimentais discutidas no Capítulo 5, de que complexos de tubos de grande diâmetro e PFO não seriam seriam estáveis. O balanço entre os parâmetros de Lennard-Jones do tubo, do solvente e do polímero é responsável por esse comportamento e, portanto, deve passar por uma investigação mais cuidadosa.

Esses resultados, até o momento, mostram que o modelo granulado ainda requer refinamento para o estudo da interação entre nanotubos de carbono e 


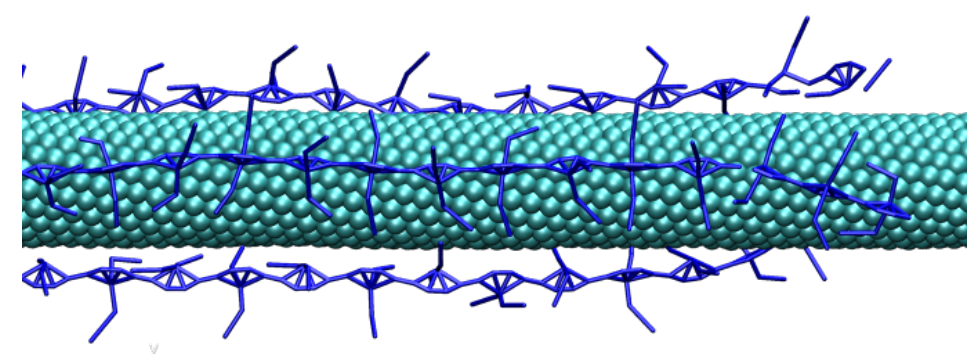

(a) Cadeia principal perpendicular ao tubo, $0 \mu \mathrm{s}$

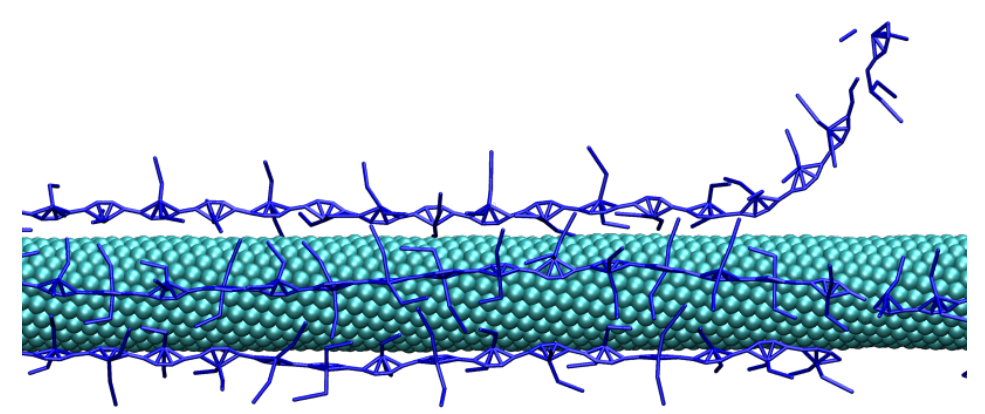

(b) Cadeia principal perpendicular ao tubo, $1 \mu \mathrm{s}$

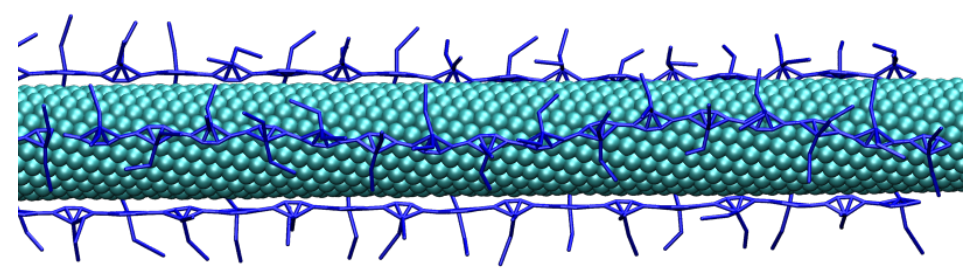

(c) Cadeia principal paralela ao tubo, $0 \mu \mathrm{s}$

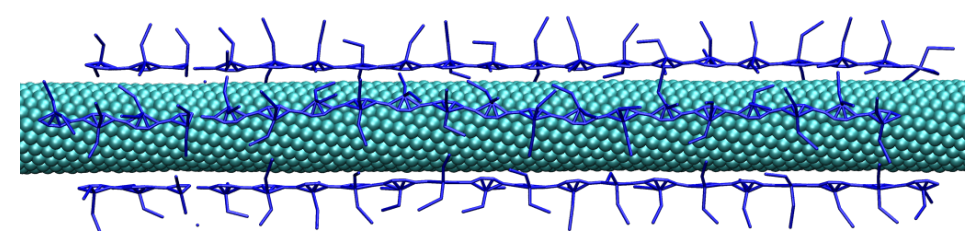

(d) Cadeia principal paralela ao tubo, $1 \mu \mathrm{s}$

Figura 6.9: Conformações do PFO granulado sobre tubo $(14,7)$

polifluorenos na presença de um solvente orgânico. A parametrização do campo de forças MARTINI foi otimizada originalmente para sistemas biológicos, em particular proteínas e bicamadas lipídicas. Nesses sistemas, o balanço entre as interações envolvendo grupos hidrofílicos e hidrofóbicos executa um papel mais 
importante que as diferenças mais sutis entre diversas estruturas de carbono. Faz-se necessária uma investigação mais cuidadosa e, possivelmente, uma extensão do campo de forças MARTINI para lidar com essas sutilezas, com a adoção de um número maior de tipos de grãos, com parâmetros de van der Waals refinados para sistemas baseados em carbono, em particular os aromáticos. A parametrização dos termos ligados no modelo do nanotubo permitirá também incluir mais efeitos dinâmicos da interação entre o tubo e o polímero, contribuindo para a melhoria do modelo granulado. 



\section{Parte III}

\section{Conclusão}





\section{Capítulo 7}

\section{Conclusão}

Buscamos neste trabalho compreender o mecanismo responsável pela seletividade dos polifluorenos ao suspender nanotubos de carbono em solução de tolueno. Para tanto, realizamos simulações de dinâmica molecular atomística e desenvolvemos um método para calcular o espectro de emissão do polifluoreno em diferentes conformações a fim de compará-lo com medidas experimentais e inferir a configuração que o polímero adota ao interagir com os nanotubos.

Inicialmente, avaliamos a estabilidade relativa de cadeias de PFO aderidas à superfície de nanotubos de cerca de $1,0 \mathrm{~nm}$ de diâmetro em duas conformações: helicoidal ou estirada ao longo do tubo. A análise da energia de ligação revelou que a conformação em hélice é mais estável em todos os tubos testados. Ao avaliar a geometria dessas estruturas, concluímos que o mecanismo de interdigitação das cadeias laterais é responsável por esse resultado. O comportamento do PFO em tolueno, ao formar fitas $\beta$, de cadeias paralelas e estiradas, ligadas entre si através das cadeias laterais interdigitadas, fortalece esse argumento.

A fim de obter propriedades experimentalmente acessíveis das cadeias de polifluoreno em torno dos nanotubos, desenvolvemos um método para calcular o espectro de emissão de uma molécula em solução. O procedimento parte da reparametrização de um campo de força de dinâmica molecular para reproduzir a geometria do estado excitado da molécula. Em seguida, coletamos um conjunto de configurações da molécula ao longo de uma simulação de dinâmica molecular e calculamos o espectro de transições eletrônicas de cada uma delas a fim de obter um espectro médio. Uma vez que as transições eletrônicas são verticais, ou seja, as coordenadas eletrônicas não variam significativamente durante a transição, podemos utilizar métodos já estabelecidos para calcular espectros de absorção. Neste trabalho, adotamos o método semiempírico ZINDO/S devido ao grande número de átomos nas cadeias de polifluoreno. O uso de diversas conformações provenientes de dinâmica molecular nos permitiu reproduzir razoavelmente a estrutura vibrônica dos espectros de emissão. Comparar os espec- 
tros calculados com aqueles obtidos experimentalmente nos permitiu identificar propriedades características que levam a concluir que, de fato, as cadeias de polifluoreno se encontram enroladas em hélice sobre os nanotubos em solução.

Passamos então a investigar o comportamento de outros derivados do polifluoreno na presença de nanotubos. Em particular, polifluorenos dotados de cadeias laterais de alquilas longas se mostraram capazes de suspender nanotubos de maior diâmetro, entre $1,2 \mathrm{~nm}$ e $1,4 \mathrm{~nm}$, enquanto não se observa esses tubos suspensos por PFO. Uma vez que esses polifluorenos de cadeias laterais longas não formam fase $\beta$ em tolueno, investigamos outras razões para o encapsulamento estável dos nanotubos maiores. Através de simulações de dinâmica de impulso, estudamos a forma com que as cadeias de polifluoreno aderem e se organizam sobre a superfície do tubo. Observamos que a interdigitação entre as cadeias laterais continua a realizar um papel importante na seletividade de tubos maiores. As cadeias de polímero tendem a se organizar de forma a maximizar a interdigitação das cadeias laterais, guiadas pelo padrão de ziguezague dos átomos de carbono da superfície do nanotubo. Com isso, caso os radicais sejam curtos em relação à circunferência do tubo, uma região da superfície do nanotubo permanecerá exposta ao solvente e, possivelmente, a outros tubos na solução, o que o leva à reagregação e precipitação. Cadeias laterais longas demais, por outro lado, afastam a cadeia principal do polímero da superfície do tubo, o que reduz a energia de ligação entre eles e desestabiliza o complexo. Assim, a capacidade desses derivados de polifluoreno de suspenderem nanotubos de grande diâmetro está relacionada à capacidade das cadeias laterais recobrirem a superfície do tubo.

Finalmente, propusemos formas de aprimorar o método de cálculo do espectro de emissão. Em particular, demos ênfase à qualidade do ensemble de conformações da molécula simulada. No caso deste trabalho, buscamos utilizar um campo de forças granulado, que reduz a complexidade das simulações de dinâmica molecular ao reduzir o número de graus de liberdade do sistema, para obter uma série de configurações iniciais dos complexos de PFO com nanotubos e permitir uma exploração mais ampla do espaço de fase. Fez-se necessário parametrizar todas as moléculas deste estudo no campo de forças MARTINI, desenvolvido originalmente para sistemas biológicos. Isoladamente, os modelos de tolueno e de polifluoreno apresentaram comportamento compatível com o modelo atomístico. As simulações de dinâmica molecular em solução, entretanto, resultaram em comportamentos distintos daquele observado experimentalmente. Isso pode ser entendido ao considerar que o campo de forças MARTINI foi parametrizado para sistemas em que o contraste entre grupos hidrofílicos e hidrofóbicos tem um papel importante e essa propriedade não se aplica aos sistemas estudados neste trabalho. Um possível desenvolvimento futuro para este trabalho seria a extensão desse campo de forças para incluir solventes orgânicos e moléculas aromáticas na parametrização. 


\section{Referências Bibliográficas}

[1] Iijima, S. \& Ichihashi, T. Single-shell carbon nanotubes of 1-nm diameter. Nature 363, 603-605 (1993). 3, 10

[2] Saito, R., Dresselhaus, G. \& Dresselhaus, M. S. Physical properties of carbon nanotubes (Imperial College Press, London, 1998). 3, 7, 10, 12, 14, 15, 16, 17

[3] Gomulya, W., Gao, J. \& Loi, M. A. Conjugated polymer-wrapped carbon nanotubes: physical properties and device applications. The European Physical fournal B 86, 1-13 (2013). 3, 4, 9, 20

[4] Hata, K. et al. Water-assisted highly efficient synthesis of impurity-free single-walled carbon nanotubes. Science 306, 1362-1364 (2004). 3, 9

[5] Baughman, R. H., Zakhidov, A. A. \& de Heer, W. A. Carbon nanotubes-the route toward applications. Science 297, 787-792 (2002). 3

[6] Demczyk, B. G. et al. Direct mechanical measurement of the tensile strength and elastic modulus of multiwalled carbon nanotubes. Materials Science and Engineering A 334, 173-178 (2002). 3

[7] Bachtold, A., Hadley, P., Nakanishi, T. \& Dekker, C. Logic circuits with carbon nanotube transistors. Science 294, 1317-1320 (2001). 3

[8] Kwak, M. et al. DNA block copolymer doing it all: From selection to self-assembly of semiconducting carbon nanotubes. Angewandte Chemie International Edition 50, 3206-3210 (2011). 4

[9] Gomulya, W. et al. Semiconducting single-walled carbon nanotubes on demand by polymer wrapping. Advanced Materials 25, 2948-2956 (2013). $3,18,21,22,77,78,79,83,96$

[10] Landi, B. J., Raffaelle, R. P., Castro, S. L. \& Bailey, S. G. Single-wall carbon nanotube-polymer solar cells. Progress in Photovoltaics: Research and Applications 13, 165-172 (2005). 3 
[11] Endo, M., Kim, C., Nishimura, K., Fujino, T. \& Miyashita, K. Recent development of carbon materials for Li ion batteries. Carbon 38, 183-197 (2000). 3

[12] Rather, S.-u., Naik, M.-u.-d., Hwang, S. W., Kim, A. R. \& Nahm, K. S. Room temperature hydrogen uptake of carbon nanotubes promoted by silver metal catalyst. Journal of Alloys and Compounds 475, L17-L21 (2009). 3

[13] Lu, Y. et al. Room temperature methane detection using palladium loaded single-walled carbon nanotube sensors. Chemical Physics Letters 391, 344348 (2004). 3

[14] Male, K. B., Hrapovic, S., Liu, Y., Wang, D. \& Luong, J. H. T. Electrochemical detection of carbohydrates using copper nanoparticles and carbon nanotubes. Analytica Chimica Acta 516, 35-41 (2004). 3

[15] Novak, J. P. et al. Nerve agent detection using networks of single-walled carbon nanotubes. Applied Physics Letters 83, 4026-4028 (2003). 3

[16] Kam, N. W. S., O'Connell, M., Wisdom, J. A. \& Dai, H. Carbon nanotubes as multifunctional biological transporters and near-infrared agents for selective cancer cell destruction. Proceedings of the National Academy of Sciences of the United States of America 102, 11600-11605 (2005). 3

[17] Dai, H., Hafner, J. H., Rinzler, A. G., Colbert, D. T. \& Smalley, R. E. Nanotubes as nanoprobes in scanning probe microscopy. Nature 384, 147-150 (1996). 3, 10

[18] Kim, S., Lee, H. W. \& Kim, S.-G. Transplanting assembly of carbonnanotube-tipped atomic force microscope probes. Applied Physics Letters 94, 193102-193103 (2009).

[19] Wilson, N. R. \& Macpherson, J. V. Carbon nanotube tips for atomic force microscopy. Nat Nano 4, 483-491 (2009). 3, 10

[20] Bronikowski, M. J., Willis, P. A., Colbert, D. T., Smith, K. A. \& Smalley, R. E. Gas-phase production of carbon single-walled nanotubes from carbon monoxide via the HiPco process: A parametric study. Journal of Vacuum Science \& Technology A 19, 1800-1805 (2001). 3, 16, 17

[21] Resasco, D. E. et al. A scalable process for production of single-walled carbon nanotubes (SWNTs) by catalytic disproportionation of $\mathrm{CO}$ on a solid catalyst. Fournal of Nanoparticle Research 4, 131-136 (2002). 4, 16, 71 
[22] Jorio, A. et al. Quantifying carbon-nanotube species with resonance raman scattering. Physical Review B 72, 1-5 (2005). 4, 71

[23] Hersam, M. C. Progress towards monodisperse single-walled carbon nanotubes. Nature nanotechnology 3, 387-394 (2008). 4

[24] Arnold, M. S., Green, A. A., Hulvat, J. F., Stupp, S. I. \& Hersam, M. C. Sorting carbon nanotubes by electronic structure using density differentiation. Nature Nanotech. 1, 60-65 (2006). 4, 21

[25] Carvalho, E. J. F. \& dos Santos, M. C. Role of surfactants in carbon nanotubes density gradient separation. ACS Nano 4, 765-770 (2010). 4, 21

[26] Zheng, M. et al. Structure-based carbon nanotube sorting by sequencedependent DNA assembly. Science 302, 1545-1548 (2003). 4

[27] Yi, W. et al. Wrapping of single-walled carbon nanotubes by a polymer: The role of polymer conformation-controlled size selectivity. The fournal of Physical Chemistry B 112, 12263-12269 (2008). 4

[28] Nish, A., Hwang, J.-Y., Doig, J. \& Nicholas, R. J. Highly selective dispersion of single-walled carbon nanotubes using aromatic polymers. Nat Nano 2, 640-646 (2007). 4, 5, 21, 22, 57, 62, 67, 72

[29] Wilkinson, C. I. et al. Enhanced performance of pulse driven small area polyfluorene light emitting diodes. Appl. Phys. Lett. 79, 171 (2001). 4

[30] Snaith, H. J., Arias, A. C., Morteani, A. C., Silva, C. \& Friend, R. H. Charge generation kinetics and transport mechanisms in blended polyfluorene photovoltaic devices. Nano Letters 2, 1353-1357 (2002). 4

[31] Knaapila, M. \& Winokur, M. Structure and morphology of polyfluorenes in solutions and the solid state. In Scherf, U. \& Neher, D. (eds.) Polyfluorenes, vol. 212 of Advances in Polymer Science, 227-272 (Springer Berlin / Heidelberg, 2008). URL http://dx.doi.org/10.1007/12_ 2008_149. 4, 5

[32] Gao, J. \& Loi, M. A. Photophysics of polymer-wrapped single-walled carbon nanotubes. Eur. Phys. F. B 75, 121-126 (2010). 5, 58, 71

[33] Hwang, J.-Y. et al. Polymer structure and solvent effects on the selective dispersion of single-walled carbon nanotubes. Fournal of the American Chemical Society 130, 3543-3553 (2008). 5, 21, 22, 58, 62 
[34] Gao, J., Kwak, M., Wildeman, J., Herrmann, A. \& Loi, M. Effectiveness of sorting single-walled carbon nanotubes by diameter using polyfluorene derivatives. Carbon 49, 333-338 (2011). 5, 24

[35] Justino, L. L. G. et al. Gel formation and interpolymer alkyl chain interactions with poly(9,9-dioctylfluorene-2,7-diyl) (PFO) in toluene solution: Results from NMR, SANS, DFT, and semiempirical calculations and their implications for PFO $\beta$-phase formation. Macromolecules 44, 334-343 (2011). 5, 62, 67, 73

[36] Gao, J., Loi, M. A., de Carvalho, E. J. F. \& dos Santos, M. C. Selective wrapping and supramolecular structures of polyfluorenecarbon nanotube hybrids. ACS Nano 5, 3993-3999 (2011). 5, 21, 67, 71, $72,73,77$

[37] Kroto, H. W., Heath, J. R., O’Brien, S. C., Curl, R. F. \& Smalley, R. E. C60: Buckminsterfullerene. Nature 318, 162-163 (1985). 9

[38] Dresselhaus, M. S., Dresselhaus, G. \& Elkund, P. C. Science of fullerenes and carbon nanotubes (Academic Press, San Diego, 1996). 9

[39] Monthioux, M. \& Kuznetsov, V. L. Who should be given the credit for the discovery of carbon nanotubes? Carbon 44, 1621-1623 (2006). 10

[40] Iijima, S. Helical microtubules of graphitic carbon. Nature 354, 56-58 (1991). 10

[41] Novoselov, K. S. et al. Electric field effect in atomically thin carbon films. Science 306, 666-669 (2004). 10

[42] Nobel Media AB. The nobel prize in physics 2010 (2013). URL http: //www.nobelprize.org/nobel_prizes/physics/laureates/2010/. [Online; acessado em 13 de novembro de 2013]. 10

[43] Castro Neto, A. H., Guinea, F., Peres, N. M. R., Novoselov, K. S. \& Geim, A. K. The electronic properties of graphene. Rev. Mod. Phys. 81, 109-162 (2009). 12

[44] Saito, R., Fujita, M., Dresselhaus, G. \& Dresselhaus, M. S. Electronic structure of chiral graphene tubules. Appl. Phys. Lett. 60, 2204 (1992). 15

[45] Ando, Y. et al. Mass production of single-wall carbon nanotubes by the arc plasma jet method. Chemical Physics Letters 323, 580-585 (2000). 16, 17 
[46] Kisielowski, C. et al. Detection of single atoms and buried defects in three dimensions by aberration-corrected electron microscope with 0.5$\AA$ information limit. Microscopy and Microanalysis 14, 469-477 (2008). 17

[47] Pfeiffer, R. et al. Dynamics of carbon nanotube growth from fullerenes. Nano Letters 7, 2428-2434 (2007). 17

[48] Kitaura, R. \& Shinohara, H. Endohedral metallofullerenes and nanopeapods. Fapanese fournal of Applied Physics 46, 881-891 (2007). 17

[49] Kataura, H. et al. Optical properties of single-wall carbon nanotubes. Synthetic Metals 103, 2555-2558 (1999). 18

[50] Kataura, H. Web page of Dr. H. Kataura in Nanosystem Research Institute/AIST (2013). URL http://staff.aist.go.jp/h-kataura/ kataurae.html. [Online; acessado em 29 de outubro de 2013]. 18

[51] Maryuama, S. Shigeo MARUYAMA's fullerene and carbon nanotube site (2002). URL http://www.photon.t.u-tokyo.ac.jp/〜maruyama/ kataura/kataura.html. [Online; acessado em 29 de outubro de 2013]. 18

[52] Choi, J. H. \& Strano, M. S. Solvatochromism in single-walled carbon nanotubes. Applied Physics Letters 90, 223114 (2007). 18

[53] Bachilo, S. M. et al. Structure-assigned optical spectra of single-walled carbon nanotubes. Science 298, 2361-2366 (2002). 19, 58

[54] Thomsen, C., Reich, S. \& Maultzsch, J. Resonant raman spectroscopy of nanotubes. Philosophical Transactions of the Royal Society of London. Series A: Mathematical, Physical and Engineering Sciences 362, 2337-2359 (2004). 20

[55] Jorio, A. et al. Characterizing carbon nanotube samples with resonance raman scattering. New fournal of Physics 5, 139 (2003). 20

[56] Saito, R. et al. Double resonance raman spectroscopy of single-wall carbon nanotubes. New fournal of Physics 5, 157 (2003). 20

[57] Hersam, M. C. Progress towards monodisperse single-walled carbon nanotubes. Nature Nanotech. 3, 387-394 (2008). 20

[58] Boul, P. et al. Reversible sidewall functionalization of buckytubes. Chemical Physics Letters 310, 367-372 (1999). 20 
[59] O'Connell, M. J. et al. Band gap fluorescence from individual single-walled carbon nanotubes. Science 297, 593-596 (2002). 21

[60] O'Connell, M. Reversible water-solubilization of single-walled carbon nanotubes by polymer wrapping. Chemical Physics Letters 342, 265-271 (2001). 21

[61] McDonald, T. J., Engtrakul, C., Jones, M., Rumbles, G. \& Heben, M. J. Kinetics of pl quenching during single-walled carbon nanotube rebundling and diameter-dependent surfactant interactions. The fournal of Physical Chemistry B 110, 25339-25346 (2006). 21

[62] Rinzler, A. G. Materials processing: Sorting out carbon nanotube electronics. Nature Nanotech. 1, 17-18 (2006). 21

[63] McNaught, A. D. \& Wilkinson, A. IUPAC. Compendium of Chemical Terminology, 2nd ed. (the "Gold Book"). (Blackwell Scientific Publications, Oxford, 1997). XML on-line corrected version: http://goldbook. iupac .org (2006-) created by M. Nic, J. Jirat, B. Kosata; updates compiled by A. Jenkins. 22

[64] Shirakawa, H., Louis, E. J., MacDiarmid, A. G., Chiang, C. K. \& Heeger, A. J. Synthesis of electrically conducting organic polymers: halogen derivatives of polyacetylene, (ch). F. Chem. Soc., Chem. Commun. 578-580 (1977). 22

[65] Nobel Media AB. The nobel prize in chemistry 2000 (2013). URL http: // www . nobelprize.org/nobel_prizes/chemistry/laureates/2000/. [Online; acessado em 8 de novembro de 2013]. 22

[66] Lee, H. W. et al. Selective dispersion of high purity semiconducting singlewalled carbon nanotubes with regioregular poly(3-alkylthiophene)s. Nat Commun 2, 541 (2011). 22, 23, 75, 76, 77

[67] Tange, M., Okazaki, T. \& Iijima, S. Selective extraction of large-diameter single-wall carbon nanotubes with specific chiral indices by poly(9-9dioctylfluorene-alt-benzothiadiazole). Journal of the American Chemical Society 113, 11908-11911 (2011). 24, 75, 76, 77, 78

[68] Mistry, K. S., Larsen, B. A. \& Blackburn, J. L. High-yield dispersions of large-diameter semiconducting single-walled carbon nanotubes with tunable narrow chirality distributions. ACS Nano 7, 2231-2239 (2013). 24, 75,77 
[69] Meier, H., Stalmach, U. \& Kolshorn, H. Effective conjugation length and UV/vis spectra of oligomers. Acta Polymerica 48, 379-384 (1997). 24

[70] Levine, I. Quantum chemistry (Prentice Hall, Upper Saddle River, NJ 07458, 2009), 6th ed. edn. 25, 26, 36, 37, 40, 44, 45, 46

[71] Accelrys, I. Cerius ${ }^{2}$ Simulation Tools User's Reference (Accelrys, Inc., 9685 Scranton Rd., San Diego, CA 92121, U.S.A., 1995). 27, 29, 30

[72] van Duin, A. C. T., Dasgupta, S., Lorant, F. \& Goddard, W. A. ReaxFF: a reactive force field for hydrocarbons. The fournal of Physical Chemistry $A$ 105, 9396-9409 (2001). 28

[73] van der Spoel, D., Lindahl, E., Hess, B. \& The GROMACS development team. GROMACS User Manual version 4.6 (www.gromacs .org, 2012). 30, 87

[74] Frenkel, D. \& Smit, B. Understanding molecular simulation: from algorithms to applications (Academic Press, San Diego, 1996). 31, 32

[75] Allen, M. P. \& Tildesley, D. J. Computer simulation of liquids (Oxford University Press, Oxford, 1989). 33

[76] Atkins, P. \& Friedman, R. Molecular Quantum Mechanics (Oxford University Press INc., New York, 2005), 4th ed. edn. 33

[77] Zerner, M. C., Loew, G. H., Kirchner, R. F. \& Mueller-Westerhoff, U. T. An intermediate neglect of differential overlap technique for spectroscopy of transition-metal complexes. ferrocene. Fournal of the American Chemical Society 102, 589-599 (1980). 38, 39

[78] Zerner, M. C. Semiempirical molecular orbital methods. In Lipkowitz, K. B. \& Boyd, D. B. (eds.) Reviews in Computational Chemistry, vol. 2, 313365 (VCH Publishers, 1991). 38

[79] Hohenberg, P. \& Kohn, W. Inhomogeneous electron gas. Phys. Rev 136, B864-B871 (1964). 40, 42

[80] Kohn, W. \& Sham, L. J. Self-consistent equations including exchange and correlation effects. Phys. Rev 140, A1133-A1138 (1965). 40, 43

[81] Nobel Media AB. The nobel prize in chemistry 1998 (2013). URL http:// www.nobelprize.org/nobel_prizes/chemistry/laureates/1998/. [Online; acessado em 13 de novembro de 2013]. 40 
[82] Levy, M. Universal variational functionals of electron densities, firstorder density matrices, and natural spin-orbitals and solution of the vrepresentability problem. Proceedings of the National Academy of Sciences 76, 6062-6065 (1979). URL http://www.pnas.org/content/76/12/ 6062. 42

[83] Parr, R. G. \& Yang, W. Density-Functional Theory of Atoms and Molecules (Oxford University Press, 198 Madison Ave., New York, NY 10016-43414, 1989), 1st edn. $42,43,45$

[84] Becke, A. D. Density-functional thermochemistry. III. the role of exact exchange. The fournal of Chemical Physics 98, 5648-5652 (1993). 46, 59

[85] Levine, I. Molecular spectroscopy. A Wiley-Interscience publication (Wiley, 1975). 47, 48, 49

[86] Valeur, B. Molecular Fluorescence (Wiley-WCH, Weinheim, 2002). 50, 51, 52,69

[87] Tretiak, S., Saxena, A., Martin, R. L. \& Bishop, A. R. Photoexcited breathers in conjugated polyenes: An excited-state molecular dynamics study. Proceedings of the National Academy of Sciences of the United States of America 100, 2185-2190 (2003). 53

[88] Tretiak, S., Saxena, A., Martin, R. L. \& Bishop, A. R. Conformational dynamics of photoexcited conjugated molecules. Phys. Rev. Lett. 89, 097402 (2002). 53

[89] Dauber-Osguthorpe, P. et al. Structure and energetics of ligand binding to proteins: Escherichia coli dihydrofolate reductase-trimethoprim, a drugreceptor system. Proteins: Structure, Function and Genetics 4, 31-47 (1988). 57

[90] Kohlstedt, K. L., Solis, F. J., Vernizzi, G. \& de la Cruz, M. O. Spontaneous chirality via long-range electrostatic forces. Phys. Rev. Lett. 99, 030602 (2007). 63

[91] Solis, F. J., Vernizzi, G. \& Olvera de la Cruz, M. Electrostatic-driven pattern formation in fibers, nanotubes and pores. Soft Matter 7, 1456-1466 (2011). 63

[92] Hoover, W. G. Canonical dynamics: Equilibrium phase-space distributions. Physical Review A 31, 1695-1697 (1985). 65 
[93] Walsh, T. An ab initio study of the low energy structures of the naphthalene dimer. Chemical Physics Letters 363, 45-51 (2002). 81

[94] Connolly, M. L. Analytical molecular surface calculation. fournal of Applied Crystallography 16, 548-558 (1983). 82

[95] Jorgensen, W. L. \& Tirado-Rives, J. The OPLS [optimized potentials for liquid simulations] potential functions for proteins, energy minimizations for crystals of cyclic peptides and crambin. Fournal of the American Chemical Society 110, 1657-1666 (1988). 87

[96] Ingólfsson, H. I. et al. The power of coarse graining in biomolecular simulations. Wiley Interdisciplinary Reviews: Computational Molecular Science (2013). http://dx.doi.org/10.1002/wcms.1169. 88

[97] Riniker, S. \& van Gunsteren, W. F. A simple, efficient polarizable coarsegrained water model for molecular dynamics simulations. The fournal of Chemical Physics 134, 084110 (2011). 88

[98] Shelley, J. C., Shelley, M. Y., Reeder, R. C., Bandyopadhyay, S. \& Klein, M. L. A coarse grain model for phospholipid simulations. The fournal of Physical Chemistry B 105, 4464-4470 (2001). 88

[99] Marrink, S. J., de Vries, A. H. \& Mark, A. E. Coarse grained model for semiquantitative lipid simulations. The fournal of Physical Chemistry $B$ 108, 750-760 (2004). 88, 89

[100] Maupetit, J., Tuffery, P. \& Derreumaux, P. A coarse-grained protein force field for folding and structure prediction. Proteins: Structure, Function, and Bioinformatics 69, 394-408 (2007). 88

[101] Marrink, S. J., Risselada, H. J., Yefimov, S., Tieleman, D. P. \& de Vries, A. H. The MARTINI force field: coarse grained model for biomolecular simulations. The journal of physical chemistry B 111, 7812-7824 (2007). 88, 89,91

[102] Xia, Z., Gardner, D. P., Gutell, R. R. \& Ren, P. Coarse-grained model for simulation of RNA three-dimensional structures. The fournal of Physical Chemistry B 114, 13497-13506 (2010). 88

[103] López, C. A. et al. Martini coarse-grained force field: Extension to carbohydrates. Journal of Chemical Theory and Computation 5, 3195-3210 (2009). 88 
[104] Pronk, S. et al. GROMACS 4.5: a high-throughput and highly parallel open source molecular simulation toolkit. Bioinformatics 29, 845-854 (2013). 88, 89

[105] Rzepiela, A. J. et al. Reconstruction of atomistic details from coarsegrained structures. Journal of Computational Chemistry 31, 1333-1343 (2010). 88

[106] Wong-Ekkabut, J. et al. Computer simulation study of fullerene translocation through lipid membranes. Nature nanotechnology 3, 363368 (2008). 89

[107] D’Rozario, R. S. G., Wee, C. L., Wallace, E. J. \& Sansom, M. S. P. The interaction of $\mathrm{C} 60$ and its derivatives with a lipid bilayer via molecular dynamics simulations. Nanotechnology 20, 115102 (2009). 89

[108] Titov, A. V., Král, P. \& Pearson, R. Sandwiched graphene-membrane superstructures. ACS Nano 4, 229-234 (2010). 89

[109] Wu, D. \& Yang, X. Coarse-grained molecular simulation of self-assembly for nonionic surfactants on graphene nanostructures. The fournal of Physical Chemistry B 116, 12048-12056 (2012). 89

[110] Wallace, E. J. \& Sansom, M. S. P. Carbon nanotube self-assembly with lipids and detergent: a molecular dynamics study. Nanotechnology 20, 045101 (2009). 89

[111] Patra, N. \& Král, P. Controlled self-assembly of filled micelles on nanotubes. Fournal of the American Chemical Society 133, 6146-6149 (2011). 91

[112] Lee, H. \& Kim, H. Self-assembly of lipids and single-walled carbon nanotubes: Effects of lipid structure and pegylation. The fournal of Physical Chemistry C 116, 9327-9333 (2012). 89

[113] Caleman, C. et al. Force Field Benchmark of Organic Liquids: Density, Enthalpy of Vaporization, Heat Capacities, Surface Tension, Isothermal Compressibility, Volumetric Expansion Coefficient, and Dielectric Constant. Journal of Chemical Theory and Computation 61-74 (2012). 90, 91

[114] Marcus, Y. The properties of solvents, vol. 1 of Wiley series in solution chemistry (Wiley, 1998). 91 
[115] Jorgensen, W. L. \& Tirado-Rives, J. Potential energy functions for atomic-level simulations of water and organic and biomolecular systems. Proceedings of the National Academy of Sciences of the United States of America 102, 6665-6670 (2005). 94

[116] Wassenaar, T. A. Molecular Dynamics of Sense Sensibility and in Processing and Analysis of Data. $\mathrm{PhD}$ in mathematics and natural sciences, Groningen Biomolecular Sciences and Biotechnology Institute, University of Groningen, University of Groningen, P.O. Box 72, 9700 AB, Groningen, The Netherlands (2006). URL http://dissertations.ub.rug.nl/ faculties/science/2006/t.a.wassenaar/. ISBN 903672753 7. 96

[117] Wassenaar, T. A., de Vries, S., Bonvin, A. M. J. J. \& Bekker, H. SQUEEZEE: The optimal solution for molecular simulations with periodic boundary conditions. Fournal of Chemical Theory and Computation 8, 3618-3627 (2012). 96 